\title{
Nurse-Patient Interaction: Characterizing Support for Women with Antenatal Depression
}

\author{
Emily C. Evans \\ Charlottesville, Virginia
}

B.S.N., University of Utah, 2001

M.S.N., University of Pennsylvania, 2003

A Dissertation Presented to the Graduate Faculty of the University of Virginia in Candidacy for the Degree of Doctor of Philosophy in the Graduate School of Arts and Sciences

\author{
School of Nursing \\ University of Virginia \\ May, 2014
}

Chairman, Linda F. C. Bullock, PhD, RN FAAN

Member, Nancy L. Deutsch, PhD

Member, Emily Drake, PhD, RN

Member, Joel G. Andersen, PhD 


\section{TABLE OF CONTENTS}

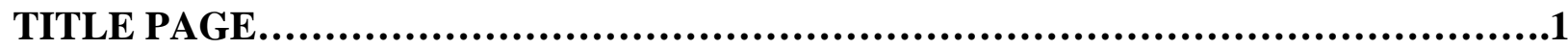

TABLE OF CONTENTS........................................................................2

FINANCIAL ACKNOWLEDGEMENTS...........................................8

ACKNOWLEDGEMENTS................................................................9

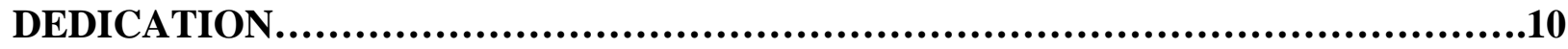

CHAPTER ONE: INTRODUCTION AND ACKGROUND ...................................11

Scope of the Problem........................................................... 11

Treatment for Depression.................................................11

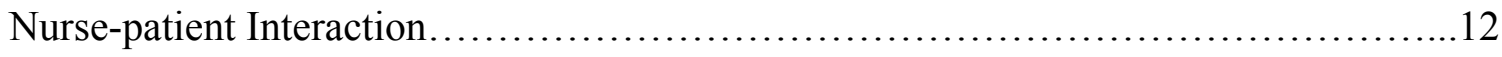

Conceptual Framework....................................................12

Research Questions.....................................................14

Organization of the Dissertation............................................ 15

Conclusion............................................................. 16

CHAPTER TWO: LITERATURE REVIEW (Manuscript One)...........................18

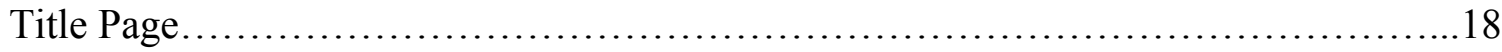

Abstract.....................................................................

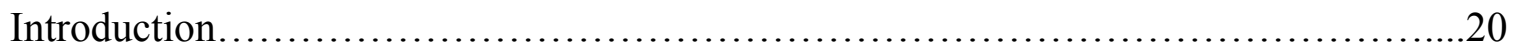

Rationale and Aims............................................................. 21

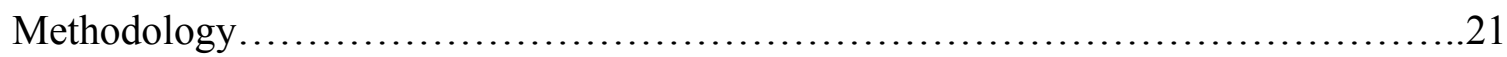

Results...................................................................22

Discussion............................................................... 30

Conclusion................................................................. 
Contributions............................................................ 35

References..............................................................

CHAPTER THREE: METHODS.....................................................40

Procedure..............................................................40

Step One: Concept Analysis...............................................40

Step Two: Pilot Work..................................................41

Step Three: Qualitative Descriptive Study..................................42

Description of Data to be used.......................................42

Quantitative Data..................................................43

Qualitative Data.................................................43

Sample Selection.................................................44

Example of Data................................................45

Strengths of the Data Set..........................................47

Qualitative Methodology ...........................................48

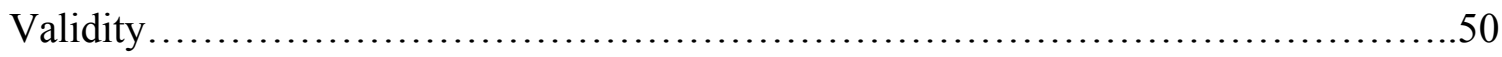

Limitations............................................................ 50

Human Subjects.......................................................51

CHAPTER FOUR: FINDINGS (Manuscripts Two and Three) $. . \ldots \ldots \ldots \ldots \ldots \ldots \ldots \ldots \ldots \ldots . . . .52$

Manuscript Two: Nurse-Patient Interaction: A Concept Analysis.........................52

Abstract..................................................................53

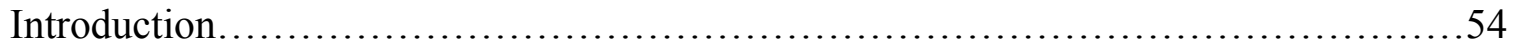

Description of the Problem............................................... 55

Rationale..............................................................55 


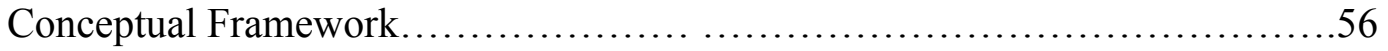

Literature Review.....................................................5

Purpose...............................................................60

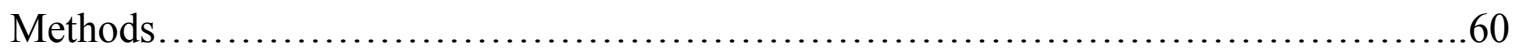

Design.........................................................6 60

Data Retrieval and Analysis..........................................60

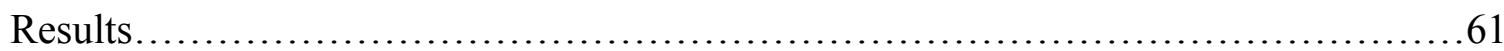

Defining Attributes...............................................61

Antecedents........................................................62

Consequences....................................................63

Empirical Referents....................................................64

Concept Map...........................................................65

Cases....................................................................... 65

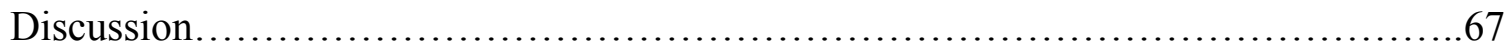

Conclusion........................................................... 70

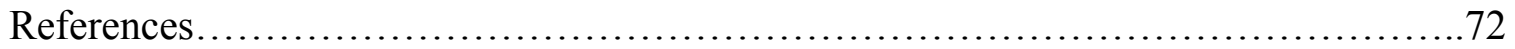

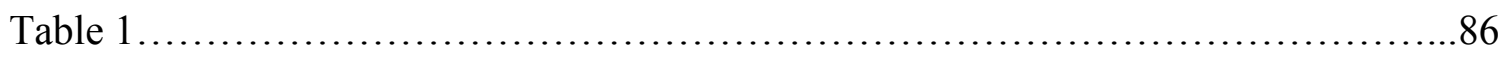

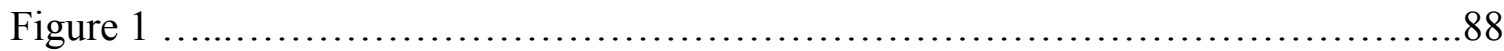

Manuscript Three: Characterizing Nurse-Patient Interactions in the Baby BEEP Study........89

Abstract...............................................................90

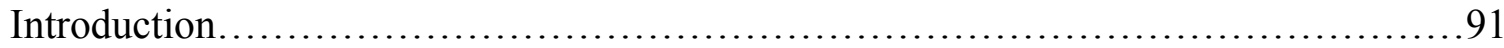

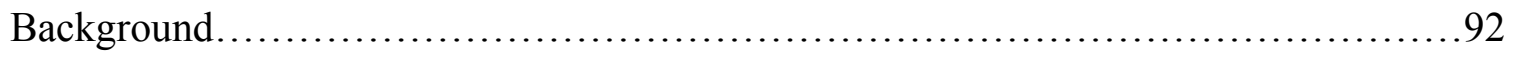

Antenatal Depression..................................................92 
Treatment Issues.................................................... 92

Conceptual Framework...............................................93

Description of Original Data..............................................93

Purpose of Study ......................................................... 95

Methods................................................................. 95

Design.................................................................... 95

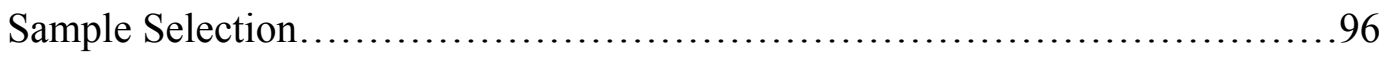

Analysis.............................................................. 97

Findings............................................................... 99

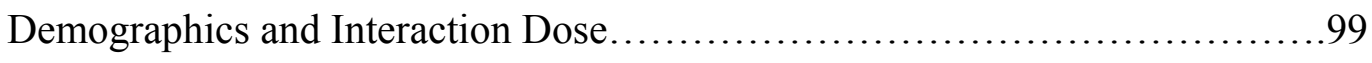

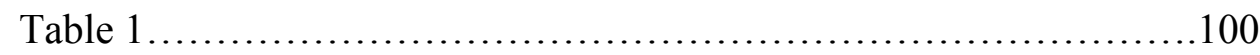

Psychosocial Variables................................................101

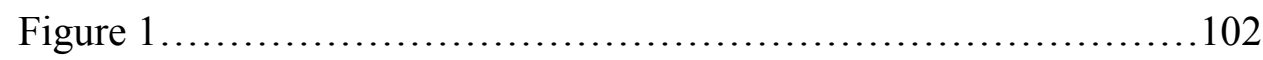

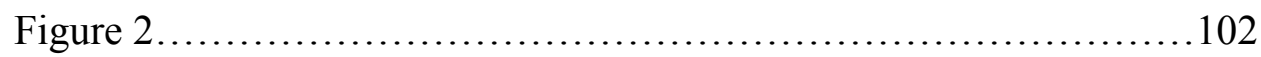

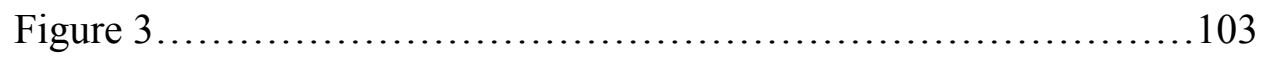

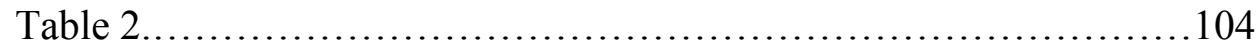

Peplau's Phases of Relationship...................................... 105

Orientation..................................................... 105

Identification............................................. 107

Exploitation............................................... 108

Resolution................................................112

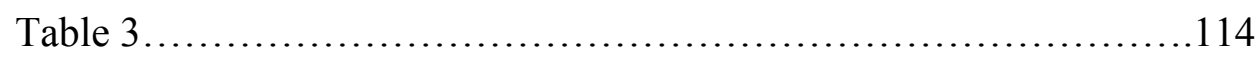

Peplau's Nursing Roles.............................................. 115 
Stranger...................................................115

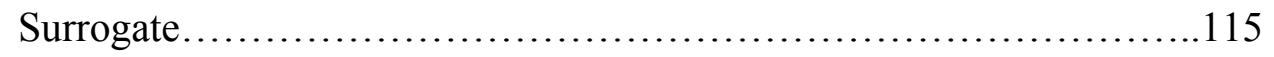

Resource..................................................116

Teacher.......................................................110

Counselor..................................................120

Leader......................................................... 124

Group Differences in Nursing Roles.................................. 125

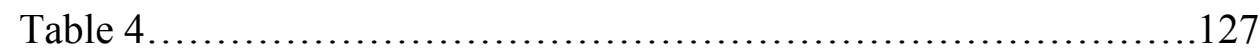

Topics Addressed within Interactions.................................. 130

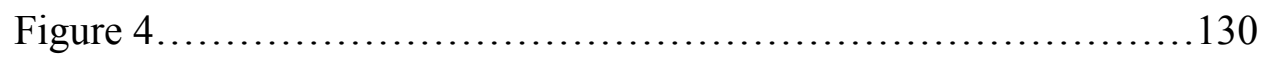

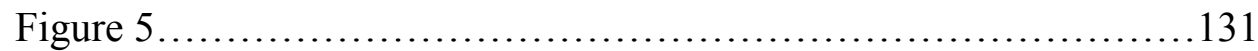

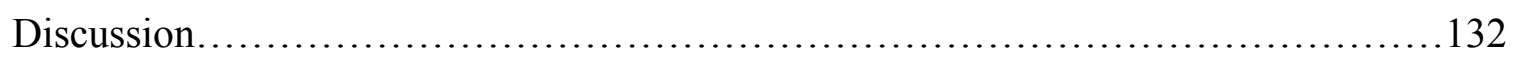

Implications for Nursing Practice.................................. 136

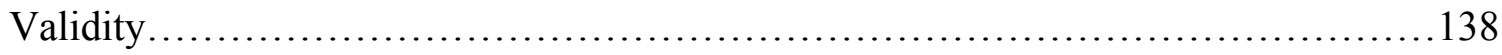

Conclusion............................................................ 139

References............................................................ 140

Appendix A............................................................. 155

Appendix B............................................................ 166

CHAPTER 5: CONCLUSION....................................................172

Impact of Antenatal Depression.......................................... 172

Treatment for Antenatal Depression........................................ 172

Evaluating Baby BEEP as an Intervention for Antenatal Depression.................173

Relevance to Nursing Theory............................................ 173 
Nurse Patient Interaction in Baby BEEP.......................................174

Need for Social and Emotional Support.........................................176

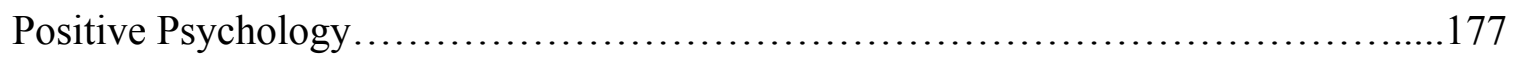

Directions for Future Research............................................. 178

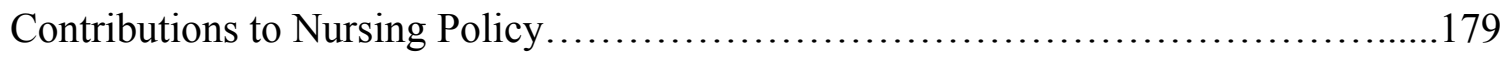

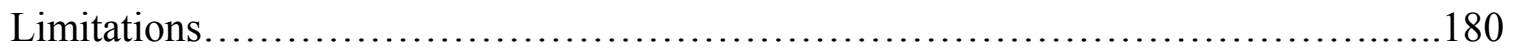

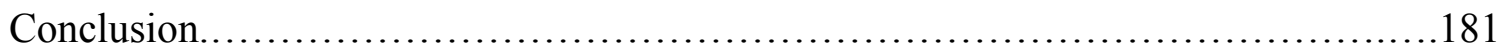

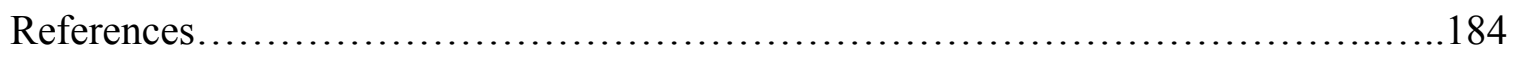




\section{Financial Acknowledgements}

I would like to acknowledge NIH Grant NR05313: Nursing Smoking Cessation Intervention during Pregnancy (Baby Behavioral Education Enhancement of Pregnancy or Baby BEEP). This grant funded the original Baby BEEP study that provided the data for this secondary analysis. 


\section{Acknowledgements}

I would like to acknowledge the University of Missouri research team that worked on the original Baby BEEP study, including Linda Bullock, Kevin D. Everett, Patricia Dolan Mullen, Elizabeth Geden, Daniel R. Longo, Richard Madsen, and the Baby BEEP Nurses.

I would like to acknowledge the generous time, help and feedback offered by my dissertation committee: Linda Bullock, Nancy Deutsch, Emily Drake, and Joel Anderson.

I would also like to acknowledge my dissertation chair and doctoral student advisor, Linda Bullock, for her support, encouragement and guidance throughout my entire doctoral experience. 


\section{Dedication}

This work is dedicated to my family. Rich, Madeline, Lucy, Claire, Amelia and soon to be baby number five. Your support, love, and presence in this world not only made this work possible, but also worth every effort. It is in hopes of making your lives and the world a better place that I put it forth. 


\section{Chapter 1: Introduction and Background}

The incidence of depression is increasing globally and is projected to be the second most common disability by 2020 (C. L. Dennis, Ross, \& Grigoriadis, 2010). Antenatal depression (AND), or depression during pregnancy, is a frequently experienced, but often undiagnosed health condition. Symptoms of depression are reported to be experienced by as many as $20 \%$ of pregnant women in the U.S., with rates as high as $47 \%$ for underserved women (Bennett, Marcus, Palmer, \& Coyne, 2010; Gaynes et al., 2005). Depressed mothers are more likely to have poor health practices, abuse drugs and alcohol, receive inadequate health care, have poor pregnancy and birth outcomes, and suffer from postpartum depression or psychological distress long after pregnancy ends (Dimidjian \& Goodman, 2009; Jomeen, 2004; Muzik, Marcus, Heringhausen, \& Flynn, 2009).

\section{Treatment for Depression}

Levels of treatment for AND are low because of the perceived risk of antidepressant medication use during pregnancy and the difficulty in accessing effective psychological treatments, particularly for underserved women. Mind-body stress reduction interventions such as exercise, yoga, massage, and acupuncture, as well as other complementary treatment modalities, are beginning to be explored in the literature, but are far from being established as effective on a large scale, or implemented for wide use by pregnant populations (Beddoe \& Lee, 2008; C. L. Dennis \& Allen, 2010; Dimidjian \& Goodman, 2009). Few studies have examined AND in women with lower incomes, specifically its prevalence, course, impact on quality of life, disease burden or effective interventions (Bennett, Einarson, Taddio, Koren, \& Einarson, 2004; Gavin et al., 2005; Lancaster et al., 2010). It is essential that nurse scientists pursue research 
aimed at identifying, developing and testing interventions that can support women suffering from AND.

\section{Nurse-Patient Interaction and Antenatal Depression}

While nurses may be in a position to provide therapeutic support to women suffering from AND, there are no studies identifying components of nursing care or nursing strategies used to this end (C. L. Dennis \& Allen, 2010; C. L. Dennis et al., 2010). Nurse-patient interaction (NPI) has long been heralded as the core of nursing care and essential in the provision of psychiatric nursing care (Caris-Verhallen, Timmermans, \& van Dulmen, 2004; Cleary, Edwards, \& Meehan, 1999; Cossette, Cara, Ricard, \& Pepin, 2005; Kandler, Behymer, Kegeles, Boyd, \& Kandler, 1952; Kasch, 1986; Peplau, 1997). Nurse-patient interaction is not, by definition, therapeutic, but has the potential to be so. The quality of NPI is influenced by many factors, including the health, knowledge, expectations and interpersonal style of both parties, in addition to the context within which the interaction occurs (Chatwin, 2008; Cleary et al., 1999; Millard, Hallett, \& Luker, 2006; Rask \& Brunt, 2007; Stoddart, 2012; Tropea, 2012). Patients who engage in high quality NPI experience greater health, an improved ability to cope, a greater sense of being cared for, increased involvement in their care and higher patient satisfaction (Cleary, Hunt, Horsfall, \& Deacon, 2012; Cossette et al., 2005; Rask \& Brunt, 2007; Shattell, 2004; Williams \& Irurita, 2004; Williams \& Kristjanson, 2009). Nurses can use this type of therapeutic NPI to support women suffering from depression during pregnancy and have a positive impact on their mental health.

\section{Conceptual Framework}

The conceptual framework used to guide this study is the Theory of Interpersonal Relations, developed by nursing theorist Hildegard Peplau in the 1950s (Peplau, 1997). This 
theory has its roots in psychiatric nursing and is based on psychoanalytic principles that Peplau applied to NPIs. Peplau identifies the nurse-patient relationship and the interpersonal interactions inherent in developing that relationship as vital and therapeutic components of nursing care. Her application of psychoanalytic and psychotherapeutic principles to nursing activity provides concepts by which nurses may understand their relationships with patients, as well as their purpose in physical, verbal and social interactions. Peplau identifies four phases of the nursepatient relationship that have distinct purposes and characteristics. The orientation phase lays the foundation for honest, meaningful interaction and therapeutic work to be done. The identification and exploitation phases are the working phases, during which interactions become more purposeful and directed at meeting patient needs. The resolution phase occurs as the relationship comes to an end and is a time for reflection and summary of the relationship, experiences and work done (Peplau, 1991; Townsend, 2009).

Peplau's theory identifies several concepts that are relevant to interaction and the development of a therapeutic relationship between patient and nurse. These concepts are interaction, relations, relationship and roles. Nursing naturally involves hundreds of interactions between nurse and patient that can be analyzed, understood and characterized. These interactions occur at the micro-level and are made up of the actions, attitudes, responses and dynamics that exist between nurse and patient when they engage in health care together. As interactions accrue over time, these develop into relations. These relations are the intermediate step between the nurse-patient interaction and the nurse-patient relationship. Peplau conceptualized relations as the "connections, linkages, bonds or patterns that develop and are identifiable within the relationship" (Peplau, 1997, p. 162). The nurse-patient relationship is the macro-level description of what exists between patient and nurse, and encapsulates how each functions within that 
sphere. In the relationship, the nurse assumes varying roles based on patient needs. Peplau identified the roles of the nurse as "teacher, resource, counselor, leader, technical expert, and surrogate" that may be used to assist the patient in regaining health and well-being (Peplau, 1991; Kim \& Collak, 2006, p.299). Each of these roles is employed through the nurse's actions and responses toward the patient in an effort to provide the needed elements of care.

This dissertation uses data collected from a previous study titled Nursing Smoking Cessation Intervention during Pregnancy (Baby Behavioral Education Enhancement of Pregnancy or Baby BEEP) (Bullock et al., 2009). As part of the Baby BEEP study, nurses provided a weekly telephone social support intervention to low-income, rural, pregnant women, many of whom experienced depressive symptoms during pregnancy. During these telephone interactions, the nurses exhibit many of Peplau's concepts and illustrate how NPI can be used to support a vulnerable population of pregnant women. Although the intervention was intended to help decrease stress for the participants, because of the prevalence of concurrent depressive symptoms, the method of providing the intervention, and the high retention rate of this study, it was decided that these data would provide insight into the possibility of using nurse-delivered telephone support as a therapeutic intervention aimed at supporting underserved women who suffer from AND.

\section{Research Questions}

The major objective of this qualitative study is to characterize the NPIs that occurred between the Baby BEEP nurses delivering telephone social support and women experiencing symptoms of depression during pregnancy. To more fully capture the phenomenon of NPI in the context of AND, the following research questions guided the dissertation research:

1. How are NPIs conceptualized in the nursing literature? 
2. In what way does a research nurse respond to pregnant women with symptoms of depression from the Baby BEEP study over the course of the intervention?

3. What characterized the interactions between the Baby BEEP research nurses and women whose symptoms of depression improved over the course of pregnancy?

3a. In what ways, if any, do the interactions reflect the phases and roles described in Peplau's theory of Interpersonal Relations?

3b. In what ways, if any, were the interactions different between the nurses and women whose symptoms of depression improved versus women whose symptoms of depression did not improve?

\section{Organization of the Dissertation}

Chapter one of the dissertation provides background information about AND, briefly describes current AND treatment issues and discusses the potential of NPI for use as a therapeutic intervention for women suffering from AND. It also introduces the purpose of the dissertation and the research questions that guided the study.

Chapter two is the first manuscript, a literature review published in Nursing and Health Science, that addresses the importance of psychosocial factors in AND treatment and the possibility of using optimism to help offset or mitigate depressive symptoms (Evans \& Bullock, 2012).

Chapter three describes, in detail, the methods used in the dissertation, including the source of data, sample selection, qualitative methodology and human subjects' considerations.

Chapter four includes the second manuscript to be submitted to the Western Journal of Nursing Research and describes the concept of NPI and its importance within nursing care as a primary means of influencing patient outcomes and satisfaction. As such, NPI holds promise as a 
feasible and potent way of supporting pregnant women at risk for depression. This chapter also includes the third manuscript to be submitted to the Journal for Nursing Scholarship. This manuscript presents the primary findings of the dissertation, the characterization of the NPIs between the Baby BEEP nurses and low-income, rural women experiencing depressive symptoms during pregnancy.

Chapter five is a summary of the research conducted for this dissertation, its relevance to the greater body of AND literature as well as its contributions to nursing science. This chapter also addresses the limitations of the dissertation, in addition to its implications for nursing research, practice and policy.

\section{Conclusion}

Antenatal depression is a serious, prevalent and debilitating health condition for many women. Treatment options for AND are limited to psychotherapy and pharmacotherapy, with little investigation into other means of depression treatment. Low-income women living in rural settings are particularly at risk for depression, with few resources at their disposal to use in preventing or treating depressive symptoms. This dissertation describes the Baby BEEP intervention that provided support to women with symptoms of depression over the course of pregnancy and explores whether the type of NPI that occurred during this telephone social support intervention is a potential model for AND treatment in other vulnerable populations.

Nurse-patient interaction has been a vital component of therapeutic nursing care across disciplines for decades, but particularly in psychiatric nursing. However, the concept of NPI, although frequently discussed in the literature, has not been demonstrated through actual nursing care delivered via telephone support. Understanding the concept of NPI and how it is enacted is the first step in assessing its value as a potential treatment for AND in vulnerable populations. 
Therapeutic NPIs also have not been examined in the prenatal context, specifically as a means to support depressed women. The Baby BEEP data provide a rich source to examine the NPI phenomenon because detailed logs were kept on a sizeable number of women as part of a study with a remarkable retention rate and the work was done by relatively few nurses, making the NPI concept easier to assess. Qualitative examination characterizing the interactions between several baccalaureate-prepared nurses and low-income rural women experiencing symptoms of depression provide insight into those components of NPIs that can be used to support this underserved and difficult to access population. 


\section{Chapter 2: Literature Review (Manuscript One)}

Optimism and Antenatal Depression: A Review

Emily C. Evans, MSN, RN and Linda F.C. Bullock, PhD, RN, FAAN

University of Virginia School of Nursing

Published in Nursing and Health Science, 2012 


\begin{abstract}
Antenatal depression is a common experience for many women with significant personal and familial sequelae. Searches of the CINAHL, MEDLINE, and ERIC databases were conducted in September 2010 to identify peer-reviewed articles relevant to our topic of study. The purpose of this integrative review is to summarize what is known about antenatal depression, discuss challenges of treatment and suggest psychosocial factors to consider when developing safe and effective interventions. We give specific attention to optimism as a potent psychosocial variable that may be modified to improve depressive symptoms.

Studies of risk factors for depression during pregnancy have consistently identified an association between psychosocial variables and antenatal depression. Low-income pregnant women living in rural settings are especially vulnerable because of decreased resources. Interventions designed to address these psychosocial variables, including optimism, may help decrease the prevalence and severity of depressive symptoms in pregnant women in safe, effective, and culturally acceptable ways.
\end{abstract}

Keywords: depression, optimism, pregnancy, psychosocial, underserved 


\section{Introduction}

Depression is a growing problem in our world, with estimates placing it at the secondmost common disability by 2020 (Dennis et al., 2007). Suffering from undiagnosed depression during pregnancy creates a complex web of biopsychosocial distresses in the mother which affect her well-being and that of her entire family, including her unborn baby. Maternal psychological distress, including antenatal depression (AND), has been correlated with significant public health concerns such as low birth weight (LBW) and preterm birth (PTB) (Mulder et al., 2002; Talge et al., 2007). Although risk factors for postpartum depression are commonly recognized, screened for, and treated in obstetric settings, risk factors for depression during pregnancy are less well known and addressed, despite prevalence equal to, if not greater than, those experienced during the postpartum period (Boyd et al., 2006; Dimidjian \& Goodman, 2009; Jomeen, 2004; Jomeen \& Martin, 2005; Reid et al., 2009). Research on depression and depressive symptoms during pregnancy, alongside their attendant risk factors and treatment issues, is relatively recent, with systematic reviews published only within the last seven years (Bennett et al., 2004; Lancaster et al., 2010). This relative inattention in the past is concerning because women are at the highest risk for depression during their childbearing years (Cardemil et al., 2005; Dimidjian \& Goodman, 2009; Luke et al., 2009; Price \& Proctor, 2009).

Many of the risk factors for depression during pregnancy relate to psychosocial factors in a woman's life. Stress and social support have been extensively studied as significant variables that impact a woman's experience of AND. Other potent psychosocial variables have only begun to emerge as promising research trajectories. Initial investigations of optimism in pregnant women indicate it may be a modifiable psychosocial variable that can protect women from developing depression or help decrease depressive symptoms already present. Positive 
psychology theory holds that some personal traits and dispositions, such as optimism, significantly contribute to a person's positive psychological experience and have the potential to decrease and prevent mental illness (Seligman \& Csikszentmihalyi, 2000; Seligman et al., 2005). Although obstetric health-care providers have increased efforts to screen patients for AND, barriers of time, safety, cultural acceptability, access, and cost prevent many women from obtaining pharmacological or psychological treatment even when adequate screening does occur.

\section{Rationale and Aims}

With well-established prevalence and compelling evidence of immediate and long-term sequelae, AND must not be overlooked. The purpose of this review is to investigate what is known about AND — specifically, prevalence, sequelae, risk factors, and treatment issues. Psychosocial factors will be reviewed in detail as they relate to the experience of AND and serve as the foundation for the design of nonpharmacological interventions to reduce depressive symptoms. This is the first review of AND considering optimism as an important variable_-one with the potential to prevent or improve depressive symptoms during pregnancy. We give special consideration to research related to low-income, rural populations because of their higher risk for depression and poor birth outcomes.

\section{Methodology}

We conducted an integrative review of the literature related to AND published after 2000 in September 2010 using the CINAHL, MEDLINE, and ERIC databases. Initial search terms included: antenatal, pregnancy, depression, nonpharmacologic, optimism, and underserved. Whenever possible, search terms were expanded to include MeSH headings. For each paper identified, we consulted its references, hand-checking for additional relevant research that could provide further context and understanding. The abstracts of 133 articles were reviewed for 
pertinence to our topic of study.

Articles with a major focus on AND, treatment of AND, or psychosocial variables and depression (including optimism) in pregnant women were included. To gain a broad understanding of AND while maintaining scientific rigor, we included qualitative and quantitative articles of review or original research that were peer-reviewed and in the English language. Narrative, comment, opinion, and dissertation research articles were excluded from this review, as were studies with samples that did not consist of pregnant women (including research that focused solely on postpartum depression). Exceptions were made for articles examining optimism and postpartum depression because of the limited amount of research available on this topic.

To focus our study, a total of 12 review and 24 original research articles were selected and reviewed as most relevant and insightful. In Table 1 we give the methodology and inclusion criteria used by the review articles. In Table 2 we give the methodology and focus of the original research articles. From our review of these 36 articles, four themes emerged as the foci of antenatal depression research to date: prevalence, risk factors (including psychosocial variables), sequelae, and treatment.

\section{Results}

\section{Prevalence}

Prevalence rates for major depressive disorder (MDD) during pregnancy vary, ranging from $10 \%$ to $16 \%$, with rates of pregnant women who experience depressive symptoms as high as 38\% (Cardemil et al., 2005; Marcus et al., 2003; Price \& Proctor, 2009). Women living in poverty or underserved areas, who are already at risk for poor health, have been shown to experience depression at higher rates (Jomeen, 2004; Rich-Edwards et al., 2006). In a screening 
of low-income, African-American women during pregnancy, Luke et al. (2009) found that 25\% had depressive symptoms equivalent to those necessary for a diagnosis of MDD (Price \& Proctor, 2009). Although studies have been criticized for not verifying diagnoses of depression with psychiatric evaluations, subclinical depression levels, which may not be diagnosed with psychiatric evaluation, remain prevalent and potentially dangerous for pregnant women (Furber et al., 2009; Jomeen, 2004).

\section{Risk Factors}

The most common risk factors for depressive symptoms during pregnancy are: high levels of anxiety, high levels of perceived life stress, history of depression, lack of social support, unwanted pregnancy, low income (those who receive Medicaid insurance in the United States), domestic violence, lack of education, smoking, and single marital status (Lancaster et al., 2010). In fact, depression, stress, and anxiety are often comorbid and have been investigated simultaneously in numerous studies (Jomeen, 2004). These three psychological experiences can be triggered by similar circumstances and produce similar physiological and psychological pathways in pregnant women (Latendresse, 2009). Psychosocial variables that have been studied in relation to depression during pregnancy include: stress, social support quality of life, selfesteem, religiosity, spirituality, fear of childbirth, locus of control, coping strategies and unwanted pregnancy, (Blaney et al., 2004; Jesse et al., 2005; Jomeen, 2004; Jomeen \& Martin, 2005). Of these variables, stress and social support are the most studied.

Stress is related to many factors, including economic status, major life events, job-place issues, daily hassles, quality of life, living conditions, and pregnancy-related changes (Grote \& Bledsoe, 2007). Stress during pregnancy is emerging as an important contributor to many adverse pregnancy outcomes, including PTB, LBW, fetal malformations, spontaneous abortion 
(SAB), preeclampsia, unplanned cesarean sections, increased hospital length of stays, and poor neonatal neurologic scores (Beddoe \& Lee, 2008; Mulder et al., 2002). Stress is closely associated with anxiety, and both act as potent variables that impact a woman's well-being (Jomeen, 2004).

Pregnancy-related anxiety $(\operatorname{PrA})$ has been identified as one of the most effective predictors of maternal stress and centers around the concerns a woman has about her pregnancy, her ability to cope with the challenges of motherhood, the health of her fetus, and whether she will have a successful labor and delivery. PrA has been associated with negative outcomes such as PTB, LBW, and infant behavioral and developmental delay (Dunkel Schetter, 2011; Mulder et al., 2002). Through immune, neuroendocrine, and metabolic pathways, high levels of maternal stress directly affect the fetus and have the potential to program the fetus for negative sequelae throughout life (Latendresse, 2009).

Social support is another critical psychosocial variable that impacts a woman's experience of stress, anxiety, and depression. A lack of social support has been associated with increased psychological distress across cultures (Tseng et al, 2008). A lack of social support, or emotional isolation, was identified as a dominant theme among women who reported feeling "low" or "depressed" during pregnancy (Raymond, 2009). These women recalled a lack of both physical and emotional support and felt uncomfortable confiding in health-care providers, stating that the providers rarely saw the same patient and seemed more focused on the fetus. They reported desires to connect with other pregnant women via the Internet or face to face to receive and give support (Raymond, 2009). In a study examining the type of social support pregnant women found helpful, Reid et al. (2009) found that primiparous women seek emotional support from friends or siblings, whereas pregnant women with children seek emotional support from 
their mothers and practical support from their spouses. Though complex in its demonstration in women's lives, the need for social support during pregnancy seems to be universal.

Although research regarding other psychosocial variables and AND has lacked scientific rigor, the studies are useful for illustrating the complex nature of psychological health during pregnancy. Cultural variables like male-gender preference, religiosity, spirituality, and physical activity patterns have been examined, though not in depth, in pregnant women, with lower rates of psychological distress found in women who were religious, spiritual, and/or physically active (Mann et al., 2008; Poudevigne \& O’Connor, 2006). Self-esteem was found to be directly correlated with early-pregnancy depression and anxiety scores in Jomeen and Martin's (2005) self-report questionnaire of 129 pregnant women. Coping strategies such as disengagement or “giving up” negatively impact a woman's psychology, whereas cognitive strategies like reframing negative life events and paying attention to positive life events have been suggested as ways to prevent or decrease depression (Boyd et al., 2006). One investigation of maternal-infant interaction and mental well-being during and after pregnancy found that mother-infant interactions were better in women who reported more positive life events (Boyd et al., 2006). These findings support the concept of optimism as a strategy for improving mental well-being and decreasing depression among pregnant women.

Optimism. According to Scheier and Carver (1985), optimism is a disposition wherein people expect better things from life — that "things will work out." Although the relationship between optimism and health has been under investigation for more than three decades, optimism during pregnancy and the postpartum period has not been examined in great depth (Scheier \& Carver, 1987; Scheier et al.,1994). Dorn et al. (1993) examined the relationships among cortisol, psychosocial variables (namely, self-esteem and optimism), anxiety, and 
depression in 40 pregnant adolescents. In this small sample, it was found that optimism and selfworth accounted for $41 \%$ of the variance in anxiety and depression reports during pregnancy and the postpartum period. Another study of optimism in pregnant adolescents $(n>900)$ posed the question: Does optimism or depression affect the risk of SAB? Although the study found no significant associations between optimism and SAB, optimism and depression scores were highly inversely correlated, providing further evidence of a link between optimism and depression during pregnancy (Nelson et al., 2003).

One of the most compelling examinations of optimism during pregnancy is a study regarding its impact on birth outcomes. In a sample of 129 medically high-risk pregnant women, the correlation of stress and optimism during pregnancy, and their correlation in turn with birth weight and gestational age at birth, was examined. Babies born to women who were least optimistic during pregnancy on average weighed less than those born to more optimistic mothers. In addition, women with higher optimism reported less stress. The impact of optimism on birth weight was comparable to the impact of ethnicity on birth weight (Lobel et al., 2000).

To more fully represent the work that has been done regarding optimism and psychological health in women of childbearing age, we also considered studies of postpartum depression. These investigations have yielded mixed results. Fontaine and Jones (1997) examined the associations among optimism, postpartum depression, and self-esteem in 45 pregnant women at three times postpartum. Although both optimism and self-esteem were inversely correlated with depression at weeks one and two, only women with low self-esteem tended to continue to be depressed at week six. More recently, Grote and Bledsoe (2007) examined the associations among optimism, stress, and postpartum depression in 179 women, hypothesizing that optimism during pregnancy would be associated with lower rates of 
postpartum depression. Optimism was significantly correlated with fewer depressive symptoms, and protective benefits of optimism were found in light of spousal, financial, and physical stress for up to one year postpartum.

In Callahan Churchill and Davis's (2010) treatment of optimism and adjustment to motherhood, the specifics of what a woman thinks (positive, negative, and realistic expectations) and her experience of postpartum depression were examined. In this sample of nondepressed women, those who — using Callahan Churchill's self-reporting tool—reported a balance of positive and negative thoughts (termed "realistic orientation"), rather than only positive thoughts, were more likely to adjust well to motherhood. Tseng et al. (2008), in their qualitative study of Taiwanese women experiencing prenatal depression, describe the discrepancy between expectations and reality that troubled many women in their sample.

Further examination of the association between negative life events and optimism was completed by Moyer et al. (2009) in their study of Ghanaian pregnant women and HIVscreening attitudes. In their study, the most optimistic women had little knowledge of, and had never been tested for, HIV. This important finding is useful as interventions aimed at decreasing depression are constructed. Although optimism may help to prevent depression or reduce its symptoms, educating women about the range of possible outcomes can help provide them with a realistic construct within which to prepare for events such as the transition to motherhood.

\section{Sequelae}

As stated earlier, the negative outcomes of depression during pregnancy are difficult to differentiate from those caused by anxiety and stress, considering the similar physiological and psychological pathways they trigger. Reviews regarding negative consequences of psychological distress have centered on behavioral effects such as poor maternal health practices, and fetal 
effects due to changes in maternal immune and neurohormonal systems (Dunkel Schetter, 2011; Knackstedt et al., 2005). Depressed mothers are more likely to: commit suicide, receive inadequate health care, have poor health practices, abuse drugs and alcohol, have poor pregnancy and birth outcomes, and suffer from postpartum depression or psychological distress long after pregnancy ends (Dimidjian \& Goodman, 2009; Grote \& Bledsoe, 2007; Jomeen, 2004; Muzik et al., 2009; Spinelli \& Endicott, 2003). Furber et al. (2009) found that mild to moderate psychological distress was debilitating in the 24 pregnant women who were a part of their qualitative study — the distress keeping them homebound and exacerbating obsessive thoughts as well as compulsive behavior.

Research on fetal programming, or the process by which the maternal environment permanently imprints changes on fetal bioneurohormonal pathways, is emerging as a promising area of investigation to help explain negative sequelae of maternal psychological distress through adulthood (Dunkel Schetter, 2011). Infants of mothers with higher levels of stress, anxiety, and depression during pregnancy are more likely to have PTB, LBW, decreased newborn neurobehavioral performance, and impaired maternal-infant attachment (Talge et al., 2007). The effects of maternal depression during pregnancy continue into childhood, as evidenced by its correlation with language delay, temperament and behavior problems, psychiatric disorders, attention deficit hyperactivity disorder (ADHD), and cognitive delay (Talge et al., 2007).

\section{Treatment}

Routine screening for depression in a prenatal setting has been strongly advocated and is now recommended by the American College of Obstetrics and Gynecologists for all pregnant patients (Blaney et al., 2004; Boyd et al., 2006; Jomeen, 2004; Lancaster et al., 2010). In a study of depression screening and provider intervention for pregnant women, Flynn et al. (2006) found 
that women diagnosed with MDD were not being treated before, during, or after pregnancy, even as depression persisted. Similar findings were reported by Marcus et al. (2003), who found that of 3472 pregnant women, only $13.8 \%$ of those who screened positive for depression were receiving any formal treatment. Traditional psychological therapies delivered in the clinic, at home, or over the phone have been shown effective in decreasing postpartum depression, but less attention has been paid to the same therapies' effectiveness during pregnancy (Dimidjian \& Goodman, 2009).

Studies indicate that nonpharmacological treatment typically aims to decrease stress, increase coping skills, or increase social support, and has included exercise, light therapy, nutritional supplementation, massage, acupuncture, parenting and psychoeducation, as well as providing social support (Cardemil et al., 2005; Dimidjian \& Goodman, 2009; Grote \& Bledsoe, 2007; Spinelli \& Endicott, 2003). Results of these studies are difficult to generalize because of their lack of scientific rigor and small sample sizes. In a Cochrane review of nonpharmacological, psychiatric, or psychosocial interventions for depression during pregnancy, only one study was found rigorous enough to be included (Dennis \& Allen, 2008). In a review of mind-body interventions for reduction of stress and anxiety during pregnancy, 12 articles were examined for evidence of improved birth outcomes. Interventions primarily consisted of progressive muscle relaxation, a psychoeducational program, or a yoga and meditation program. We found evidence of health benefits to these practices, but the helpfulness of the evidence was limited due to methodological concerns such as the utilization of small, non-random sample selection and the lack of control groups (Beddoe \& Lee, 2008).

Treatment rates for depression are even lower in underserved populations, which face additional barriers to care. In a chart review of 3327 low-income pregnant women who were 
treated for depression before pregnancy, antidepressant use as well as depression care visits dropped significantly during pregnancy and remained low throughout the postpartum period when compared to a nonpregnant control group with similar characteristics (Bennett et al., 2010). In one study of depressive symptoms during pregnancy, minority women were unlikely to participate in the study compared to their Caucasian counterparts (Flynn et al., 2006). Rural women have been found to be more likely to refer themselves for help in nontraditional settings where costs were low and seeking help was more culturally acceptable (Price \& Proctor, 2009). Many women self-treat for depression by seeking information on the Internet or in books; talking about their feelings with friends, family members, or religious leaders; "doing something for themselves"; or engaging in physical activity, spiritual or religious activities, repetitive behaviors, crying while alone, or negative behaviors such as smoking or substance abuse (Flynn et al., 2006; Furber et al., 2009; Mann et al., 2008; Poudevigne \& O’Connor, 2006).

\section{Discussion}

AND is a prevalent condition that warrants greater obstetric and gynecological healthcare provider attention. Pregnancy is an important time to identify depression in women and assist them in their efforts to cope with the demands of pregnancy and become healthier. Difficulty lies in the fact that when screening occurs and women at risk for depression are identified, few obtain treatment. When a positive screening for depression occurs in a prenatal setting, many providers and women alike are left wondering what to do next. Lack of training and familiarity with depression screening and treatment among obstetric providers makes it difficult, and potentially uncomfortable, to address depression in such a setting (Jomeen, 2004). For health-care providers, addressing the array of psychosocial variables that may impact psychological health during pregnancy is daunting and not a part of routine prenatal care. 
Typical prenatal appointments involve assessing weight gain, blood pressure, fetal heart tones, fundal height, and signs or symptoms of complications, as well as performing any testing required to detect pregnancy problems. However, even when the individuals involved are familiar with depression, its identification, and treatment, many providers and women are reluctant to use pharmacotherapy because of concern for fetal safety or cost—or both (Muzik et al., 2009).

Traditional therapies of pharmacology and psychotherapy (including Cognitive Behavioral Therapy), though effective at reducing depressive symptoms, remain underused due to lack of cultural acceptability, limited resources (financial and time), difficulty with access to treatment, and safety concerns for the fetus. The study of nonpharmacological treatment for depression is relatively recent, and further investigation of its use with pregnant women is greatly needed (Cardemil et al., 2005; Furber et al., 2009). The dearth of opportunities to obtain nonpharmacological treatment for depression is a large reason why undertreatment is so pervasive.

Undertreatment of AND is most concerning with respect to underserved populations, which face additional health disparities. Decreased resources not only increase women's propensity toward stress and depression but also limit women's access to and ability to receive treatment. Limited resources (time, financial, educational, and practical), lack of health care, patient mistrust of health-care providers, and instability caused by life events preclude utilization of available treatment. Cultural beliefs and perceptions about depression may make traditional psychological and pharmacological treatments undesirable for underserved women (Cardemil et al., 2005; Dimidjian \& Goodman, 2009). Forums for social support, group feedback, mentoring, and validation rarely exist for this group (Cardemil et al., 2005). Mobile technology and internet 
based interventions are nontraditional means to connect with underserved women and hold promise as effective, safe, culturally acceptable, and easily accessible interventions.

Even symptoms of depression and psychological distress have been shown to cause a decrease in quality of life for pregnant women and potential damage to their offspring. Psychosocial variables such as stress, social support, and optimism have an impact on the presence and severity of depressive symptoms, and their consideration could help in designing effective nonpharmacological interventions. The degree to which these variables either protect from or predispose a woman to depression depends on their presence, magnitude, and interactions with one another. For example, a pregnant woman experiencing high levels of stress may not develop depression because of her optimistic outlook and active coping mechanisms. By contrast, a woman with a history of psychological distress, low quality of life, and poor selfesteem may be predisposed to developing depression during pregnancy, and might furthermore have few resources to protect from its development. The negative effects of stress and their likelihood of contributing to depression may be buffered by other psychosocial variables such as optimism, self-esteem, spirituality, active coping methods, or social support (Jesse \& Swanson, 2007; Reid et al., 2009).

Not only can positive psychology buffer against depression, but it can impact a woman's overall health, directly and through health behaviors. Many of the characteristics that contribute to positive psychology are reflected in the psychosocial variables that impact depression: optimism, faith, hope, and the perception of stress. Although Callahan Churchill and Davis (2010) found a significant inverse correlation between optimism scores and levels of depression, because the sample did not consist of depressed women, their findings that women with positive outlooks still did not adjust well to motherhood may not be applicable to women with depression 
during pregnancy. These mixed results may also be due to differences in the studies' respective sample sizes, demographics, sampling techniques, and/or observation period lengths. Depression scores one, two, and six weeks postpartum may vary to different degrees than depression scores at six weeks, six months, and one year. Further research is needed to understand the ways in which optimism affects depression scores in the present and over time.

The ability to modify optimism in pregnant women by means of intervention has not been studied. However, studies in psychology that have shown improved depression scores after participation in on-line "happiness exercises" support the design and study of such interventions for pregnant women (Seligman, et al., 2005). Across cultures, support of a relationship between education level and optimism has been documented by Moyer et al. (2009). Optimism levels in women from the USA, Ghana, and China were found to vary with education levels, countries of origin, numbers of previous deliveries, and whether or not women had paid employment. The possibility of life experiences — such as abuse, trauma, or serious illness — to affect optimism during pregnancy remains unstudied.

This review did not examine research in published textbooks or unpublished dissertations, nor did it include works that were not peer-reviewed, thus limiting our sample size. Additionally, all studies included in this review were published after 2000, with the exception of relevant review articles. Because of the recent attention to AND as a significant maternal health issue, this review has been broad in scope and considered some studies lacking scientific rigor in order to characterize the full set of research directions that have been introduced. Pregnancy is an ideal time to foster optimism because of the receptive nature of pregnant women to health improvement, the powerful impact on women and children (including the unborn) that health improvement during this period offers, and the protective effects optimism may have on women 
and their families even in the face of psychological distress and subsequent negative health outcomes.

\section{Conclusion}

The experience of depression during pregnancy, whether diagnosed or subclinical, is a prevalent and dangerous health concern for women and their families. To alleviate symptoms and improve pregnancy and birth outcomes, there is a dire need for nonpharmacological support for women who experience depressive symptoms. Health-care providers in obstetric settings have opportunities to assess psychosocial factors such as stress and social support, as well as women's available resources for coping with depressive symptoms. Attention to well-established variables that may predispose women to, or protect them from, experiencing depression is warranted in all obstetric settings, particularly in cases where there is an unwanted pregnancy, a history of psychological distress, a lack of social support, high levels of stress, and an absence of coping strategies.

Much research remains to be done regarding the complex interactions of psychosocial factors and their impact on women's psychological health as well as interventions designed to address areas of concern. Interventions to decrease depression in pregnant women may be most effective when targeting psychosocial variables that can be altered through psychoeducation, support, and provision of resources. This review is the first to examine optimism as a potential basis for depression interventions during pregnancy. Optimism holds promise as a modifiable variable that could help protect pregnant women from the development of depression in a culturally acceptable, easily accessible, and effective way. 


\section{References}

Beddoe AE, Lee KA. Mind-body interventions during pregnancy. JOGNN_J Obst Gyn Neo. 2008; 37(2): 165-175.

Bennett HA, Einarson A, Taddio A, Koren G, Einarson TR. Prevalence of depression during pregnancy: systematic review. Obstet. Gynecol. 2004; 103(4): 698-709.

Bennett IM, Marcus SC, Palmer SC, Coyne JC. Pregnancy-related discontinuation of antidepressants and depression care visits among Medicaid recipients. Psychiat. Serv. 2010; 61(4): 386-391.

Blaney NT, Fernandez MI, Ethier KA, Wilson TE, Walter E, Koenig LJ. Psychosocial and behavioral correlates of depression among HIV-infected pregnant women. AIDS Patient Care St. 2004; 18(7): 405-415.

Boyd RC, Zayas LH, McKee MD. Mother-infant interaction, life events and prenatal and postpartum depressive symptoms among urban minority women in primary care. Matern Child Hlth J. 2006; 10(2): 139-148.

Callahan Churchill A, Davis CG. Realistic orientation and the transition to motherhood. J Soc Clin Psychol. 2010; 29(1): 39-67.

Cardemil EV, Kim S, Pinedo TM, Miller IW. Developing a culturally appropriate depression prevention program: the family coping skills program. Cult Divers Ethn Min. 2005; 11(2): 99-112.

Dennis C, Allen K. Interventions (other than pharmacological, psychosocial or psychological) for treating antenatal depression. Chichester, UK: John Wiley \& Sons, 2008.

Dennis C, Ross Lori E, Grigoriadis S. Psychosocial and psychological interventions for treating antenatal depression. Chichester, UK: John Wiley \& Sons, 2007. 
Dimidjian S, Goodman S. Nonpharmacologic intervention and prevention strategies for depression during pregnancy and the postpartum. Clin Obstet Gynecol. 2009; 52(3): 498-515.

Dorn LD, Susman EJ, Petersen AC. Cortisol reactivity and anxiety and depression in pregnant adolescents: a longitudinal perspective. Psychoneuroendocrino. 1993; 18(3): 219-239.

Dunkel Schetter C. Psychological science on pregnancy: stress processes, biopsychosocial models, and emerging research issues. Annu Rev Psychol. 2011; 62: 531-558.

Flynn HA, O’Mahen H, Massey L, Marcus S. The impact of a brief obstetrics clinic-based intervention on treatment use for perinatal depression. J Womens Health. 2006; 15(10): 1195-1204.

Fontaine KR, Jones LC. Self-esteem, optimism, and postpartum depression. J Clin Psychol. 1997; 53(1): 59-63.

Furber CM, Garrod D, Maloney E, Lovell K, McGowan L. A qualitative study of mild to moderate psychological distress during pregnancy. Int J Nurs Stud. 2009; 46(5): 669677.

Grote NK, Bledsoe SE. Predicting postpartum depressive symptoms in new mothers: the role of optimism and stress frequency during pregnancy. Health Soc Work. 2007; 32(2) 107118.

Jesse DE, Swanson MS. Risks and resources associated with antepartum risk for depression among rural southern women. Nurs Res. 2007; 56(6): 378-386.

Jesse DE, Walcott-McQuigg J, Mariella A, Swanson MS. Risks and protective factors associated with symptoms of depression in low-income African American and Caucasian women during pregnancy. J Midwifery Wom Heal. 2005; 50(5): 405-410. 
Jomeen J. The importance of assessing psychological status during pregnancy, childbirth and the postnatal period as a multidimensional construct: a literature review. Clin Eff Nurs. 2004; 8(3-4): 143-155.

Jomeen J, Martin CR. Self-esteem and mental health during early pregnancy. Clin Eff Nurs. 2005; 9(1-2): 92-95.

Knackstedt MK, Hamelmann E, Arck PC. Mothers in stress: consequences for the offspring. Am J Reprod Immunol. 2005; 54(2): 63-69.

Lancaster CA, Gold KJ, Flynn HA, Yoo H, Marcus SM, Davis MM. Risk factors for depressive symptoms during pregnancy: a systematic review. Am J Obstet Gynecol. 2010; 202(1): $5-14$.

Latendresse G. The interaction between chronic stress and pregnancy: preterm birth from a biobehavioral perspective. J Midwifery Wom Heal. 2009; 54(1): 8-17.

Lobel M, DeVincent CJ, Kaminer A, Meyer BA. The impact of prenatal maternal stress and optimistic disposition on birth outcomes in medically high-risk women. Health Psychol. 2000; 19(6): 544-553.

Luke S, Salihu HM, Alio AP, et al. Risk factors for major antenatal depression among lowincome African American women. J Womens Health. 2009; 18(11): 1841-1846.

Mann JR, McKeown RE, Bacon J, Vesselinov R, Bush F. Religiosity, spirituality and antenatal anxiety in Southern U.S. women. Arch Women Ment Hlth. 2008; 11(1): 19-26.

Marcus SM, Flynn HA, Blow FC, Barry KL. Depressive symptoms among pregnant women screened in obstetrics settings. J Womens Health. 2003; 12(4): 373-380. 
Moyer CA, Yang H, Kwawukume Y, et al. Optimism/pessimism and health-related quality of life during pregnancy across three continents: a matched cohort study in China, Ghana, and the United States. BMC Pregnancy Childbirth. 2009; 9(1): 39.

Mulder EJ, Robles de Medina PG, Huizink AC, Van den Bergh BR, Buitelaar JK, Visser GH. Prenatal maternal stress: effects on pregnancy and the (unborn) child. Early Hum Dev. 2002; 70(1-2): 3-14.

Muzik M, Marcus SM, Heringhausen JE, Flynn H. When depression complicates childbearing: guidelines for screening and treatment during antenatal and postpartum obstetric care. Obstet Gynecol Clin North Am. 2009; 36(4): 771-88, ix-x.

Nelson DB, McMahon K, Joffe M, Brensinger C. The effect of depressive symptoms and optimism on the risk of spontaneous abortion among innercity women. J Womens Health. 2003; 12(6): 569-576.

Poudevigne MS, O’Connor PJ. A review of physical activity patterns in pregnant women and their relationship to psychological health. Sports Med. 2006; 36(1): 19-38.

Price SK, Proctor EK. A rural perspective on perinatal depression: prevalence, correlates, and implications for help-seeking among low-income women. J Rural Health. 2009; 25(2): $158-166$.

Raymond JE. "Creating a safety net": Women's experiences of antenatal depression and their identification of helpful community support and services during pregnancy. Midwifery. 2009; 25(1): 39-49.

Reid H, Power M, Cheshire K. Factors influencing antenatal depression, anxiety and stress. Brit J Midwifery. 2009; 17(8): 501-508. 
Rich-Edwards JW, Kleinman K, Abrams A, et al. Sociodemographic predictors of antenatal and postpartum depressive symptoms among women in a medical group practice. $\mathrm{J}$ Epidemiol Commun H. 2006; 60(3): 221-227.

Scheier MF, Carver CS. Dispositional optimism and physical well-being: the influence of generalized outcome expectancies on health. J Pers. 1987; 55(2): 169-210.

Scheier MF, Carver CS. Optimism, coping, and health: assessment and implications of generalized outcome expectancies. Health Psychol. 1985; 4: 219-247.

Scheier MF, Carver CS, Bridges MW. Distinguishing optimism from neuroticism (and trait anxiety, self-mastery, and self-esteem): a reevaluation of the Life Orientation Test. J Pers Soc Psychol. 1994; 67: 1063-1078.

Seligman ME, Csikszentmihalyi M. Positive psychology. An introduction. Am Psychol. 2000; 55(1): 5-14.

Seligman ME, Steen TA, Park N, Peterson C. Positive psychology progress: empirical validation of interventions. Am Psychol. 2005; 60(5): 410-421.

Spinelli MG, Endicott J. Controlled clinical trial of interpersonal psychotherapy versus parenting education program for depressed pregnant women. Am J Psychiat. 2003; 160(3): 555-562.

Talge NM, Neal C, Glover V. Antenatal maternal stress and long-term effects on child neurodevelopment: how and why? J Child Psychol Psychiatry. 2007; 48(3-4): 245-261.

Tseng Y, Hsu C, Liu Y, Chen C. The experiences of prenatal depression among Taiwanese women. J Adv Nurs. 2008; 64(5): 495-503. 


\section{Chapter 3: Methods}

The dissertation study proceeded in three steps in response to each of the three research questions guiding the analysis. First, a concept analysis of nurse-patient interaction (NPI) was undertaken to provide a clearer understanding of how NPIs are conceptualized in the nursing literature. Second, pilot work was undertaken to identify how one of the nurses responded to depressed women from the Baby Behavioral Education Enhancement of Pregnancy (BEEP) study ${ }^{1}$. Third, a qualitative descriptive study was conducted to characterize the NPIs of all the Baby BEEP nurses with depressed women, comparing the interactions of women who remained depressed to those who improved by the end of pregnancy. Specific attention was given to how the interactions did or did not reflect the phases and roles identified in Peplau's theory of Interpersonal Relations, as well as identifying those elements of the interactions that may be replicable and help to inform the development of nursing interventions to support depressed women. This triangular approach to the dissertation was designed to help establish the validity of the findings, providing a solid understanding of interaction from which to develop evidencebased interventions and connect the research to contemporary nursing practice.

\section{Concept Analysis}

A concept analysis of interaction was undertaken using the method of Avant and Walker (2005). This method was developed as an adaptation of the Wilsonian concept analysis method and is commonly used in nursing research. This method is particularly useful as it is applied to conceptual frameworks, nursing theory and measurement of phenomena, and provides an indepth understanding of how interaction has been defined and examined in the nursing literature

\footnotetext{
${ }^{1}$ From this point on, women with symptoms of depression will simply be referred to as depressed. Depression was indicated by Mental Health Index-5 scores of 65 or less, which has been shown to have a sensitivity of 0.87 and specificity of 0.70 at detecting DSM-IV Axis I mood disorders, such as depression (Rumpf et al., 2001).
} 
(Walker \& Avant, 2005). Avant and Walker (2005) emphasize the identification and description of the concept's defining attributes, antecedents, consequences and empirical referents. The method takes a positivist approach by assuming that in following the proscribed steps, a concrete definition, working knowledge and understanding of the concept is possible and attainable. The Avant and Walker Method consists of the following steps:

1. Select a concept for analysis.

2. Determine the aims/purpose of the analysis.

3. Identify all uses of the concept.

4. Determine the defining attributes.

5. Construct a model case.

6. Construct a borderline and contrary case.

7. Identify antecedents and consequences.

8. Define empirical referents (Walker \& Avant, 2005).

Understanding the defining attributes and antecedents of interaction allows for its recognition within the data and a more comprehensive grasp of those factors that influence interaction. Recognizing the consequences of interaction in the data provides insights as to the quality of the interaction and its potential effect on depression scores, laying the foundation for the use of NPI as a therapeutic tool for supporting mental health in vulnerable women.

\section{Pilot Work}

To gain a preliminary grasp of the data and generate potential codes for the qualitative descriptive study of NPI, pilot work was undertaken to describe the nursing actions of one nurse toward depressed women from the Baby BEEP study. The sample was selected to represent the most depressed women in one nurse's caseload. This was accomplished by identifying those 
participants who received telephone support from one of the Baby BEEP nurses and then selecting those with Mental Health Index-5 (MHI-5) scores in the lowest tenth percentile (the MHI-5 has been validated for use in detecting levels of depression comparable to those identified through diagnostic interview) (Rumpf, Meyer, Hapke, \& John, 2001).

The data were formatted to differentiate between nurse and patient responses. Coding of the logs involved several different strategies identified by Saldana (2013) to identify and describe best all potential nursing responses used over the phone. Throughout the coding process, memos were kept to facilitate analysis and reflection, as well as replication of the methodology. After an initial cycle of open coding, a second cycle of sub-coding was used to further define and clarify the nurse responses identified in the first cycle. A final cycle of coding was used to identify the topics brought up by the pregnant women (Saldana, 2013).

\section{Qualitative Descriptive Study}

The final step in the dissertation was a qualitative descriptive study, using secondary analysis of the previously obtained Baby BEEP data. The aim of this study was to characterize the weekly interactions between the Baby BEEP research nurses and women who experienced depression at the baseline $\left(\mathrm{T}_{1}\right)$ measurement of the study.

\section{Description of Data Used for the Dissertation}

The data to be used for the dissertation study were obtained from grant NR05313:

Nursing Smoking Cessation Intervention during Pregnancy (Baby Behavioral Education Enhancement of Pregnancy or Baby BEEP) (Bullock et al., 2009). The Baby BEEP study was a randomized controlled trial (RCT) of a smoking cessation program for pregnant women conducted from 2001-2006 by the dissertation advisor, Dr. Linda Bullock. Baby BEEP was a prospective, longitudinal study that examined smoking, stress, social support, self-esteem and 
mental health at three time points during the perinatal period. Data were collected at baseline, time one ( $\mathrm{T}_{1}$, up to 24 weeks of pregnancy), time two ( $\mathrm{T}_{2}$, between 28-36 weeks of pregnancy), and time three ( $\mathrm{T}_{3}$, up to six weeks postpartum). The primary outcome measures for the RCT were smoking status, patterns of abstinence and partner influence on smoking status. The sample for the original study $(N=695)$ was recruited at Women Infants and Children (WIC) clinics in central Missouri. Inclusion criteria for the original study were as follows: 18 years of age or older; less than 24 weeks pregnant based on last menstrual period; a smoker; English speaking; and access to a telephone. Women were excluded from the study if they were less than 18 years of age or a non-smoker.

Quantitative data. Quantitative data were used to provide a demographic description of the sample (age, relationship status, abuse, education, stress, self-esteem and social support), to screen for depression (MHI-5), and to select the sample to be used in the qualitative analysis phase of the dissertation. Validated instruments were used to collect all other quantitative data. All instruments involved self-report and were administered in an interview format using paper and pencil by baccalaureate-prepared Registered Nurses. The complete battery of items for the study took under 30 minutes to complete at each time point. Further description of the development and psychometric properties, and a copy of each instrument are provided in the appendices of Chapter 4 (manuscript three).

Qualitative data. As part of the Baby BEEP study, 345 women were randomly selected to receive weekly social support phone calls from a registered nurse, in addition to 24-hour access to the nurse via "beeper" as part of the intervention. The purpose of these phone calls was to "use empathetic listening skills and provide social, emotional and/or informational support in response to each woman's individual needs, such as stressors she was facing and ways she could 
manage her stress responses" (Bullock et al., 2009). The nurses kept detailed records of what took place during each contact with the participant creating 'phone logs' that span the entire course of the study. This generated over three thousand pages of single-spaced notes about the interactions between nurse and patient that provided the descriptive data for the dissertation study. These phone logs contain rich data about the approach, attitudes and responses of nurse and patient, the communication that occurred between them, and the context that shaped their relationship throughout the course of pregnancy. For the dissertation study, only those phone logs that were generated during pregnancy, as opposed to postpartum, were analyzed.

Sample selection. The sample to be analyzed for the qualitative descriptive study was selected using the following process:

1. There were 695 women enrolled in the original Baby BEEP study. Of these, 345 received the social support intervention and 318 completed the study, providing quantitative and qualitative data at of the three time points.

2. To identify those women who experienced depression during pregnancy, women with MHI-5 scores less than or equal to 65 at $\mathrm{T}_{1}$ were selected $(n=170)$ according to cut-off values consistent with a diagnosis of major depressive disorder (Rumpf et al., 2001). This cut-off value was selected because it provides a high level of sensitivity (0.87) and would enable the identification of a large number of cases of poor mental health (Rumpf et al., 2001).

3. Of the women who were depressed at $\mathrm{T}_{1}$, two groups were created based on MHI-5 scores at $\mathrm{T}_{2}$. Women whose MHI-5 scores were equal to or below 65 at $\mathrm{T}_{1}$ and $\mathrm{T}_{2}$ were considered the "depressed" group. Women whose MHI-5 scores were above 65 at $\mathrm{T}_{2}$ were considered the "improved" group. 
4. Women in each depression group were separated into six sub-groups based on the

Baby BEEP research nurse who provided the telephone support. Figure 1 illustrates this process.

Figure 1.

Sample Selection Process

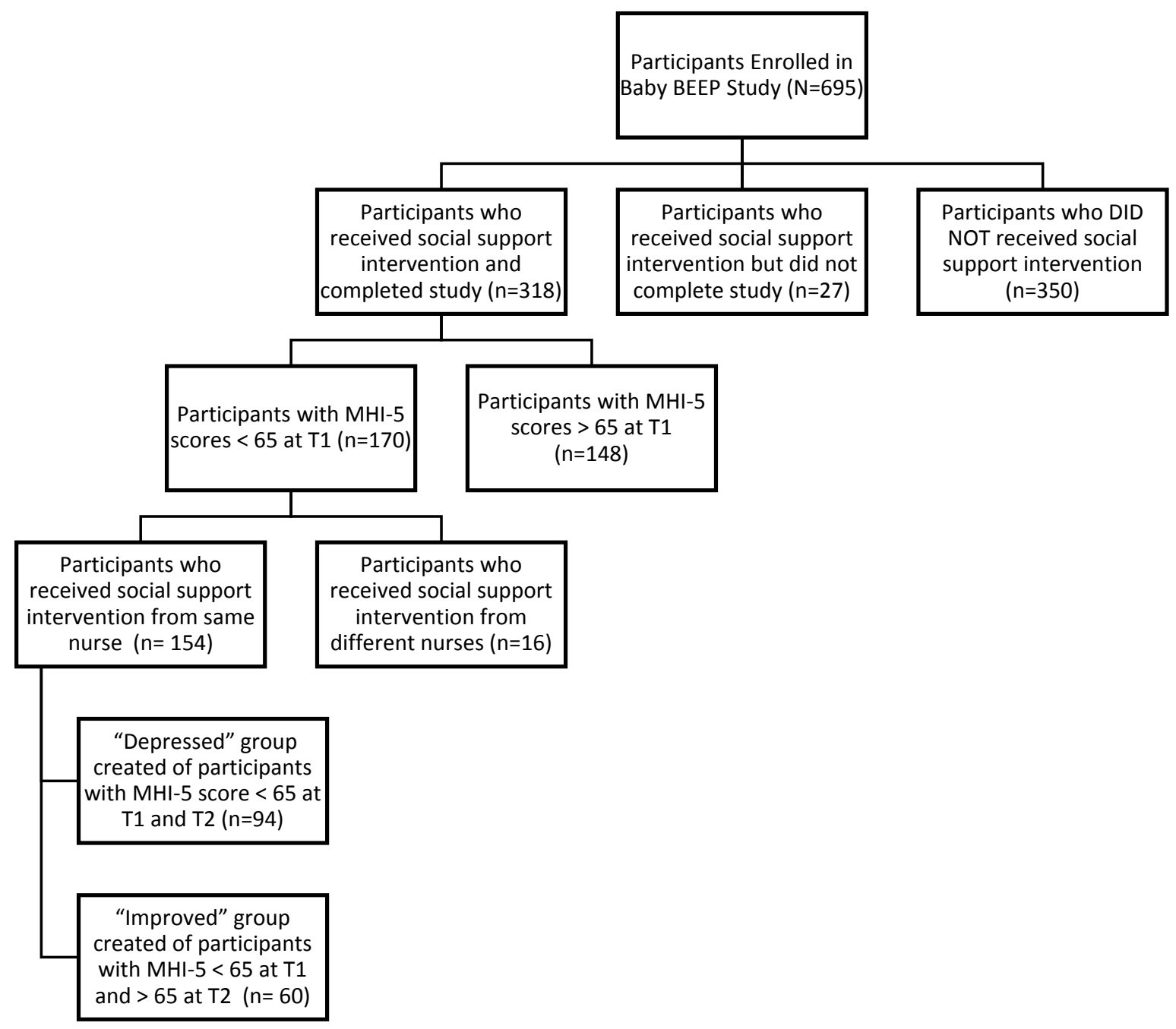

5. One woman was randomly selected from each nurse's "depressed" and "improved" groups to obtain an initial sample of 12 cases. This process was repeated, as necessary, to generate sufficient evidence or until no new coding themes emerged.

Example of data from one nurse. To illustrate the type of data that were generated by the phone logs, an example is given of one nurse's caseload of Baby Beep participants. This 
nurse had a caseload of 43 participants, 21 of whom were randomly assigned to receive telephone support. Of these, ten participants were depressed at $\mathrm{T}_{1}$ and received weekly phone calls throughout the course of pregnancy. In this exemplar, the nurse initiated phone calls as early as week 10 of pregnancy and attempted calls on a weekly basis through six weeks postpartum. Her phone calls lasted anywhere from one to 54 minutes. This resulted in a range of seven to 30 interactions per participant with an average of 20 interactions. Phone logs for each participant averaged 10 pages of detailed notes. One example of an interaction that occurred between this nurse and one of the patients is given below, with nurse responses indicated with italics:

841 BB 4-10-06, 31weeks, paged, 10:15-10:22am. Client paged me. She said she was upset and felt like talking to someone. She was sitting at a restaurant talking to me. I asked if she was alone. She was. She said her boyfriend just left to go to work and she's upset with him. Client told me she felt frustrated, tired, and hormonal; she felt like a big baby. I said that she's pregnant with twins, her hormones are probably all over the place! I asked what happened. She said her boyfriend gets mad b/c she doesn't want to talk sometimes. She said that sometimes she has nothing to talk about and it just upsets him when she talks about the babies. I asked if that was b/c they weren't his. She said that's part of it; but it's also b/c he knows she isn't going to be wanting to have any more kids for a while. His mom says she doesn't think the kids should be exposed to them being in a relationship together and not being married. I asked if her boyfriend agrees with that. Client said he's a momma's boy, and is easily influenced by that. Client wants a real wedding with a wedding dress that she's excited about; not a wedding 
at a courthouse. His mom is really pressuring them. She keeps telling them that she'll buy the marriage license and everything. I agreed that would be really frustrating. Client said she only has $\$ 5$ to her name, and she just spent it at the restaurant. I asked if she wanted me to meet her for a saliva sample, so at least she'd have that. She said that she could meet me in the lobby. Client then asked me if I would go to the food pantry with her b/c she doesn't have a caseworker anymore, and she doesn't like to go alone. I said I would go with her, but I would just follow her there in the car. Client said she'd see me in a few minutes.

Strengths of the data set. Strengths of this dataset for use as secondary data lie in its size, cost-efficiency, the unique insight it offers into the nursing process and perspective, and its breadth of variables and depth of content. In addition, the presence of quantitative and qualitative types of data provide for triangulation of findings, enhancing the trustworthiness and perspective offered through analysis. Quantitative data were collected for 625 of the 695 women at all three time points of the study, encompassing the majority of pregnancy and up to six weeks postpartum. Qualitative data were provided by nursing phone logs kept by nurses providing the intervention for 345 patients.

Reusing these valuable data is a cost-effective way to pursue rigorous nursing research without spending additional financial, institutional or personal capital. The phone logs from the dataset lend themselves to a focused, qualitative investigation that would be difficult to replicate in the real world. The phone logs contain observational data that were consistently and thoroughly collected by the research nurses over years. This type of data is particularly suited to provide unique insight into the nursing side of the NPI, specifically those nursing words, actions and thoughts that were used to support depressed women. The ability to validate findings and 
round out the study through the use of quantitative and qualitative data analyses also is beneficial as it allows for a more detailed examination of AND in this vulnerable and difficult to reach population.

\section{Qualitative Methodology}

The methodology for the dissertation study draws upon Miles and Huberman's processes of data reduction, data display, conclusion drawing and verification (Huberman \& Miles, 1994). This approach was developed to provide a more rigorous and comprehensive methodology for qualitative research. Each of the three processes is complementary and iterative with the others, deepening the analysis of the data and moving the researcher toward valid conclusions. A crosscase analysis of the interactions between nurse and women who remained depressed versus women whose depression improved by the end of pregnancy allows for comparison and contrast of NPIs across depression groups as well as across nurses (Huberman \& Miles, 1994).

Several different hand coding methods were used to facilitate the data analysis process based on the coding strategies of Miles, Huberman and Saldana (2013). In preparation for analysis, each case was read and a narrative summary generated to capture first impressions, obtain an overall picture of the data and begin to understand the process of interaction as it plays out in each case (Bazeley, 2013). Holistic coding was used to capture general topics and themes of interaction. The data were prepared, reduced further, and organized for analysis through preliminary coding of the nurse versus patient side of the interaction and the timing of the phone call (by week, trimester, and number of call).

Analysis began with a first cycle of provisional coding, using codes identified through the pilot work, as well as phases of the relationship and nurse roles identified in Peplau's theory. As provisional coding proceeded, simultaneous coding of additional nurse actions and responses 
occurred using process coding (Miles et al., 2013). Process coding also was used to identify patient actions and responses to the interaction. As coding continued, data were analyzed and continually reduced as redundant codes were eliminated and overlapping codes were collapsed. A second cycle of coding gave further meaning to the content and context of the provisional and process codes by seeking to identify patterns in the interaction between nurse and patient (Huberman \& Miles, 1994). Sub-coding and magnitude coding were used simultaneously during the second cycle to clarify and deepen the analysis of the data.

Overall, the coding process followed a confirmatory approach to the data, looking for concepts, patterns and themes of interaction that have been extensively examined in the concept analysis (Huberman \& Miles, 1994). Throughout the coding process, analytic memos, reflective journals and other writing strategies were used to clarify the researcher's thought process and insights about the data. As needed, other coding strategies were used to increase rigor, improve reliability and validate quantitative findings. Data display occurred throughout the coding process as patterns, themes and categories began to emerge, leading to the formation and testing of conclusions. The initial coding strategy is presented as follows:

1. Read through each case and create narrative summary.

2. Code for nurse versus patient side of interaction.

3. Code for timing by trimester, week, number phone call.

4. Provisional coding using codes developed in pilot work.

5. Provisional coding by Peplau's stage of interaction.

6. Provisional coding by Peplau's role of nurse within interaction.

7. Process coding of additional nursing responses and patient responses.

8. Pattern coding of interplay between nurse and patient (timing, topics). 
9. Continual elimination of redundant codes and collapsing of overlapping codes.

10. Sub-coding of initial codes.

11. Magnitude coding.

\section{Validity}

Validity and trustworthiness of the proposed qualitative research was enhanced through a variety of methods. First, retention of all study materials and documentation of the process by which the data were reduced, displayed and analyzed allowed for the replication of the process by other researchers to verify and validate findings. Second, to allow for the examination of negative cases or competing explanations, some cases of NPI in which depressed patients remained depressed were included in the analysis. This allowed for a greater degree of comparison and contrast of NPIs, identifying those processes, constructs and explanations that were unique versus shared (Huberman \& Miles, 1994). Thirdly, the researcher checked and rechecked findings, assessed data for representativeness, and kept in mind potential assumptions and biases through analytic memos and reflective journaling throughout the analysis process (Huberman \& Miles, 1994, p.438). Authenticity of the findings will be ascertained through contacting the nurses who provided the intervention, sharing with them the conclusions of the qualitative analysis and receiving their perspective as to the trustworthiness of the results.

\section{Limitations}

Limitations of using this dataset to examine NPI in low income women include the absence of primary data from the patients' perspectives, the lack of opportunity for follow up with the patients, and the self-reported nature of the instrument used to identify depression. Because these data were recorded by nurses, it is predominantly their perspectives that are obtained from the phone logs; however, the nurses use their own words to describe what the patients say and are 
experiencing in great detail. To fully understand the patients' perspectives, written records, interviews or focus group data displaying the patients' perspectives would be needed. Additionally, because the data are archival, there was no access to subjects for follow up or clarification of findings from measures or phone logs.

\section{Human Subjects}

Federal regulations require that all research involving human subjects at the University of Virginia undergo review by the University's Institutional Review Board (IRB). In accordance with this policy, this research was submitted for review by the Social and Behavioral Sciences IRB. This project was classified as "exempt" by the IRB, in alignment with the Code of Federal Regulations. In accordance with IRB policy, this research must be conducted within four years from review date, which was July 12, 2013. De-identification of the data (removal of birth dates and last names) provided further protection to human subjects by preserving the anonymity of the patients as well as the nurses. 


\title{
Chapter 4: Results (Manuscript Two)
}

\section{Nurse-Patient Interaction: A Concept Analysis}

\author{
Emily C. Evans, University of Virginia, RN, MSN \\ 4763 Dick Woods Road, Charlottesville, VA, 22903 \\ Fax 434295 3414, Phone 4342953414 \\ emilyccevans@gmail.com
}

To be submitted to: Western Journal of Nursing Research

This research received no specific grant from any funding agency in the public, commercial, or not-for-profit sectors. No conflict of interest has been declared by the author. 


\begin{abstract}
Patient satisfaction is a major priority in health-care across the United States and internationally. Nurse-patient interaction (NPI) is essential to the provision of nursing care and has a direct effect on patient satisfaction. Using the Avant and Walker method of concept analysis, this paper provides further exploration of the factors that shape NPI, describing its defining attributes, antecedents, consequences and empirical referents. Cases are provided that illustrate NPI and the concept is discussed in light of current nursing research trends and priorities. Developing nursing research agendas and interventions that support the highest levels of patient satisfaction cannot occur without due attention to what occurs during NPI.
\end{abstract}

Keywords: nurse-patient interaction, relationships, patient satisfaction, care, quality 


\section{Introduction}

Patient satisfaction has taken center-stage in the health care arena as a major factor in ensuring high-quality care (Brooks-Carthon, Kutney-Lee, Sloane, Cimiotti, \& Aiken, 2011; Goldzwieg et al., 2013; Lieber, 2014; Tejero, 2012). Nurses have been recognized as elemental to the experience of patient satisfaction since the 1960s (Wagner \& Bear, 2008). Although the definition of patient satisfaction continues to evolve as it is re-conceptualized in the literature and measured using a variety instruments, the relationship of nursing care to patient satisfaction remains constant (Chatwin, 2008; Cossette, Pepin, Côté, \& de Courval, 2008a; Rask, Brunt, \& Fridlund, 2008a; Tropea, 2012). Recent reviews suggest that nurse-patient interaction (NPI) may be one of the most influential factors shaping the patient care experience and should be “vigilantly considered" (Sharac et al., 2010; Shattell, 2004, p.720). Understanding the way in which nurses interact with patients, how interactions are shaped and the results of interaction is essential to ensuring high-quality nursing practice and relevant nursing research. The Concept of Interaction

Interaction is a concept that pervades our experience as humans. From the moment we are conceived, we are constantly in contact and communication with another being. According to the Merriam-Webster dictionary, interaction is "a mutual or reciprocal action or influence." Examination of interaction occurs in nearly every academic setting and field. In psychology, the interactions of the mind are studied. Within anthropology and sociology, the interactions of people are studied, with particular attention given to the cultural and social influences and consequences of interaction. In education, the interactions of people also are studied, but extended to concepts and ideas as presented through educational curricula. The study of interaction in the hard sciences involves genetic codes, human cells, substrates, molecules and 
elements. In the health care field, interaction is commonly examined in the context of physiology, pharmacology and biochemistry, as the interaction between substrates or entities within the human body.

Within the field of nursing, interaction has been examined between nurses and other health care professionals, nurses and nursing students, and nurses and patients, as well as their families. This has occurred in a variety of specialties, including mental health, women's health, pediatrics, geriatrics, oncology, and acute and primary care (Boström, Isaksson, Lundman, Graneheim, \& Hörnsten, 2014; Michelle Cleary et al., 2012; Donohue, 2003; Konradsen, Kirkevold, \& Zoffmann, 2009; Saghafi, Hardy, \& Hillege, 2012; Shin \& White-Traut, 2005). The purpose of this paper is to examine the concept of NPI in the health care arena to clarify what happens between nurse and patient, and provide a greater understanding of the factors that shape nursing care and the patient experience today.

\section{Description of the Problem}

Rationale

Nurse-patient interactions constitute the core of nursing care and must be understood to facilitate optimal patient outcomes. Interactions may occur intentionally, with therapeutic purpose, or inadvertently. In either case, the interaction between nurse and patient is the primary vehicle for health care delivery, with the potential to transform patients' experiences from mundane to meaningful (Haugan, Innstrand, \& Moksnes, 2013). Nurses, too, are transformed by interaction as individuals and caregivers (Millard et al., 2006). Understanding how to use their intellectual and interpersonal skills to guide interactions that facilitate health will enable nurses in any specialty to become expert clinicians and appreciate the full impact of their interactions with patients. In addition, research about NPI can help to guide the development of high-quality 
nursing interventions that will result in patient satisfaction. Nurse educators stand to benefit from a greater understanding of NPI and its application to nursing curricula that will teach students how to foster a therapeutic nurse-patient relationship.

Conceptual Framework

Nurse theorist Hildegard Peplau identified NPI as the core of nursing care in her theory of Interpersonal Relations (Peplau, 1997). This theory has its roots in psychiatric nursing and is based on psychoanalytic principles that Peplau applied to NPIs. Peplau identifies the nursepatient relationship and the interpersonal interaction inherent in developing that relationship as the vital and therapeutic component of nursing care. Her application of psychoanalytic and psychotherapeutic principles to nursing activity provides concepts by which nurses may understand their relationships with patients, as well as their purpose in physical, verbal and social interactions.

Nursing naturally involves hundreds of interactions between nurse and patient that can be analyzed, understood and characterized as relations. These relations include the "connections, linkages, bonds or patterns that develop and are identifiable within the relationship" (Peplau, 1997, p. 162). In these relationships, nurses assume varying roles based on patient needs. The role of "teacher, resource, counselor, leader, technical expert, and surrogate" (Peplau, 1997, p. 299) are all used to assist the patient in regaining health and well-being. The nurse-patient relationship is dynamic and reflexive, with each partner's actions "reciprocally oriented toward fulfilling the expectations of the other" (Peplau, 1997, p. 55). In addition, social norms and health care governance affect each partner's perception of what their role is and the acceptable parameters of the relationship. Within the nurse-patient relationship, nurses provide goods or services to the patient in the form of interaction. The nurse may be sympathetic, professional, 
and respectful or caustic, dismissive, and hurried. The foundation for the nurse's interaction is laid by personal style, nursing knowledge and interpersonal skills (Peplau, 1997).

Other nurse scientists have used the concept of NPI in their theories and models. Allen sets forth a "model of health and nursing that define(s) the participation of both the nurse and the client in health-promoting interactions" based on developmental principles (Allen \& Warner, 2002). In Watson's Theory of Caring and Humanistic Care, NPI is the means through which caring acts occur (Watson, 2009). Orem sees NPI as serving to assist the patient in correcting those areas in which deficits occur so that they may regain full capacity for self-care (Denyes, Orem, \& Bekel, 2001). King identifies NPI as an essential component of goal attainment (King, 2007). In all of these theories, NPI is the basic means whereby the nursing process is accomplished, as well as an essential component of what defines and distinguishes nursing care. Literature Review

Nurse-patient interaction emerged as an important topic in nursing literature with the Theory of Interpersonal Relations put forth by Hildegard Peplau in the 1950s (Peplau, 1997). Since that time, NPI has been measured in a variety of ways in a diversity of settings. Initial measurement took an ethnographic approach through observing interactions in their natural setting. In 1952, “the first ANA-sponsored project designed to study relationships between nurse and patients was inaugurated in a psychiatric hospital” (Kandler et al., 1952, p.1100). This examination of NPI was undertaken to understand better how nurses foster the development of emotionally beneficial care. Observation was used to ascertain the amount, direction, outcomes, and tone of interaction between patients and nurses, as well as other hospital staff.

In the next decade, NPI continued to be a topic of nursing research; however, nurse scientists shifted from a positivist exploration of this concept to a more post-positivist view, 
incorporating an awareness of the social constructs that significantly affect interaction. In 1967, Brown and Goldstein examined the amount of interaction between nurses and patients in a psychiatric ward after substitution of street clothes for traditional white uniforms. They found that the number of NPIs did increase over the study period, but also was influenced by shift timing, part or full time employment, and patient staff ratios (Brown \& Goldstein, 1967). This study demonstrates how social antecedents, such as culture and societal norms, influence NPI through the shaping of nurse and patient roles, power and authority. Findings from this study are surprisingly contemporary, highlighting the logistical factors in health care that significantly influence the amount of NPI, such as staffing ratios and shift work.

As nursing science continued to move forward, investigation of NPI became more prevalent in nursing theory and research and expanded to an international setting. Interaction was featured in the theories of Watson, Orem, King and Allen (Allen \& Warner, 2002; Denyes et al., 2001; King, 2007; Watson, 2009). Studies sought to define and clarify what occurs during NPI, differentiating it from other health care professions (Fosbinder, 1994; Kasch, 1986; Rickelman, 1971). Models were developed to explain the many factors that influence nurse and patient behavior, as well as the results of those behaviors coming together in interaction (Morse, Havens, \& Wilson, 1997; Poggenpoel, 1994). In addition, research about NPI extended beyond the psychiatric arena to other areas of nursing (Rundell, 1991). During this period, interaction was examined through a professional lens and dominated by the perspectives of nurses and researchers.

Increased attention toward the measurement of interaction began to emerge as nurses recognized the need to justify, defend and quantify their work. Instruments were developed to measure and quantify components of NPI (Fosbinder, 1994; Ravert, Williams, \& Fosbinder, 
1997). This quantification of interaction captured nursing perspectives, but more often sought the perception of interaction from the experience of the patient. This reflects another dramatic shift in the approach to understanding NPI, moving from the post-positivist perspective to a more constructionist viewpoint. No longer was priority given to what nurses or researchers thought of NPI; now the patient's perspective and the meaning they attributed to NPI became paramount. This coincided with health care culture increasingly prioritizing patient satisfaction, and recognizing the relationship between NPI and patient satisfaction. In developing the Interpersonal Competence Model, Ravert, Williams and Fosbinder found that "when patients were asked what was most important to them during nursing care, they recounted the nurse's interactions with them rather than tasks performed" (Ravert et al., 1997, p. 782).

As patient-centered care and patient-satisfaction became priorities in health care, the analytic philosophy guiding the approach to NPI continued to change. In addition to considering the social context within which interaction occurs, scientists began to incorporate concepts from symbolic interactionism. This approach "views human-to-human interaction not according to response and stimulus but through interpretation and meaningful and purposeful action and interaction" (Shattell, 2004, p. 715). Thus, NPI became more than the means by which nurses administered orders and accomplished tasks. The value and meaning of the interaction were constructed by the patients. Instrumentation began to shift toward identifying patients' perspectives of interaction and demonstrating the relationship to patient satisfaction and outcomes (Cossette, Pepin, Côté, \& de Courval, 2008b; Millard et al., 2006; Mikael Rask \& Brunt, 2007; Williams \& Irurita, 2004). This propelled NPI research to the forefront of health care quality assessment as one of the most important determinants of quality of care across all nursing specialties (Millard et al., 2006; Wagner \& Bear, 2008). 


\section{Purpose}

A critical examination of the concept of NPI is often overlooked because it is so universal. The aim of this concept analysis is to describe the concept of NPI, discover the unique factors that influence interaction in a health care setting, and understand those elements of interaction that significantly affect its quality. Using a well-developed method of concept analysis to analyze NPI, identify its components and explore its impact will help nurse scientists to understand the power and potency of this concept in effecting health care outcomes.

\section{Methods}

\section{Design}

The method of Avant and Walker (2005) was used to analyze the concept of interaction for this paper. This method was developed as an adaptation of the Wilsonian concept analysis method and is commonly used in nursing research to facilitate a greater depth and breadth of knowledge surrounding concepts relevant to nursing care. Avant and Walker's method consists of the following steps: selection of a concept for analysis; determination of the aims/purpose of the analysis; identification of all uses of the concept; determination of the defining attributes; construction of a model case; construction of a borderline and contrary case; identification of antecedents and consequences; and definition of empirical referents (Walker \& Avant, 2005). Data Retrieval and Analysis

A wide variety of health databases were searched to obtain a broad perspective of NPI. Searches in each database were conducted for the terms "nurse" AND "interaction" AND "patient" in the title. This was done to focus the search toward only those interactions that directly involved a nurse. Further limits were applied to the search when available, such as English language only, abstract available, peer reviewed journal and human studies. No date 
limits were applied to capture the origin and evolution of the concept over time. The search yielded a total of 214 articles from seven databases: CINAHL (44), Medline (28), PsychINFO (37), Sociological Abstracts (5), Web of Science (88), ERIC (4), and the Cochrane Library (8). More general research to characterize how "interaction" is used in other fields was obtained via searches on Academic Search Complete.

A systematic review of each title and abstract was undertaken to identify those articles that put forth a model, concept, instrument or theory about NPI, reviewed a significant number of articles about NPI, or provided historical perspective. Articles were excluded if these were book chapters, commentaries, duplicates, involved interactions of nurses with other health care professionals, or if the article did not address the concept of interaction as a whole. This yielded a total of 27 articles. Additional articles that were identified in the references and met inclusion criteria also were included in the sample, creating a final sample of 33. Details of the articles included in this analysis are included in Table 1.

\section{Results}

\section{Defining Attributes}

The defining attributes of a concept are those aspects that must exist for the concept to be present (Walker \& Avant, 2005). The defining attributes of NPI, as identified in the literature, are that it is health directed, involves exchange, and is dynamic, multi-dimensional and subjective. Interactions between nurse and patient are health directed, meaning, the purpose and priority is to facilitate health. As the vehicle through which nursing care is provided, nurse and patient come to interact with each other with goals and expectations for the interaction that will benefit health (Chatwin, 2008; Cossette, Cara, Ricard, \& Pepin, 2005; Rask, Brunt, \& Fridlund, 2008b). Exchange within the NPI occurs between nurse and patient and can be verbal or 
nonverbal. Both means of exchange are powerful and set the stage for analysis of interaction through language and observation (Caris-Verhallen, Timmermans, \& van Dulmen, 2004; Cleary, Edwards, \& Meehan, 1999; Holyoake, 1997; Rask et al., 2008b; Rickelman, 1971; Tropea, 2012).

As subjective experiences, NPIs are perceived uniquely by each patient and their meaning is generated by those experiencing the interaction (Aranda \& Street, 1999; Chatwin, 2008; Tropea, 2012). This leads to a complex and often conflicted experience, particularly when patients' perceptions of their roles are at odds. In a related sense, NPIs are multi-dimensional, occurring simultaneously on several different dimensions that are perceived by the individuals involved therein. Dimensions of interaction between nurse and patient that have been identified in the literature include physical/biological, psychological, social, professional, spiritual, and informative/instructional (Caris-Verhallen et al., 2004; Cossette et al., 2005; Millard et al., 2006; Williams \& Kristjanson, 2009). Nurse-patient interactions are not static, but constantly change as a result of the exchange that occurs on many dimensions as nurse and patient subjectively experience this phenomenon. This is the dynamic quality of NPI, and reflects the adaptation of each individual to each other and the environment, in addition to changes that occur with time (Kandler et al., 1952; Rask et al., 2008b; Rundell, 1991; Stoddart, 2012; Våga, Moland, EvjenOlsen, Leshabari, \& Blystad, 2013).

Antecedents

Antecedents are those events that must occur prior to the concept. For NPI, antecedents include health concerns, knowledge, expectations, interpersonal style and setting. Within each of these categories, several factors can affect the type of NPI that occurs. For any NPI to be initiated, a health concern must arise. The setting and boundaries of the NPI are significantly 
influenced by the specific health concern it is intended to address. As the interaction begins, each patient brings his or her knowledge of health, the health care system, self and care to the exchange. The patient holds knowledge about him or herself and his or her condition that is essential for the nurse to understand in facilitating health. The nurse holds knowledge about health, personhood and well-being that allow him or her to assist the patient in regaining health. Expectations have significant bearing on NPI and include the perceptions of both nurse and patient regarding the purpose of the interaction, their role within the interaction, and their preferences for how the interaction will proceed. Expectations are influenced by the past experiences, values, attitudes and culture of each individual.

Another antecedent is the interpersonal style of each patient. This style is shaped by personalities and social development. Patients have reported that imagination, a sense of humor, non-judgmental attitudes, patience, calmness, and respect as important aspects of a nurse's interpersonal style (Cleary, Hunt, Horsfall, \& Deacon, 2012). Finally, the setting has significant bearing on the type of NPI that occurs and is influenced by proximal and distal factors (Brown \& Goldstein, 1967; Chatwin, 2008; Holyoake, 1997). The proximal setting in which the interaction occurs is influenced by the location, staffing, privacy, unit dynamics and organizational structure. The larger setting is shaped by distal factors such as economics, culture, health care policies and other socio-political factors.

Consequences

The consequences of NPI occur in varying degrees depending on the quality of the interaction and have been described by the patient as involvement, power, satisfaction, coping, self-transcendence, a sense of being cared for, in addition to health-related outcomes. Many of these consequences are interrelated and somewhat sequential, with high levels of one leading to 
high levels of another. Caring has been measured as a specific component of NPI, with those patients experiencing higher quality NPI reporting an increased sense of being cared for (Cossette et al., 2005). Similarly, high-quality NPIs have been shown to increase patient involvement and power, significantly influencing patient satisfaction and coping (Hewison, 1995; Millard et al., 2006; Wagner \& Bear, 2008; Williams \& Irurita, 2004; Williams \& Kristjanson, 2009). These consequences are interrelated and occur in a cyclical pattern. As the nurse and patient use verbal and nonverbal exchanges to increase involvement and power, a subsequent increase in satisfaction and coping ensues; this motivates continued positive NPI. Health-related outcomes that have been associated with high quality NPIs are recovery times and length of hospital stay, as well as physical and psychological morbidity and mortality (Castillo \& Sanche-Sosa, 2002; Cossette, Cote, Pepin, Ricard, \& D’Aoust, 2006; Poggenpoel, 1994). Empirical Referents

Early measurement of NPI was sought through the Interpersonal Competence Instrument for Nurses (Ravert et al., 1997). This instrument was developed to be used by patients and to identify those aspects of interaction that conveyed nursing competence. Further instrumentation was developed to measure specific components of interaction, such as care or competence, and to identify the consequences of those interactions, like decision-making, control and emotional care (Cossette et al., 2005; Millard et al., 2006; Mikael Rask \& Brunt, 2007; Stoddart, 2012; Williams \& Irurita, 2004). The Patient Evaluation of Emotional Care during Hospitalization (PEECH) scale was developed to ascertain patients' perspectives on the interpersonal interaction that occurred with nurses and contributed to their emotional care through four dimensions: level of security; level of knowing; level of personal value; and level of connection (Williams \& Kristjanson, 2009). Finally, the Caring Nurse-Patient Interactions Scale was developed to 
measure the elements of caring present in NPI, enabling links between nursing care and patient outcomes to more readily be identified and measured (Cossette et al., 2008a). This is the most examined instrument for examining NPI, in terms of validity and reliability, and is extremely relevant to contemporary nursing theory; however, it approaches NPI as beneficial in only the caring dimension, overlooking other important aspects of this concept.

\section{Concept Map}

To more fully illustrate the concept of NPI, a concept map is presented in Figure 1. The circle at the center signifies the centrality of NPI in the provision of nursing care and includes its defining attributes. The antecedents and consequences bracket NPI as those things that precede and result from the interaction. The iterative process is indicated by the arrows that connect the consequences back to the antecedents, illustrating the reciprocal influence on each. These cycles of interaction can develop into patterns that dictate how each patient acts and responds throughout the course of the nurse-patient relationship.

\section{Cases}

Avant and Walker's method of concept analysis suggests that cases be used to illustrate the concept to varying degrees as experienced in real-life. The model case provides an example of the concept with all of its defining attributes; the borderline case displays only some of the attributes, with the contrary case providing a clear example of what the concept is not. Model Case

Jerri has been a nurse for Ryan as he has recovered from a traumatic brain injury for the past three months. Jerri has provided nursing interventions for Ryan, including medication administration, teaching, dressing changes and physical therapy. Ryan frequently confides in Jerri about emotional and familial issues. Jerri used to just listen and nod, but after a day when 
Ryan was particularly despondent, Jerri now responds and offers encouraging suggestions that provide Ryan with a sense of hope and empowerment. Ryan continues to confide in Jerri and Jerri reciprocates, frequently discussing personal as well as professional issues.

This case is health-directed and involves exchange between the nurse and patient. Both experience a dynamic interaction, altering their responses to each other according to their subjective perception of the encounter. This interaction is multi-dimensional, addressing components of the professional, social and spiritual dimensions, and results in a high quality of care and patient satisfaction.

Borderline Case

Bill is performing Jade's initial assessment upon arrival in the Labor and Delivery Unit. Jade is breathing hard and getting uncomfortable. Bill quickly puts the fetal monitor and contraction belt on her, faces the computer, and begins the intake history. Bill notices that Jade is breathing harder and closing her eyes, so he speeds up his assessment. When Jade looks to Bill saying, "Is this normal?" Bill replies, "Unfortunately, yes," then quickly leaves the room.

This interaction is health-directed, involves exchange, is dynamic and subjective, but is not multi-dimensional. As such, it is a borderline case of NPI and would most likely not result in high-quality care or patient satisfaction.

Contrary Case

Suzie shares nursing care for Angela in the pediatric unit. Another nurse is responsible for assessing Angela's vital signs. Suzie likes to make sure all of Angela's medications and orders are properly transcribed and recorded in the computer. She quickly and efficiently carries out any orders without talking to Angela or even making eye contact. When Angela calls for a nurse, Suzie does not respond, but instead, waits for the other nurse to "get that call light." 
This is a contrary case because it does not demonstrate the essential components of NPI. The primary nurse's interactions with the patient do not involve exchange, they are not dynamic, nor are they multi-dimensional. Nursing care of this quality rarely results in high levels of patient satisfaction.

\section{Discussion}

The importance of NPI has been examined in the context of a changing health care system, with emphasis on its value and importance in all areas of nursing and its direct relationship with patient satisfaction and quality of care (Chatwin, 2008; Wagner \& Bear, 2008). Nurse-patient interaction has received attention from nurse scientists and has been examined to establish the validity of nursing as a profession, identify the distinct contributions of nurses, provide empirical evidence of nursing care, and encapsulate the phenomenon of nursing (Shattell, 2004). As such, it has been examined in relationship to caring, patient satisfaction, patient involvement, decision making, self-care and emotional care (Haugan et al., 2013; Millard et al., 2006; Williams \& Kristjanson, 2009). However, the idea of interaction between nurse and patient is taken for granted, in that the purpose, effect and activities of the interaction are often assumed. In actuality, NPI is a complex and essential phenomenon that has the potential to transform health-related experiences for patients and providers. This paper specifies what constitutes NPI, the factors that influence it, and how it shapes the patient care experience.

The measurement of NPI has been exclusively subjective. There is no lab test, blood value or standardized instrument for measuring interaction. Measurement has typically occurred through observation, self-report, interviews, and focus groups. Initial measurement of NPI in the second half of the 1900s was approached from a positivist perspective, with researchers tallying the frequency, topic and type of interactions observed (Brown \& Goldstein, 1967; Kandler et al., 
1952). Current research is framed in a symbolic interactionist perspective (Tropea, 2012). This paradigm shift adjusts the focus of NPI research toward understanding the meaning of interaction for patients and nurses, in addition to the ways in which NPI facilitates holistic dimensions of health. The consequences of NPI identified in this paper, such as caring, coping, involvement, and satisfaction, have become the focus of many instruments that identify and measure NPI (Cossette et al., 2006; M Rask et al., 2008a; Williams \& Irurita, 2004).

Alternative paradigms from which to approach NPI, such as "therapeutic emplotment," create an alternative view of this experience that is more in line with the mutuality and reciprocity of the concept, versus the linear, positivist approach that has dominated much of NPI research (Tropea, 2012, p.939). This paper is aligned with these contemporary perspectives in that it provides a more complete picture of what occurs during NPI, shifting the focus from taskoriented inventories to a broader perspective on all the elements of interaction that shape and effect patient satisfaction. In the Future of Nursing Report issued by the Institute of Medicine, nurses are encouraged to practice to the fullest extent of their education and attain the highest levels of education possible (Medicine, 2010). This position supports the view and practice of nursing as much more than a task-oriented regimen of procedures, but a complex and powerful tool that is therapeutic itself and significantly shapes patient outcomes. Chatwin (2008) moves health care research in a similar direction, suggesting the use of content analysis in the examination of nurse and patient conversations to capture all the therapeutic exchange involved in nursing care and to provide a more comprehensive and in-depth examination of all that occurs within NPI.

Understanding the concept of NPI is essential to the development of nursing research and theory that is relevant and applicable to nursing practice. To do this, nursing studies must 
examine and account for all the elements of NPI, catalogue the variety of ways in which it is implemented in patient care, and undertake a meaningful exploration of how to maximize this abundant resource in creating the best possible clinical outcomes. Specific attention to the components of NPI identified by this paper, and the degree to which these are evident during patient care, will provide the basis for generating nursing research that is true, relevant and useful in ensuring high-levels of quality and patient satisfaction. Nurse scientists must give adequate consideration to NPI in their research agendas and interventions, recognizing that there is an optimal way to interact with patients to facilitate health and satisfaction. Understanding the defining attributes, antecedents and consequences of NPI is essential to informing this process. Limitations of this study are the result of the limited samples in which NPI has been examined and the weaknesses of Avant and Walker's method. Interactions between nurses and patients have been examined primarily in the psychiatric/mental health field, and have been typified by small sample sizes (Brunt \& Rask, 2013; Cleary et al., 2012; Sharac et al., 2010; Shattell, 2004; Shin \& White-Traut, 2005; Williams \& Irurita, 2004). In addition, the Avant and Walker method offers some limitations because it is grounded in a positivist tradition. The steps of the method do not account for additional perspectives offered through race, gender and class. In addition, it does not account for the evolution of the concept over time; however, discussion of the concept of NPI and how it has been addressed over time is provided in the results section. However, using the Avant and Walker method to understand NPI provides clarification about what occurs during NPI and will help nurses and other health care professionals recognize and value this important aspect of health care. 


\section{Conclusion}

Nursing science stands to benefit from a greater understanding of NPI in several ways. A careful characterization of each attribute can provide great insight into the quality of the interaction and direct the development of educational programs intended to enhance nursing knowledge and skill. Further explanation of the impact of NPI may arise as theorists examine the relationship between qualities of NPI and patient, as well as nurse consequences. Recognizing how NPI affects patient outcomes will illuminate the critical role nurses play in promoting health and motivate a more mindful approach to nursing care. Understanding the defining attributes of NPI allows for its distinction in the health care arena and provides clear constructs that enable its measurement in research. Identifying components of therapeutic interactions provides evidence for the development of nursing interventions. The antecedents and consequences offer insights into the factors and settings that dramatically shape NPI and can be used in conceptual frameworks of nursing care. Finally, nursing educators must understand the concept of NPI to develop well-suited curricula that will address the intellectual and interpersonal skills needed by nursing students today. 


\section{References}

Allen, F. M., \& Warner, M. (2002). A developmental model of health and nursing. Journal of Family Nursing, 8(2), 96-135. doi:10.1177/107484070200800202

Aranda, S. K., \& Street, A. F. (1999). Being authentic and being a chameleon: Nurse-patient interaction revisited. Nursing Inquiry, 6(2), 75-82. Retrieved from http://www.ncbi.nlm.nih.gov/pubmed/10696199

Bazeley, P. (2013). Qualitative Data Analysis Practical Strategies. (J. Seaman, Ed.) (p. 444). Thousand Oaks, CA: Sage Publications.

Beddoe, A. E., \& Lee, K. A. (2008). Mind-body interventions during pregnancy. Journal of Obstetric, Gynecologic, and Neonatal Nursing : JOGNN / NAACOG, 37(2), 165-75. doi:10.1111/j.1552-6909.2008.00218.x

Bennett, H. A., Einarson, A., Taddio, A., Koren, G., \& Einarson, T. R. (2004a). Depression during pregnancy : Overview of clinical factors. Clinical Drug Investigation, 24(3), 157-79. Retrieved from http://www.ncbi.nlm.nih.gov/pubmed/17516702

Bennett, H. A., Einarson, A., Taddio, A., Koren, G., \& Einarson, T. R. (2004b). Prevalence of depression during pregnancy: systematic review. Obstetrics and Gynecology, 103(4), 698709. doi:10.1097/01.AOG.0000116689.75396.5f

Bennett, I. M., Culhane, J. F., Webb, D. a, Coyne, J. C., Hogan, V., Mathew, L., \& Elo, I. T. (2010). Perceived discrimination and depressive symptoms, smoking, and recent alcohol 
use in pregnancy. Birth (Berkeley, Calif.), 37(2), 90-7. doi:10.1111/j.1523-

536X.2010.00388.x

Bennett, I. M., Marcus, S. C., Palmer, S. C., \& Coyne, J. C. (2010). Pregnancy-related discontinuation of antidepressants and depression care visits among Medicaid recipients. Psychiatric Services, 61(4), 386-91. doi:10.1176/appi.ps.61.4.386

Bhandari, S., Bullock, L. F. C., Bair-Merritt, M., Rose, L., Marcantonio, K., Campbell, J. C., \& Sharps, P. (2012). Pregnant women experiencing IPV: impact of supportive and nonsupportive relationships with their mothers and other supportive adults on perinatal depression: a mixed methods analysis. Issues in Mental Health Nursing, 33(12), 827-37. doi: $10.3109 / 01612840.2012 .712628$

Bhandari, S., Levitch, A. H., Ellis, K. K., Ball, K., Everett, K., Geden, E., \& Bullock, L. (2008). Comparative analyses of stressors experienced by rural low-income pregnant women experiencing intimate partner violence and those who are not. Journal of Obstetric, Gynecologic, and Neonatal Nursing : JOGNN / NAACOG, 37(4), 492-501. doi:10.1111/j.1552-6909.2008.00266.x

Bloom, T., Glass, N., Curry, M. A., Hernandez, R., \& Houck, G. (2012). Maternal stress exposures, reactions, and priorities for stress reduction among low-income, urban women. Journal of Midwifery \& Women's Health, 58(2), 167-74. doi:10.1111/j.15422011.2012.00197.x

Boström, E., Isaksson, U., Lundman, B., Graneheim, U. H., \& Hörnsten, Å. (2014). Interaction between diabetes specialist nurses and patients during group sessions about self- 
management in type 2 diabetes. Patient Education and Counseling, 94(2), 187-92. doi:10.1016/j.pec.2013.10.010

Brooks-Carthon, J. M., Kutney-Lee, A., Sloane, D. M., Cimiotti, J. P., \& Aiken, L. H. (2011). Quality of care and patient satisfaction in hospitals with high concentrations of black patients. Journal of Nursing Scholarship : An Official Publication of Sigma Theta Tau International Honor Society of Nursing / Sigma Theta Tau, 43(3), 301-10. doi:10.1111/j.1547-5069.2011.01403.x

Brown, J., \& Goldstein, L. (1967). Nurse-patient interaction before and after the substitution of street clothes for uniforms. International Journal of Socail Psychiatry, 14(1), 32-43.

Brunt, D., \& Rask, M. (2013). Validation of the Verbal and Social Interaction questionnaire: carers' focus in the carer-resident relationship in supported housing facilities for persons with psychiatric disabilities (VSI-SH). Journal of Psychiatric and Mental Health Nursing, 20(3), 279-85. doi:10.1111/j.1365-2850.2012.01925.x

Bullock, L., Everett, K. D., Mullen, P. D., Geden, E., Longo, D. R., \& Madsen, R. (2009). Baby BEEP: A randomized controlled trial of nurses' individualized social support for poor rural pregnant smokers. Maternal and Child Health Journal, 13(3), 395-406. doi:10.1007/s10995-008-0363-z

Caris-Verhallen, W., Timmermans, L., \& van Dulmen, S. (2004). Observation of nurse-patient interaction in oncology: Review of assessment instruments. Patient Education and Counseling, 54(3), 307-20. doi:10.1016/j.pec.2003.12.009 
Castillo, J., \& Sanche-Sosa, J. J. (2002). Well-being and medical recovery in the critical care unit: The role of the nurse-patient interaction. Salud Mental, 25(2), 21-31.

Chatwin, J. (2008). Hidden dimensions : The analysis of interaction in nurse - patient encounters. Quality in Primary Care, 16, 109-115.

Cleary, M., Edwards, C., \& Meehan, T. (1999). Factors influencing nurse-patient interaction in the acute psychiatric setting: An exploratory investigation. The Australian and New Zealand Journal of Mental Health Nursing, 8(3), 109-16. Retrieved from http://www.ncbi.nlm.nih.gov/pubmed/10661080

Cleary, M., Hunt, G. E., Horsfall, J., \& Deacon, M. (2012). Nurse-patient interaction in acute adult inpatient mental health units: A review and synthesis of qualitative studies. Issues in Mental Health Nursing, 33(2), 66-79. doi:10.3109/01612840.2011.622428

Cossette, S., Cara, C., Ricard, N., \& Pepin, J. (2005). Assessing nurse-patient interactions from a caring perspective: Report of the development and preliminary psychometric testing of the Caring Nurse--Patient Interactions Scale. International Journal of Nursing Studies, 42(6), 673-86. doi:10.1016/j.ijnurstu.2004.10.004

Cossette, S., Cote, J. K., Pepin, J., Ricard, N., \& D’Aoust, L.-X. (2006). A dimensional structure of nurse-patient interactions from a caring perspective: Refinement of the Caring NursePatient Interaction Scale (CNPI-Short Scale). Journal of Advanced Nursing, 55(2), 198214. doi:10.1111/j.1365-2648.2006.03895.x 
Cossette, S., Pepin, J., Côté, J. K., \& de Courval, F. P. (2008a). The multidimensionality of caring: A confirmatory factor analysis of the Caring Nurse-Patient Interaction Short Scale. Journal of Advanced Nursing, 61(6), 699-710. doi:10.1111/j.1365-2648.2007.04566.x

Cossette, S., Pepin, J., Côté, J. K., \& de Courval, F. P. (2008b). The multidimensionality of caring: A confirmatory factor analysis of the Caring Nurse-Patient Interaction Short Scale. Journal of Advanced Nursing, 61(6), 699-710. doi:10.1111/j.1365-2648.2007.04566.x

Curry, M. A., Burton, D., \& Fields, J. (1998). The Prenatal Psychosocial Profile: A research and clinical tool. Research in Nursing and Health, 21(3), 211-9. Retrieved from http://www.ncbi.nlm.nih.gov/pubmed/9609506

Dennis, C., \& Dowswell, T. (2013). Interventions ( other than pharmacological , psychosocial or psychological ) for treating antenatal depression. Cochrane Database of Systematic Reviews, (7). doi:10.1002/14651858.CD006795.pub3.Copyright

Dennis, C. L., \& Allen, K. (2010). Interventions ( other than pharmacological, psychosocial or psychological ) for treating antenatal depression ( Review ). The Cochrane Library, (6).

Dennis, C. L., Ross, L. E., \& Grigoriadis, S. (2010). Psychosocial and psychological interventions for treating antenatal depression ( Review ). In The Cochrane Collaboration. John Wiley \& Sons, Ltd.

Denyes, M. J., Orem, D. E., \& Bekel, G. (2001). Self-care: A foundational science. Nursing Science Quarterly2, 14(1), 48-55. 
Dimidjian, S., \& Goodman, S. (2009). Nonpharmacologic intervention and prevention strategies for depression during pregnancy and the postpartum. Clinical Obstetrics and Gynecology, 52(3), 498-515. doi:10.1097/GRF.0b013e3181b52da6

Donohue, R. K. (2003). Nurse practitioner - client interaction as resource exchange in a women ' s health clinic : an exploratory study, 011(617), 717-725.

Evans, E. C., \& Bullock, L. F. C. (2012). Optimism and other psychosocial influences on antenatal depression: A systematic review. Nursing \& Health Sciences, 14(3), 352-61. doi:10.1111/j.1442-2018.2012.00700.x

Fisher, J., Cabral de Mello, M., Patel, V., Rahman, A., Tran, T., Holton, S., \& Holmes, W. (2012). Prevalence and determinants of common perinatal mental disorders in women in low- and lower-middle-income countries: a systematic review. Bulletin of the World Health Organization, 90(2), 139G-149G. doi:10.2471/BLT.11.091850

Fosbinder, D. (1994). Patient perceptions of nursing care: an emerging theory of interpersonal competence. Journal of Advanced Nursing, 20(6), 1085-93. Retrieved from http://www.ncbi.nlm.nih.gov/pubmed/7860855

Furber, C. M., Garrod, D., Maloney, E., Lovell, K., \& McGowan, L. (2009). A qualitative study of mild to moderate psychological distress during pregnancy. International Journal of Nursing Studies, 46(5), 669-77. doi:10.1016/j.ijnurstu.2008.12.003 
Gavin, N. I., Gaynes, B. N., Lohr, K. N., Meltzer-brody, S., Gartlehner, G., \& Swinson, T. (2005). Perinatal depression: A systematic review of prevalence and incidence. Obstetrics and Gynecology, 106(5), 1071-1083.

Gaynes, B. N., Gavin, N., Meltzer-Brody, S., Lohr, K. N., Swinson, T., Gartlehner, G., ... Miller, W. C. (2005). Perinatal depression: Prevalence, screening accuracy, and screening outcomes. Evidence Report/technology Assessment (Summary), (119), 1-8. Retrieved from http://www.ncbi.nlm.nih.gov/pubmed/15760246

Goldzwieg, C. L., Orshansky, G., Paige, N. M., Twosgih, A. A., Haggstrom, D. A., Maike-Lye, I., ... Shekelle, P. G. (2013). Annals of internal medicine review electronic patient portals : Evidence on health outcomes, satisfaction, efficiency, and attitudes. A review. Annals of Internal Medicine, 159(10), 679-.

Grigoriadis, S., VonderPorten, E. H., Mamisashvili, L., Tomlinson, G., Dennis, C.-L., Koren, G., ... Ross, L. E. (2013). The impact of maternal depression during pregnancy on perinatal outcomes: a systematic review and meta-analysis. The Journal of Clinical Psychiatry, 74(4), e321-41. doi:10.4088/JCP.12r07968

Haugan, G., Innstrand, S. T., \& Moksnes, U. K. (2013). The effect of nurse-patient interaction on anxiety and depression in cognitively intact nursing home patients. Journal of Clinical Nursing, 22(15-16), 2192-205. doi:10.1111/jocn.12072

Hewison, a. (1995). Nurses' power in interactions with patients. Journal of Advanced Nursing, 21(1), 75-82. Retrieved from http://www.ncbi.nlm.nih.gov/pubmed/7897081 
Holyoake, D. (1997). Exploring the nature of nurse interaction using an interaction interview schedule: The results. Psychiatric Care, 4, 83-87.

Huberman, A. M., \& Miles, M. B. (1994). Handbook of Qualitative Research. (N. K. Denzin \& Y. S. Lincoln, Eds.) (1st ed., pp. 428-444). Thousand Oaks, CA: Sage Publications.

Jeong, H.-G., Lim, J.-S., Lee, M.-S., Kim, S.-H., Jung, I.-K., \& Joe, S.-H. (2013). The association of psychosocial factors and obstetric history with depression in pregnant women: Focus on the role of emotional support. General Hospital Psychiatry, 35(4), 354-8. doi:10.1016/j.genhosppsych.2013.02.009

Jesse, D. E., Dolbier, C. L., \& Blanchard, A. (2008). Barriers to seeking help and treatment suggestions for prenatal depressive symptoms: focus groups with rural low-income women. Issues in Mental Health Nursing, 29(1), 3-19. doi:10.1080/01612840701748664

Jomeen, J. (2004). The importance of assessing psychological status during pregnancy, childbirth and the postnatal period as a multidimensional construct: A literature review. Clinical Effectiveness in Nursing, 8(3-4), 143-155. doi:10.1016/j.cein.2005.02.001

Kandler, H., Behymer, A. F., Kegeles, S. S., Boyd, R. W., \& Kandler, B. H. (1952). A study of nurse-patient interaction in a mental hospital. The American Journal of Nursing, 52(9), $1100-1103$.

Kasch, C. R. (1986). Toward a theory of nursing action: Skills and competency in nurse-patient interaction. Nursing Research, 35(4), 226-230. 
Kim, H. S., \& Collak, I. (2006). Nursing Theories: Conceptual and Philosophical Foundations. (H. suzie Kim \& I. Kollak, Eds.) (2nd ed.). New York, NY: Springer Publishing Company.

King, I. M. (2007). King's conceptual system, theory of goal attainment, and transaction process in the 21st century. Nursing Science Quarterly, 20(2), 109-111.

Knackstedt, M. K., Hamelmann, E., \& Arck, P. C. (2005). Mothers in stress: consequences for the offspring. American Journal of Reproductive Immunology (New York, N.Y. : 1989), 54(2), 63-9. doi:10.1111/j.1600-0897.2005.00288.x

Konradsen, H., Kirkevold, M., \& Zoffmann, V. (2009). Surgical facial cancer treatment: the silencing of disfigurement in nurse-patient interactions. Journal of Advanced Nursing, 65(11), 2409-18. doi:10.1111/j.1365-2648.2009.05102.x

Kopelman, R. C., Moel, J., Mertens, C., Stuart, S., Arndt, S., \& O’Hara, M. W. (2008). Barriers to care for antenatal depression. Psychiatric Services (Washington, D.C.), 59(4), 429-32. doi:10.1176/appi.ps.59.4.429

Krouse, Helene, J., Krouse, J. H., \& Roberts, S. J. (1988). Preliminary validation of a nursepatient interaction tool. Perceptual and Motor Skills, 67, 281-282.

Lancaster, C. A., Gold, K. J., Flynn, H. A., Yoo, H., Marcus, S. M., \& Davis, M. M. (2010). Risk factors for depressive symptoms during pregnancy: A systematic review. American Journal of Obstetrics and Gynecology, 202(1), 5-14. doi:10.1016/j.ajog.2009.09.007.Risk 
Levy, L. B., \& O’Hara, M. W. (2010). Psychotherapeutic interventions for depressed, lowincome women: a review of the literature. Clinical Psychology Review, 30(8), 934-50. doi:10.1016/j.cpr.2010.06.006

Lieber, J. L. (2014). How do your patient satisfaction scores measure up? Nursing Management, 45(2), 22-5. doi:10.1097/01.NUMA.0000442647.39442.32

McFarlane, J., Parker, B., Soeken, K., \& Bullock, L. (1992). Assessing for abuse during pregnancy. Journal of American Medical Association, 267(23), 3167-3178.

Medicine, I. of. (2010). The future of nursing: leading change, advancing health. Journal for Nurses in Professional Development (Vol. 29). Washington, DC. doi:10.1097/NND.0b013e318287d1ad

Miles, M. B., Huberman, A. M., \& Saldana, J. (2013). Qualitative Data Analysis: A Methods Sourcebook (3rd ed., pp. 69-104). Thousand Oaks, CA: Sage Publications.

Millard, L., Hallett, C., \& Luker, K. (2006). Nurse-patient interaction and decision-making in care: Patient involvement in community nursing. Journal of Advanced Nursing, 55(2), 14250. doi:10.1111/j.1365-2648.2006.03904.x

Morse, J. M., Havens, G. A. D., \& Wilson, S. (1997). The comforting interaction: Developing a model of nurse-patient relationship. Scholarly Inquiry for Nursing Practice: An International Journal, 11(4), 321-347.

Muzik, M., Marcus, S. M., Heringhausen, J. E., \& Flynn, H. (2009). When depression complicates childbearing: Guidelines for screening and treatment during antenatal and 
postpartum obstetric care. Obstetrics and Gynecology Clinics of North America, 36(4), 77188, ix-x. doi:10.1016/j.ogc.2009.10.006

Norton, L. B., Peipert, J., Zeirler, S., Lima, B., \& Hume, L. (1995). Battering in pregnancy: An assessment of two screening methods. Obstetrics and Gynecology, 85(3).

Peplau, H. (1997). Peplau's theory of interpersonal relations. Nursing Science Quarterly, 10(4), $162-167$.

Peplau, H. E. (1991). Interpersonal relations in nursing: A conceptual frame of reference for psychodynamic nursing (p. 355). New York, NY: Springer Publishing Company.

Poggenpoel, M. (1994). Psychiatric nurse-patient interaction facilitating mental health. Curationis, 17(1), 51-57.

Rask, M., \& Brunt, D. (2007). Verbal and social interactions in the nurse-patient relationship in forensic psychiatric nursing care: A model and its philosophical and theoretical foundation. Nursing Inquiry, 14(2), 169-76. doi:10.1111/j.1440-1800.2007.00364.x

Rask, M., Brunt, D., \& Fridlund, B. (2008a). Validation of the verbal and social interaction questionnaire: nurses' focus in the nurse-patient relationship in forensic nursing care. Journal of Psychiatric and Mental Health Nursing, 15(9), 710-6. doi:10.1111/j.13652850.2008.01292.x

Rask, M., Brunt, D., \& Fridlund, B. (2008b). Validation of the verbal and social interaction questionnaire: nurses' focus in the nurse-patient relationship in forensic nursing care. 
Journal of Psychiatric and Mental Health Nursing, 15(9), 710-6. doi:10.1111/j.13652850.2008.01292.x

Rasmussen, H. N., Scheier, M. F., \& Greenhouse, J. B. (2009). Optimism and physical health: a meta-analytic review. Annals of Behavioral Medicine : A Publication of the Society of Behavioral Medicine, 37(3), 239-56. doi:10.1007/s12160-009-9111-x

Ravert, P., Williams, M., \& Fosbinder, D. M. (1997). The interpersonal competence instrument for nurses. Western Journal of Nursing Research, 17(6), 781-791.

Records, K., \& Rice, M. (2007). Psychosocial Correlates of Depression of Pregnancy, 231-242. doi:10.1111/J.1552-6909.2007.00140.x

Reichenheim, M. E. (2004). Comparison between the abuse assessment screen and the revised conflict tactics scales for measuring physical violence during pregnancy. Journal of Epidemiology \& Community Health, 58(6), 523-527. doi:10.1136/jech.2003.011742

Reid, B. H., Power, M., \& Cheshire, K. (2007). Factors influencing antenatal depression , anxiety and stress.

Rickelman, B. L. (1971). Bio-psycho-social linguistics: A conceptual approach to nurse-patient interaction. Nursing Research, 20(5), 398-403.

Rose, L., Alhusen, J., Bhandari, S., Soeken, K., Marcantonio, K., Bullock, L., \& Sharps, P. (2010). Impact of intimate partner violence on pregnant women's mental health: mental distress and mental strength. Issues in Mental Health Nursing, 31(2), 103-11. doi: $10.3109 / 01612840903254834$ 
Rumpf, H. J., Meyer, C., Hapke, U., \& John, U. (2001). Screening for mental health: Validity of the MHI-5 using DSM-IV Axis I psychiatric disorders as gold standard. Psychiatry Research, 105(3), 243-53. Retrieved from http://www.ncbi.nlm.nih.gov/pubmed/11814543

Rundell, S. (1991). A study of nurse-patient interaction in a highg dependency unit. Intensive Care Nursing, 7, 171-178.

Saghafi, F., Hardy, J., \& Hillege, S. (2012). New graduate nurses' experieces of interactions in the critical care unit. Contemporary Nurse, 42(1), 20-27.

Saldana, J. (2013). The Coding Manual for Qualitative Researchers (Second ed.). Thousand Oaks, CA.

Scheier, M. F., \& Carver, C. S. (1985). Optimism, coping, and health: assessment and implications of generalized outcome expectancies. Health Psychology : Official Journal of the Division of Health Psychology, American Psychological Association, 4(3), 219-47. Retrieved from http://www.ncbi.nlm.nih.gov/pubmed/4029106

Schetter, C. D. (2009). Stress Processes in Pregnancy and Preterm Birth. Current Directions in Psychological Science, 18(4), 205-209. doi:10.1111/j.1467-8721.2009.01637.x

Schlachta-Fairchild, L., Elfrink, V., \& Deickman, A. (2008). Patient Safety, Telenursing , and Telehealth. Patient Safety and Quality: An Evidence-Based Handbookfor Nurses. Rockville, MD: Agency for Healthcare Research and Quality. Retrieved from http://www.ahrq.gov/professionals/cliniciansproviders/resources/nursing/resources/nurseshdbk/index.html 
Sharac, J., McCrone, P., Sabes-Figuera, R., Csipke, E., Wood, A., \& Wykes, T. (2010). Nurse and patient activities and interaction on psychiatric inpatients wards: a literature review. International Journal of Nursing Studies, 47(7), 909-17. doi:10.1016/j.ijnurstu.2010.03.012

Shattell, M. (2004). Nurse-patient interaction: A review of the literature. Journal of Clinical Nursing, 13(6), 714-22. doi:10.1111/j.1365-2702.2004.00965.x

Shin, H., \& White-Traut, R. (2005). Nurse-child interaction on an inpatient paediatric unit. Journal of Advanced Nursing, 52(1), 56-62. doi:10.1111/j.1365-2648.2005.03564.x

Stoddart, K. M. (2012). Social meanings and understandings in patient-nurse interaction in the community practice setting: A grounded theory study. BMC Nursing, 11, 14. doi:10.1186/1472-6955-11-14

Tejero, L. M. S. (2012). The mediating role of the nurse-patient dyad bonding in bringing about patient satisfaction. Journal of Advanced Nursing, 68(5), 994-1002. doi:10.1111/j.13652648.2011.05795.x

Tropea, S. (2012). “Therapeutic emplotment”: A new paradigm to explore the interaction between nurses and patients with a long-term illness. Journal of Advanced Nursing, 68(4), 939-47. doi:10.1111/j.1365-2648.2011.05847.x

Våga, B. B., Moland, K. M., Evjen-Olsen, B., Leshabari, S. C., \& Blystad, A. (2013). Rethinking nursing care: an ethnographic approach to nurse-patient interaction in the context of a HIV prevention programme in rural Tanzania. International Journal of Nursing Studies, 50(8), 1045-53. doi:10.1016/j.ijnurstu.2012.11.025 
Wagner, D., \& Bear, M. (2008). Patient satisfaction with nursing care: a concept analysis within a nursing framework. Journal of Advanced Nursing, 65(3), 692-701. doi:10.1111/j.13652648.2008.04866.x

Walker, L. O., \& Avant, K. C. (2005). Strategies for theory construciton in nursing (4th ed.). Upper Saddle River, JH: Pearson Education.

Watson, J. (2009). Caring science and human caring theory: Transforming personal and professional practices of nursing and health care. Journal of Health and Human Services Administration, 31(4), 466-482.

Williams, A. M., \& Irurita, V. F. (2004). Therapeutic and non-therapeutic interpersonal interactions: The patient's perspective. Journal of Clinical Nursing, 13(7), 806-15. doi:10.1111/j.1365-2702.2004.01020.x

Williams, A. M., \& Kristjanson, L. J. (2009). Emotional care experienced by hospitalised patients: Development and testing of a measurement instrument. Journal of Clinical Nursing, 18(7), 1069-77. doi:10.1111/j.1365-2702.2008.02586.x 
Table 1.

Articles Reviewed for Nurse-Patient Interaction Concept Analysis

Authors, year

Aranda \& Street, 1999

Brown, 1967

Caris-Verhallen,

Timmermans \& van

Dulmen, 2004

Castillo \& Sanchez-

Sosa, 2002

Chatwin, 2008

Cleary, Edward \&

Meehan, 1999

Cleary, Hunt,

Horsfall \& Deacon, 2012

Cossette \& Pepin et al., 2004, 2005, 2007

Duffy, 2010

Haugan, Innstrand \& Moksnes, 2012

Haugan, Innstrand \&

Moksnes, 2013

Hewison, 1995

Holyoake, 1997

Kandler, 1952

Kasch, 1986

Krouse, Krouse \& Roberts, 1988
Purpose

Explore contradictory components of NPI

Explore effect of nurse clothing on NPI

Review NPI and communication

instruments used in oncology nursing

Examine ability of nurse training program on NPI

Use of conversation analysis in NPI

Explore factors influencing NPI in acute psychiatric facility

Review of qualitative studies of NPI in inpatient psychiatric units

Develop scale to measure caring in NPI; based on Watson's caritas factors

Explore impact of electronic record on NPI

Sense of well-being and meaningfulness obtained through NPI

Examine depression, anxiety and NPI in nursing home patients

Examine nurses' power interactions with patients through use of language

Describe the use of Interview Schedule to explore nurses perceptions of NPI

Explore NPI on psychiatric ward

Conceptualization of nursing action to link theory, research, and clinical practice

Assess patients' characteristics and behaviors
Concept attributes

Intersubjectivity, reflexivity, intrapersonal conflict

Time, therapeutic quality

Communication, provision of nursing care, rule bound

Can be either positive or negative (element of quality)

Behavioral and linguistic, meaning constructed by participants, mutual Heart of psychiatric nursing, variation in quality, requires time

Time, therapeutic quality, verbal communication

Process, wide range of behaviors and activities, vehicle for caring, dimensional

Time, attention, communication (verbal and non-verbal), center of nursing practice

Intersubjectivity; caring behavior

Caring, expert nursing practice, interpersonal sensitivity, intimate relationships

Language, power dynamic, intrapersonal conflict, exchange

Two people, information exchange or mixing, routine or informal, time

Dynamic, requires time

Functions: comfort, relate, influence, give information

Assists patients with self-care, involves level of control 
Authors, year

Millard, Hallett \&

Luker, 2006

Morse, Havens \&

Wilson, 1997

Poggenpoel, 1994

Rask \& Brunt, et al. 2007, 2008

Ravert, Williams \&

Fosbinder, 1997

Rickelman, 1971

Rundell, 1991

Shattell, 2004

Sharac et al., 2010

Shin \& White-Traut, 2004

Stoddart, 2012

Tropea, 2011

Vaaga, Moland, Evjen-Olsen, Leshabari, Blystad, 2013

Wagner \& Bear, 2009

Williams, \& Krisjarson, 2009
Purpose

Identify the extent to which patients are involved in decision making in NPI

Present the comforting interactionrelationship model

Describe model of psychiatric NPI facilitating mental health

Describe categories of NPI in forensic psychiatric nursing care

Develop a tool to define and measure nurses' interpersonal competence

Approach NPI from biopsychosocial linguistic perspective

Develop model of NPI in high dependency units

Theoretical model for developing knowledge related to NPI

Review NPI on inpatient psychiatric wards

Describe NPI in pediatric unit

Social meanings and understandings of NPI in community practice setting

Use of therapeutic emplotment to understand and create beneficial NPI

Illustrate that NPI must be considered from an ethnographic approach

Concept analysis of patient satisfaction with nursing care

Measures emotional care provided by staff as perceived by the patient
Concept attributes

Patient participation, social \& professional dimensions, use of language

Mutual negotiation and shaping of quality of relationship

Scientifically based, mutual, goal-directed, use of self (nurse), includes nursing process

Goal-directed, supportive, skills training, reflective

Function of nursing competence, as defined by patient

Social process, reciprocal, received through cognitive, affective and conative realms, reciprocal

Communication, mutual, dynamic/changes over time, exists within its own sphere

Power laden, contextually formed, interpersonal competence, time

Time, quality

Nursing activities, monitoring, patient care, affective behaviors, communication

Continually re-constructed, uncertain, based upon experience and expectations

Mutual, subjective, communication

Authoritative, instructional, extend beyond professional sphere, culturally constructed

Affective support, health information, decisional control and professional/technical competencies

Facilitates knowing, security, connection and personal value, related to control and emotional care 
Figure 1.

Concept Map of Nurse Patient Interaction

NURSE PATIENT RELATIONSHIP

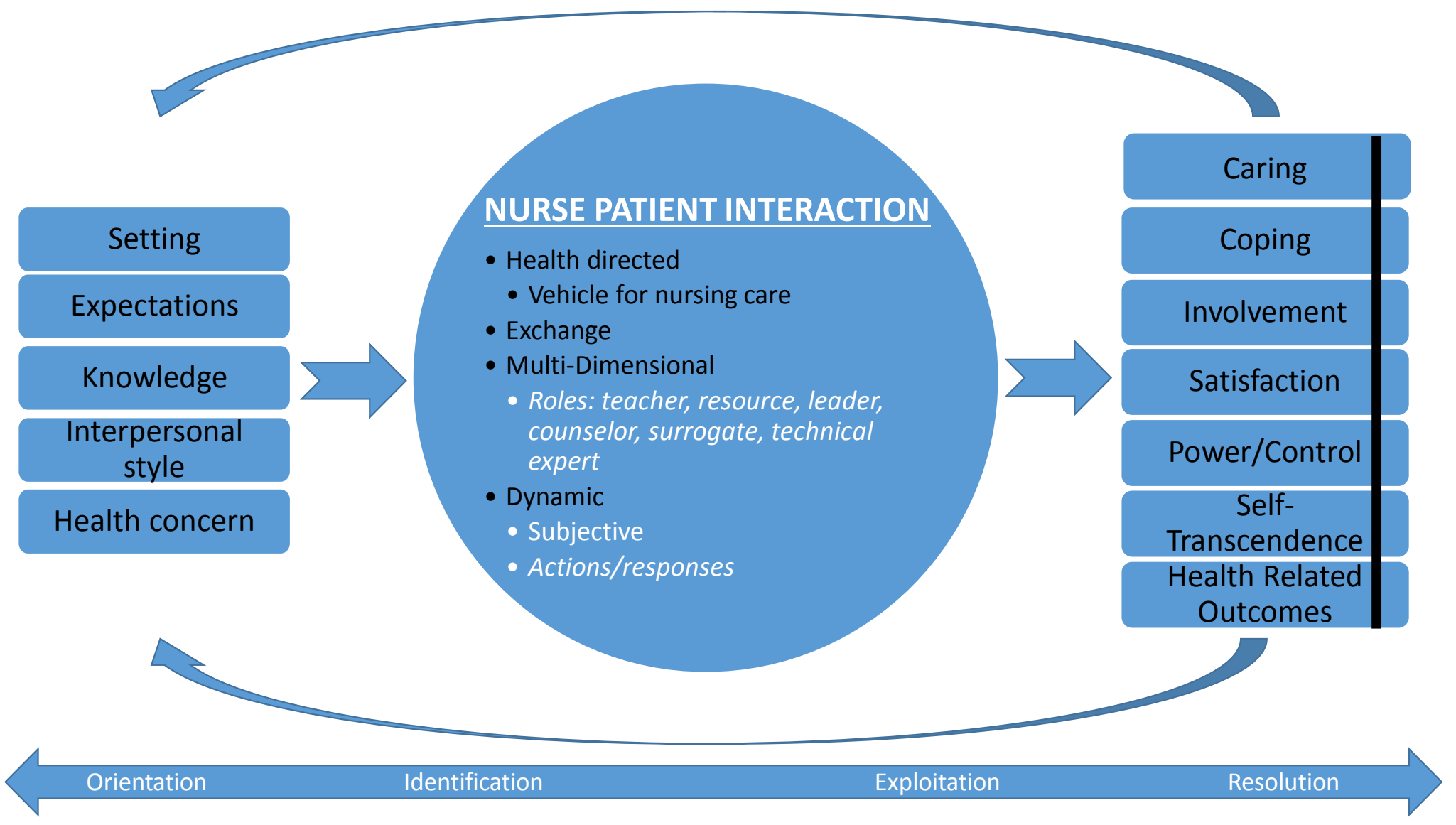




\title{
Chapter 4: Results (Manuscript Three)
}

\section{Nurse-Patient Interaction: Characterizing Support for Women with Antenatal Depression}

\author{
Emily C. Evans, RN, MSN, Beta Kappa Chapter \\ Linda F. C. Bullock, RN, PhD, FAAN, Beta Kappa Chapter \\ Nancy L. Deutsch, PhD \\ University of Virginia, Charlottesville, Virginia
}

To be submitted to: Journal of Nursing Scholarship

Corresponding Author: Emily C. Evans

4763 Dick Woods Road, Charlottesville, VA, 22903

Phone: (434) 295-3414, Fax: (434) 295-3414, emilyccevans@gmail.com

lcb2u@virginia.edu

nld7a@eservices.virginia.edu

This research utilized data funded by grant NR05313: Nursing Smoking Cessation Intervention during Pregnancy (Baby Behavioral Education Enhancement of Pregnancy or Baby BEEP) (Bullock, et al. 2009). 


\begin{abstract}
Purpose: To describe the nurse-patient interaction (NPI) between women experiencing antenatal depression (AND) and the Baby Behavioral Education Enhancement of Pregnancy (BEEP) nurses. Design: This is a descriptive qualitative study of 24 phone logs kept by six research nurses as part of a weekly telephone social support intervention provided from early pregnancy through six weeks postpartum. Data were collected from low-income, rural women living in the Midwest of the United States from 2001-2006. Peplau's Theory of Interpersonal Relations was used as a framework to guide this study.
\end{abstract}

Findings: Depressed women receiving telephone support from the Baby BEEP study nurses experienced improved depression scores over the course of the pregnancy and postpartum. Evidence of Peplau's phases of relationship and nursing roles were abundant, with nurses acting as teachers, resources, counselors and leaders. During the NPIs, nursing services were well utilized by the women, with depressed women experiencing a higher prevalence of Peplau's phases and roles, and addressed different topics than their counterparts who were improved.

Conclusions: Nurse-patient interaction may be a viable strategy to use in supporting women with AND. This study addresses a significant gap in the literature, suggesting a feasible, beneficial and well-received non-pharmacological intervention for women with AND.

Clinical Relevance: Nurses can use Peplau's phases of relationship and encourage the use of nursing services by acting in many different nursing roles when seeking to support depressed women. Given the variation in mental health over the course of pregnancy and the instability in the lives of underserved women, use of NPI as an intervention to improve AND would ideally begin early in pregnancy and continue up through six weeks postpartum.

Keywords: antenatal depression, nurse-patient interaction, theory, pregnancy, low-income. 


\section{Introduction}

Nurse-patient interaction (NPI) has long been heralded as the core of nursing care and essential in the provision of psychiatric nursing care (Caris-Verhallen, Timmermans, \& van Dulmen, 2004; Cleary, Edwards, \& Meehan, 1999; Cossette, Cara, Ricard, \& Pepin, 2005; Kandler, Behymer, Kegeles, Boyd, \& Kandler, 1952; Kasch, 1986; Peplau, 1997). Nurse-patient interaction is not, by definition, therapeutic, but has the potential to be so. The quality of the interaction is influenced by many factors, including the health, knowledge, expectations and interpersonal style of both parties, in addition to the context within which the interaction occurs (Chatwin, 2008; Cleary et al., 1999; Millard, Hallett, \& Luker, 2006; Rask \& Brunt, 2007; Stoddart, 2012; Tropea, 2012). Patients who experience high quality NPI have been shown to experience less anxiety and depression as well as improved health, ability to cope, sense of being cared for, as well as increased satisfaction and involvement (Cleary, Hunt, Horsfall, \& Deacon, 2012; Cossette et al., 2005; Rask \& Brunt, 2007; Shattell, 2004; Williams \& Irurita, 2004; Williams \& Kristjanson, 2009).

By interacting with depressed pregnant women in this expert, therapeutic way throughout the course of pregnancy, nurses have the potential to play a significant role in enhancing the mental health of women during the perinatal period. The aim of this study was to characterize the weekly interactions provided by research nurses who delivered social support to pregnant women, many of whom experienced symptoms of depression during their pregnancy, using data from a large randomized controlled trial of smoking cessation (NR05313: Nursing Smoking Cessation Intervention during Pregnancy [Baby Behavioral Education Enhancement of Pregnancy or Baby BEEP]) (Bullock, et al. 2009). Using Peplau's theory of Interpersonal Relations as a framework for understanding what occurred helps to explain the nurse delivered intervention, and provides insight 
into whether this non-pharmacological, low-cost intervention could be used in a clinical population of depressed pregnant women.

\section{Background}

\section{Antenatal Depression}

The incidence of depression is increasing globally and is estimated to be the second most common disability by 2020 (C. L. Dennis et al., 2010). Antenatal depression (AND), or depression during pregnancy, has been estimated to occur at a frequency of $7.4 \%, 12.8 \%$ and $12.0 \%$ in the first, second and third trimesters of pregnancy (H. A. Bennett, Einarson, Taddio, Koren, \& Einarson, 2004b). Symptoms of depression are reported to be experienced by as many as $20 \%$ of pregnant women in the U.S., with rates as high as $47 \%$ for underserved women (Bennett, A. Einarson, Taddio, Koren and T. Einarson, 2004; Gaynes et al., 2005). Depressed mothers are more likely to have poor health practices, abuse drugs and alcohol, receive inadequate health care, have poor pregnancy and birth outcomes and suffer from postpartum depression or other forms of psychological distress (Dimidjian \& Goodman, 2009; Jomeen, 2004; Muzik et al., 2009).

\section{Treatment Issues}

Treatment levels for AND are low because of the perceived risk of using antidepressant medications during pregnancy, such as selective serotonin reuptake inhibitors (SSRIs), as well as a variety of personal and resource related barriers to using effective psychological treatments (Levy \& O'Hara, 2010). Complementary treatment modalities are beginning to be explored in the literature, but are far from being substantiated as effective on a large scale, or implemented for wide use by pregnant populations (Beddoe \& Lee, 2008; C. L. Dennis \& Allen, 2010; Dimidjian \& Goodman, 2009). While nurses may be in a position to provide therapeutic support to women suffering from AND, there are no studies identifying components of nursing care or nursing 
strategies used to this end (C. L. Dennis \& Allen, 2010; C. L. Dennis et al., 2010). In addition, few studies have examined AND in women with lower incomes, specifically its prevalence, course, impact on quality of life, disease burden or effective interventions (Bennett, Einarson, Taddio, Koren, \& Einarson, 2004; Gavin et al., 2005; Lancaster et al., 2010). It is essential that nurse scientists pursue research aimed at identifying, developing and testing interventions that can support underserved women suffering from AND.

\section{Conceptual Framework}

The conceptual framework used to guide this study is the Theory of Interpersonal Relations developed by nursing theorist Hildegard Peplau in the 1950s (Peplau, 1997). Further description of the conceptual framework is given in Chapter $4 \mathrm{~b}$ of the dissertation, under the heading theoretical examination of NPI.

\section{Description of Original Data}

The data to be used for the proposed study were obtained from grant NR05313: Nursing Smoking Cessation Intervention during Pregnancy (Baby Behavioral Education Enhancement of Pregnancy or Baby BEEP) (Bullock et al., 2009). Baby BEEP was a prospective, longitudinal study conducted from 2001-2006 that examined smoking, stress, social support, self-esteem and mental health at three time points during the perinatal period. The primary outcome measures for Baby BEEP were smoking status, patterns of abstinence and partner influence on smoking status. The sample for the original study $(N=695)$ was recruited from Women Infants and Children (WIC) clinics in the Midwest of the United States. Inclusion criteria for the original study were women who were 18 years of age or older, less than 24 weeks pregnant based on last menstrual period, a smoker, English speaking, and had access to a telephone. 
All instruments used in the study were self-reported and were administered using an interview format with paper and pencil by a baccalaureate-prepared Registered Nurse. The complete battery of items for this study took under 30 minutes to complete at each interview. Interviews were conducted at three different time points over the course of the study: before 24 weeks gestation at time one $\left(\mathrm{T}_{1}\right)$; between 28 and 36 weeks gestation at time two $\left(\mathrm{T}_{2}\right)$; and up to six weeks postpartum at time three $\left(\mathrm{T}_{3}\right)$. Further description of the development and psychometric properties of the instruments, as well as samples of each, are provided in Appendices A and B. For this study, quantitative data were used to provide a demographic description of the sample (age, relationship status, education, and abuse), indicate the perception of stress and social support in the participants' lives, screen for depression, and select the sample to be used in the qualitative analysis.

As part of the Baby BEEP study, 345 women were randomly selected to receive weekly phone calls from a Registered Nurse, in addition to 24-hour access to the nurse via "beeper" as part of the intervention. The purpose of these phone calls was to "use empathetic listening skills and provide social, emotional and/or informational support in response to each woman's individual needs, such as stressors she was facing and ways she could manage her stress responses" (Bullock et al., 2009). The nurses kept detailed records of what took place during each and every contact with the patient, creating 'phone logs' that span the entire course of the pregnancy and six weeks postpartum. This generated over three-thousand pages of single spaced notes about the interactions between nurse and patient from time of enrollment in the study through the entire course of the pregnancy. These phone logs contain rich data about the approach, attitudes and responses of nurse and patient, the communication that occurred between them, and the context that shaped their relationship through the course of pregnancy. 


\section{Purpose of Study}

This qualitative descriptive study aimed to characterize the interaction between the Baby BEEP nurses and women who experienced depression during pregnancy. For this study, depression was not identified with a formal diagnostic interview, but screened for using the Mental Health Index-5 (MHI-5) with a cut-off value of $\leq 65$. This instrument has been validated for use in detecting mood disorders, such as depression, with adequate sensitivity and specificity (further description of its psychometric properties are given in Appendix A) (Rumpf et al., 2001).

To more fully capture the phenomenon of NPI in the context of AND, the following research questions were developed to guide the analysis. What characterized the interactions between the Baby BEEP research nurses and women whose depression improved over the course of pregnancy? In what ways, if any, do the interactions reflect the phases and roles described in Peplau's Theory of Interpersonal Relations? In what ways, if any, was the interaction different between the nurses and women whose depression improved versus women whose depression did not improve?

\section{Methods}

\section{Design}

This was a qualitative descriptive study, using secondary analysis of existing data. The aim of this study was to characterize the weekly interactions between the Baby BEEP nurses and women who experienced depression during pregnancy using Peplau's Theory of Interpersonal Relations as a framework for understanding what occurred during the interactions and exploring their usefulness as a potential intervention for AND. 


\section{Sample Selection}

Phone logs for analysis were identified by the following process. Using IBM SPSS

Statistics Version 21, descriptive statistics were used to identify those women who had a MHI-5 score $\leq 65$ at $\mathrm{T}_{1}$. Then, those women who had received the telephone support intervention were identified. These women were split into two groups based on their MHI-5 scores at $\mathrm{T}_{2}$; those with MHI-5 scores $\leq 65$ were labeled the "depressed" group and those with scores $>65$ were labeled the “improved" group. MHI-5 scores for T3 were not considered in the sample selection process because the study intended to identify only those women experiencing AND, as opposed to postpartum depression. Next, these two groups of women were split into sub-groups by the Baby BEEP nurses providing telephone support (nurse A, B, C, D, E or F). This created 12 sub-groups, two for each nurse, one made up of "depressed" women and one of "improved" women. Finally, the study IDs for all the women were placed into separate envelopes by nurse and depression group and one case was randomly selected from each envelope to determine which phone logs to analyze. This led to an initial sample of 12 women, two from each nurse, one of whom was depressed and one who was improved at $\mathrm{T}_{2}$.

Once the initial list of women was identified, MHI-5 scores were checked against SPSS data to ensure accurate representation of depression status and to retrieve other quantitative data for each case. The qualitative data for each case was imported for analysis into QSR International NVivo 10 for Windows. After coding for the first group of phone logs was completed, it was determined that more data were needed to develop and support emerging findings more fully; therefore, another group of 12 cases were selected following the same process, generating a final sample size of 24. During the course of the analysis, four of the randomly selected cases were dropped: two because of insufficient data; one as a result of patient disclosure of using 
antidepressant medication during the pregnancy; and one because of a change in the study nurse midway through the intervention period. In each of these cases, women were replaced by other randomly selected cases from the same depression classification and nurse group.

\section{Analysis}

Miles and Huberman's (1994) approach to data processing was used to guide the analysis. This approach emphasizes the iterative process of data reduction, data display and conclusion drawing/verification in initiating, expanding and deepening analysis. To facilitate this process, reflective journals, analytic memos and other writing strategies were used throughout the study to provide reflection, clarity, connection of ideas, and exploration of findings and articulation of tentative conclusions. The approach to coding was guided by Miles and Huberman (1994), Bazeley (2013), and Saldana (2013). Miles, Huberman and Saldana each note that the purpose of codes is to allow for the researcher to "retrieve and categorize similar data chunks" and then use the organized chunks to relate to the "research question, hypothesis, construct or theme" (Miles et al., 2013, p. 73). Overall, the process of analysis used the following steps:

1. Each case was read in its entirety and a narrative summary of what occurred between nurse and patient was written. This helped to provide an overview of what happened over the course of the relationship and to give initial impressions of the dynamics of the NPI, as well as its impact on the patient.

2. Additional quantitative data for each case were generated by creating a timeline, plotting the interactions and the lengths against weeks of gestation. This enabled an assessment of the number of attempts at interaction, the number of completed interactions and the amount of time spent in each interaction. 
3. NVivo was used to code each case using provisional codes generated from Peplau's Theory of Interpersonal Relations. These codes identified the phases of the relationship (orientation, identification, exploitation and resolution) as well as the roles played by the nurses (stranger, surrogate, resource, teacher, counselor and leader).

4. Additional types of coding were used to provide greater context and to identify unique nurse and patient factors that may have influenced the interaction. Open coding was used to pinpoint and label the parts of the NPI not contained within the provisional codes. Descriptive coding was used to isolate the topics around which the interaction was based. Process and emotion coding was used to recognize other nursing and patient responses (Bazeley, 2013).

5. Throughout each of these coding cycles, patterns began to emerge from the data as it was displayed in various ways. Queries were used to create matrices of the data, identifying those elements of coding that were similar among groups. Tables, charts and analytic memos also helped to capture impressions and to detect patterns that became evident as coding continued. During this stage, exploration of patterns focused on differences between groups based on their depression status at $T_{2}$. Coding slowed down as several of Bazeley's criteria were met: regularities in the data began to emerge; the categories were fully developed and described; no new categories emerged; and some variations of categories had become apparent (Bazeley, 2013).

6. Drawing conclusions occurred as the data were continually reduced and displayed, and then re-examined to assess validity and relevance of the preliminary conclusions. Reducing the data helped to focus the analysis, retrieve more precise answers to the research questions and crystalize the findings as portions of the data were re-coded with more clarity and precision. Data display enabled viewing of the stratification of codes and the prevalence across different segments of the sample. In addition to examining differences between groups based on depression scores at $\mathrm{T}_{2}$, 
groups also were examined on the basis of change in depression scores, as well as initial depression scores. Quantitative data were examined for trends and group averages of demographic variables, "dose" (length, frequency and duration) of the NPI and psychosocial variables.

This approach to data processing provided consistent and in-depth exploration of the data, as well as a clear image of what characterized the NPIs for depressed women in the Baby BEEP study. The insights and findings from each of these stages moved the analysis forward to generate clear ideas and concepts that could be asserted and then re-examined and defended or discarded. Time spent analyzing the data was essential for generating conclusions that were relevant to the sample and grounded in the conceptual framework. The qualitative analysis provided clear examples and deeper insight into what occurred during the interaction, supporting and explaining the quantitative findings.

\section{Findings}

\section{Demographics and Interaction Dose}

Table 1 reports the average values of demographic characteristics and NPI parameters for both the group of women $(n=12)$ who remained depressed at $\mathrm{T}_{2}(\mathrm{MHI}-5 \leq 65)$ and the group of women $(n=12)$ who were no longer depressed at T2 $($ MHI-5 $>65)$. Ages between the two groups differed only by two years. The depressed women had a slightly higher incidence of high school graduation and perinatal abuse. The group who were improved had a higher incidence of living in a marital like relationship. The time spent on the phone also was similar between groups in terms of total minutes, average minutes per call and total number of interactions. Differences between groups were calculated using Mann-Whitney U and Chi-Square tests. 
Table 1.

Demographics and Interaction Dose for Depressed and Improved Groups

\begin{tabular}{cccc}
\hline & $\begin{array}{c}\text { Depressed } \\
(n=12)\end{array}$ & $\begin{array}{c}\text { Improved } \\
(n=12)\end{array}$ & $p$-value \\
\hline Demographics & & .08 \\
Age (yrs) & $24(3.2)$ & $22(2.3)$ & .06 \\
High School Grad & & & \\
Yes & 11 & 7 & .21 \\
No & 1 & 5 & \\
Marital Status & & & .21 \\
Yes & 6 & 9 & \\
No & 6 & & .63 \\
Perinatal Abuse & & 4 & .24 \\
Yes & 5 & 8 & .27 \\
No & Phone Interactions & & .11 \\
\hline Starting point (in weeks gestation) & $13(4.0)$ & $14(4.8)$ & .51 \\
Number of weeks from starting & $21(5.3)$ & $23(5.9)$ & \\
point to delivery & $21(8.0)$ & $18(6.3)$ & $11(5.4)$ \\
Number of calls (per patient) & $9(5.1)$ & $196(151.2)$ & \\
Minutes per call & $195(158.4)$ & 2348 & \\
Minutes per patient & 2338 & & \\
Total minutes &
\end{tabular}

Note. Means and standard deviations are listed for all continuous variables. Mann-Whitney U used to calculate all $p$-values for continuous variables. Chi-square used to calculate $p$-values for categorical variables. 


\section{Psychosocial Variables}

Sample values for psychosocial variables are reported in Table 2 . At $\mathrm{T}_{1}, \mathrm{~T}_{2}$ and $\mathrm{T}_{3}$ the mean MHI-5 scores for the depressed group were 45 (13.0), 53 (8.3) and 66 (17.0), respectively, whereas the mean MHI-5 scores for the improved group were 57 (6.1), 74 (6.5) and 73 (15.1). Depression scores for both groups improved throughout the pregnancy $\left(\mathrm{T}_{1}\right.$ to $\left.\mathrm{T}_{2}\right)$ and over the entire course of the study $\left(T_{1}\right.$ to $\left.T_{3}\right)$. Both of these changes in depression scores were statistically significant $(p=.00)$. Those women in the "improved" group showed more rapid improvement, reporting a MHI-5 score above 65 by T2. However, the majority of women in both groups had reached a state of not being depressed after receiving the entire Baby BEEP phone intervention $\left(\mathrm{T}_{3}\right)$. Thus, we see that the group with more depression continued to show improved MHI-5 scores over the course of the intervention, compared with those who were improved and experienced an initial increase in MHI-5 scores that leveled off. In addition, the difference in average MHI-5 scores between the two groups decreases from 12 points at $\mathrm{T}_{1}(57 \mathrm{vs} .45)$ to seven points at $\mathrm{T}_{2}(73 \mathrm{vs}$. 66). This difference was also statistically significant $(p=.00)$. Figures 1,2 and 3 illustrate the change in MHI-5 scores by group over time for each patient, as well as the group averages.

Group differences also were evident in partner and other support, with the depressed group reporting less support throughout the pregnancy. Partner support across the study averaged 42 for the depressed group, compared to 49 for the improved group. Average other support only differed by one point across the study period, but at $\mathrm{T}_{2}$ (the end of pregnancy) was 46 for the depressed group and 50 for the group who were improved. Stress for the two groups decreased over time for both groups, with the depressed group reporting an average score of 11 across all three time points and the group who were improved reporting nine. 

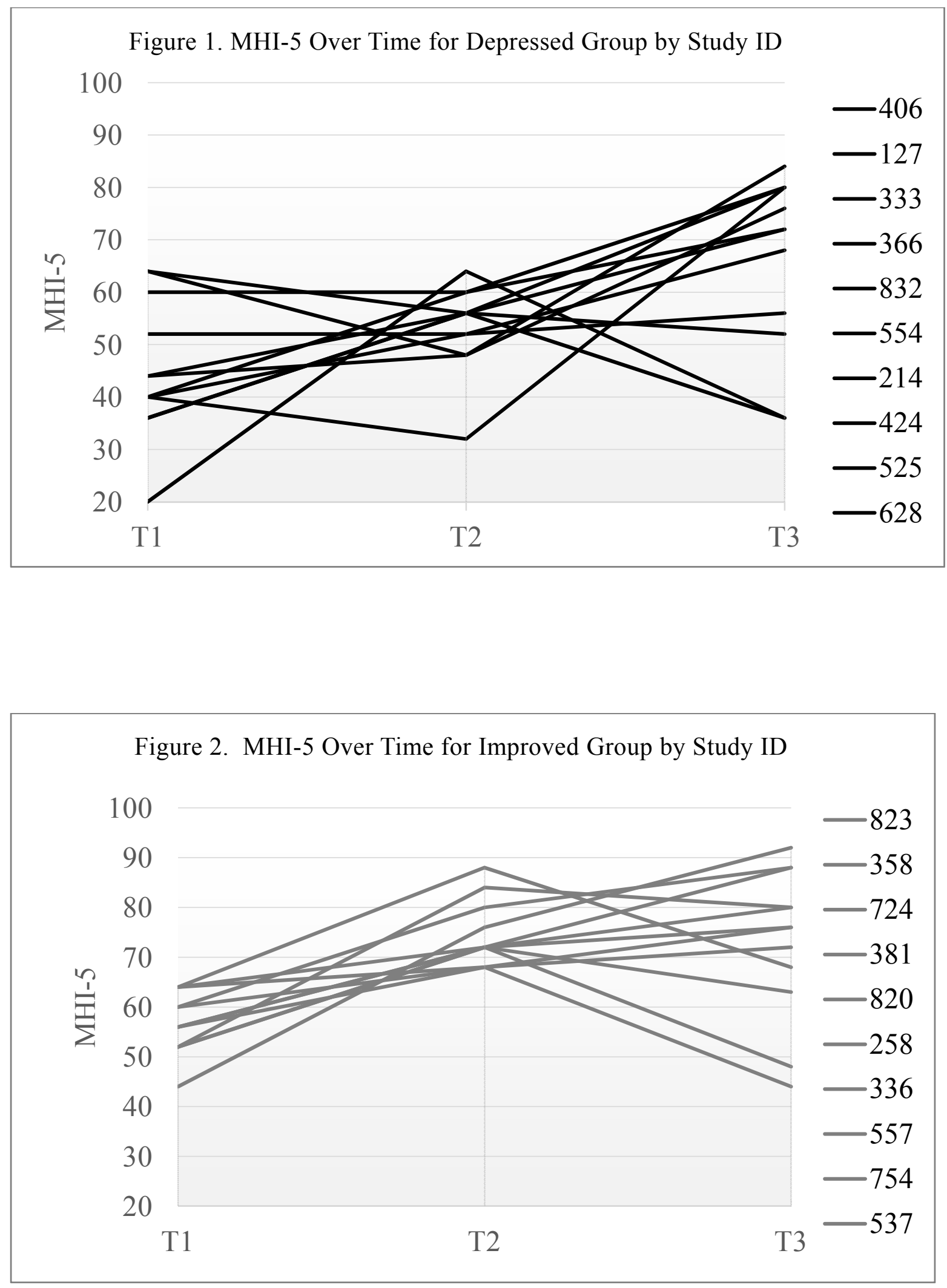


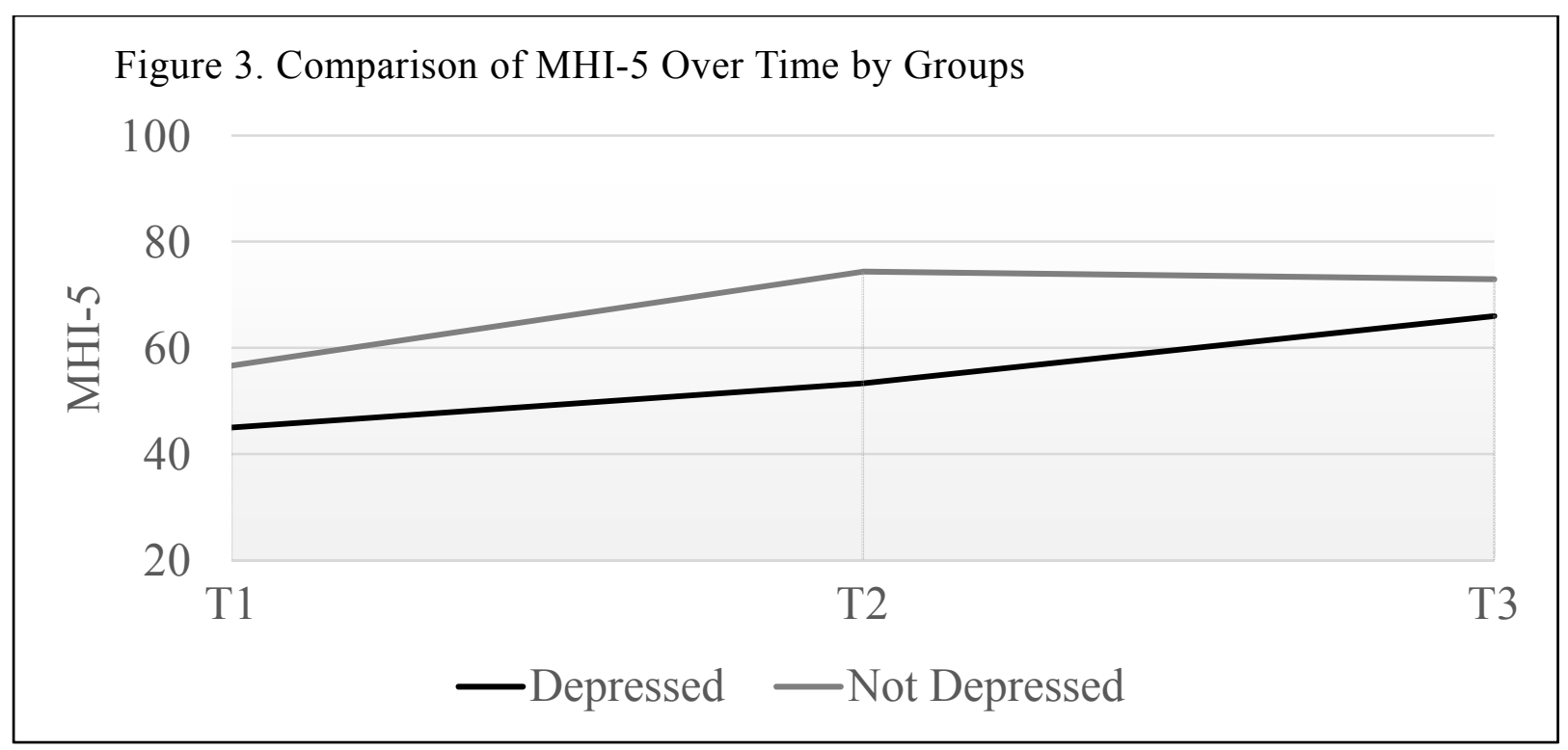


Table 2.

Psychosocial Variables

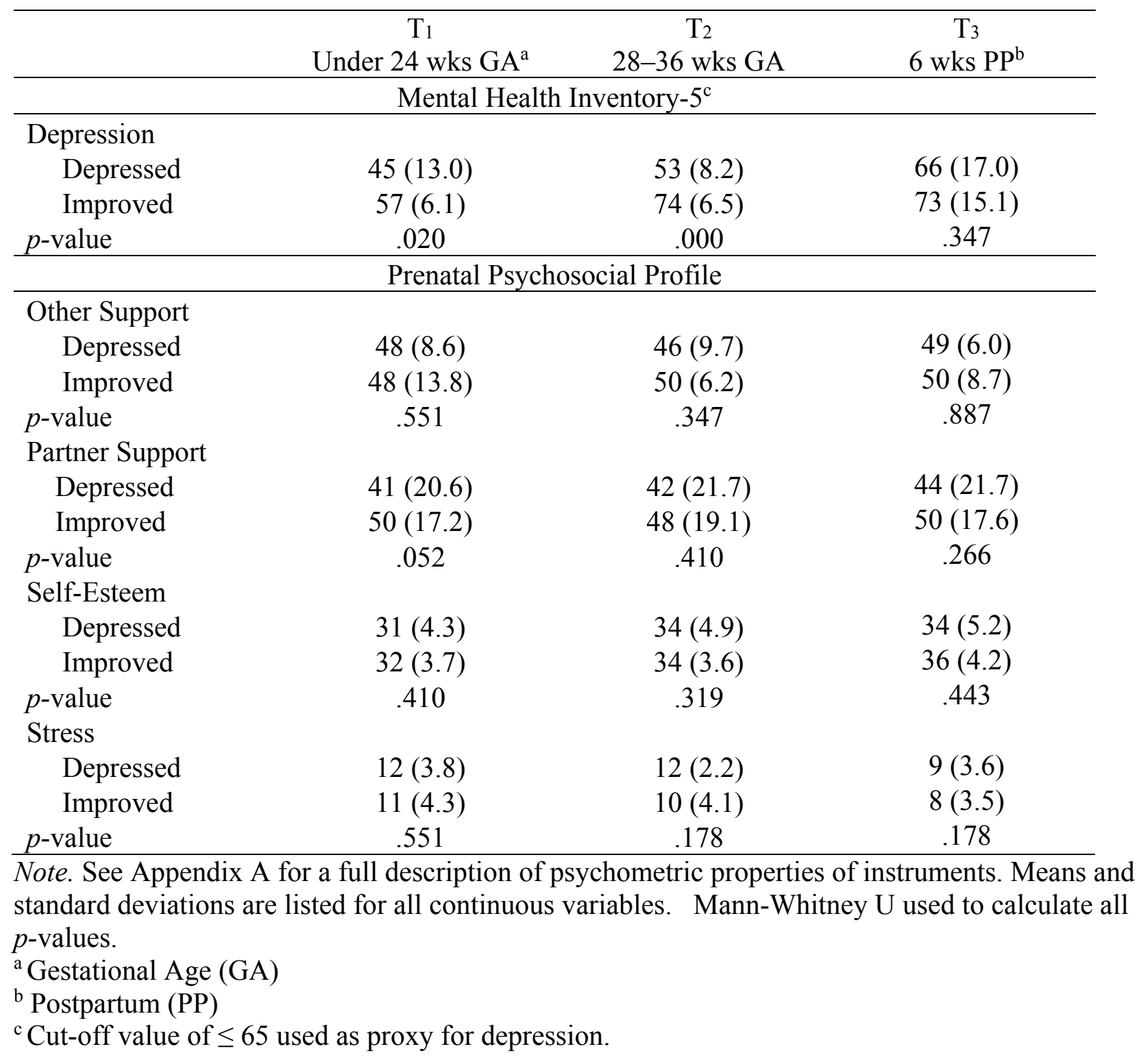




\section{Qualitative Analysis of Phone Logs: Peplau's Phases of Relationship}

Peplau identified four phases of the nurse-patient relationship that may overlap and occur simultaneously, but through which each dyad must pass to achieve a mutually acceptable outcome. The telephone interactions of the Baby BEEP nurses and participants illustrate the differences between these stages, their value in the relationship and how the work done therein may help to improve mental health. Each stage is discussed in the section below and summarized in Table 3.

Orientation. Remnants of the orientation phase were evident in the initial interactions of many of the logs. Having previously explained the purpose of the study and the parameters of their relationship during the informed consent process, the nurses focused on reestablishing contact and reaffirming the connection they had made, if any, during the first interview. Often, several attempts were made to establish contact with the patient, with nurses having to leave messages, try various phone numbers, talk with family members or, in some cases, driving out to where the patient was living to make contact in person.

During the initial contact, the nurses typically asked about smoking and sought to align their goals, in terms of the intervention, with that of the participants. They also sought to learn more about the patient, assessing their risks, resources, barriers and the contextual factors that could have a bearing on the interaction, as well as progress in achieving goals. In this excerpt, the nurse reestablishes contact with the patient, identifies relevant issues in patient's life and begins to address the goals of the relationship:

Client paged me in response to the messages I had left. I called her back. She told me that she just got her phone hooked up today and that's why she hadn't called. I said I completely understand. She told me things are going much smoother now that she is all moved in to her new place. She told me she is having a boy. I said I remembered from the first 
interview that she has one son already. I joked that she wouldn't have to buy clothes for the baby now. She said if only she hadn't had that huge garage sale last year and gotten rid of most of it! We laughed. I asked how much she was smoking and if she intends to cut down or quit. Client said she wants to quit. She told me she only had five yesterday and none today. I said that was great. (\#820, Improved) $)^{2}$

In most cases, such as this one, the participants responded positively, reflecting their initial commitment and desire to be a part of the study, and offering details about their lives and their smoking status. In most cases, the nurse and patient moved beyond this orientation phase to the identification stage, where they could begin to understand each other and their roles and to align themselves with one another in pursuit of health-related goals. In those cases that did not move beyond orientation, the nurse and patient continued to have contact but very superficial conversations that generated more of an "update" on the woman's life, with no evidence of mutual work toward health-related goals. This seemed to occur with more frequency in the group that remained depressed. In these cases, as illustrated below, the orientation phase seemed to last most of the relationship, with few interactions discussing topics beyond the events and happenings of the patients' lives rather than their feelings and goals:

Called client to see how things are going, she is doing well, she is lonesome in new place with boyfriend. She tells me the TV is keeping her company. He is gone at work all day so she is home alone. She has unpacked everything so really doesn't have a lot to do. Baby is coming soon. I asked client how she is feeling with move since she's been there a couple of weeks now and she says she is feeling okay. Client does not talk about what she is feeling

\footnotetext{
${ }^{2}$ All quotations from the phone logs include the study ID number of the participant and the depression sub-group for reference. In addition, nursing responses are indicated by italics.
} 
very much. I told her that she can beep me anytime that she would like to talk. I also told her I'll be getting recipe in mail to her soon. (This client enjoys cooking, she enjoys most things associated with making a home). (\#628, Depressed)

Identification. The identification stage was evident in all of the relationships in varying degrees. To identify with each other and develop the trust that would enable progression to the next phase, exploitation, nurses sought to establish rapport with the patient and become connected by listening to their stories and feelings. Identification was evident in interactions that displayed a sense of trust and common interest in working together and pursuing the relationship to its fullest potential. In this excerpt, the nurse clarifies her role and reassures the patient of her desire to work together,

I told her that I really wanted this to all work out well for her. I let her know that she can always page me and I'll help no matter which way things go. Client said that's nice to know. She said that she thought it would be weird; at first, talking to a stranger, but it's really not. She told me that a lot of people tell her that she's crazy and she brings it on herself. I told her I didn't know if she did or not, but I heard her saying that it's time to make a change and that she's got to do it. I told her that is a good attitude and that's all she can do. (\#812, Depressed)

Here, the patient appreciated the nurse and became open to receiving the help she had to offer. Factors that appeared to affect whether or not the nurse and patient identified with each other included interpersonal style, preconceptions about their relationship and roles, and the willingness of the patient to involve the nurse in her life.

At least some attempt was made by each nurse to identify with the patient and initiate work toward the goal of smoking cessation. In some cases where the patient showed little progress or 
interest in decreasing smoking, the interactions reverted back to the orientation phase, showing little evidence of actual work or use of nursing services. In other cases, the nurse and patient were able to shift focus to other issues and areas of the patient's life in which the nurse could be of service and further advance through Peplau's phases in their relationship. At times, patients were unsure of what they should discuss with the nurse. In many cases, the nurses responded with reassurance that they were available to talk about anything. In the excerpt below, the client reveals her perception that the purpose of the interactions is only to help with smoking cessation. The nurse records:

I asked how things had been going, and she said that she was still smoking about half a pack, and she felt bad because she thought she was wasting my time by my sending the books to her in the mail. I assured her that she was not wasting my time, and that if she even glanced at them, then she was getting something from them. I also told her that it was not my job to scold her for smoking, I was simply here to encourage and support her. I reiterated that my calls to her were for her and we could talk about whatever she wanted to talk about. (\#333, Depressed)

As the nurse offered assurance, positive feedback and clarification about her role, the patient became more willing to communicate about other issues that were bothering her, extending the use of nursing services to areas outside of smoking cessation.

Exploitation. In the exploitation phase, the patients demonstrated a willingness to make use of the services offered by the nurses. This phase contained the majority of the work done by nurses and patients to progress toward mutually agreed upon goals. The goals were not stated directly by either party, except in the case of smoking cessation, but were mutually agreed upon as the patient disclosed specific difficulties and the nurse offered specific help. 
In the phone logs, exploitation was identified by a specific pattern of communication between nurse and patient. In response to a concern or issue raised by the patient, the nurse would offer concrete advice, direction or coaching, based on her nursing knowledge and interpersonal skill. Exploitation was more than just listening, offering sympathy or talking about social events. Exploitation occurred as the nurse offered her professional expertise and service to the patient and, recognizing the value added by the nurse, the patient accepted. In this exemplar case, the nurse helped the patient process her feelings of experiencing an unwanted pregnancy:

I asked about how she was feeling about this pregnancy, and she said to be honest, she's not happy about being pregnant because she already has so much stress and money issues. $I$ agreed that it must be hard, but that she had done very well for herself so far. I acknowledged her feelings, and said that they were very normal, and that having a baby can be stressful for anyone. She seemed reassured by what I was saying, and seemed relieved to either be telling someone, or just to finally tell me. We chatted for a little while, and then I told her that I really enjoyed talking to her and appreciated her feeling like she could tell me private things. She said that she liked being able to get things off her chest. (\#333, Depressed)

It was not uncommon for the patients to respond positively, expressing gratitude to the nurse for her help. This was an indication that she had accepted the nurse's help, and often led to deeper communication about the issue in future interactions.

Exploitation was evident to a much greater degree in the interactions of the nurses with women who were more depressed. Only 52 instances of exploitation were coded for the women who were improved by $\mathrm{T}_{2} ; 100$ instances of exploitation were coded for the women who remained 
depressed at $\mathrm{T}_{2}$. Examples of the nursing services used during exploitation are vast and range in scope. Nurses gave advice and information, such as:

I asked her how her kidney infection is doing and she told me it is much better. I told her I was really glad to hear that. I told my client that I'd been hopeful that I could go over some information with her over the phone that I'd found on kidney/urinary tract infections...I did quickly review what came to mind which was take showers as opposed to baths. Client did not know this. She has been taking baths. I also quickly told her to be very careful about wiping after using the toilet, only moving from the front to the back and never back to front. I told her it is very important to keep the urinary area free from bacteria. I also suggested she drink plenty of fluids and if she likes cranberry juice, it is a good choice. (\#686, Depressed)

During the exploitation phase, nurses also offered support and encouragement, helping the patients navigate difficult personal situations:

I told her that it was a really good idea to make sure he does support her and that it is okay to let people know that she is trying to quit and remove herself from that difficult situation of being around people when they smoke. I told her it will be hard no matter what though, but she can do it. (\#127, Depressed)

Nurses helped the patients to reflect on their feelings and choices, often using these to motivate the client toward change:

Client says I just don't want to make another mistake, I told her I thought that was a very good desire and proud of her for thinking that way. I asked my client if she sometimes found herself thinking about what she would like to do with her life, if she thought about making goals. She said the last time she thought about goals was in high school and her 
goal was to be a stay at home Mom, I told her that was great. I also asked her if she ever thought about where she would like to live, she said she'd like to live where she is now living, I asked her what she thought it would take to live there and she thought she'd need to think about that. She concluded that she didn't know what she wanted to do, so I suggested that maybe she think in the reverse and think about things she would not want to do in the future. (\#628, Depressed)

Finally, the nurses helped to facilitate decision making and problem solving, in many areas of the patient's life. In this example, the nurse responds to the patient's feelings about her life situation:

She described her problems with alcohol and drugs, and the people that she associates with. I commented that it seems that she's very frustrated with the situation. She said that she is. I asked what she thought might help the situation. She said that she was going to talk to him today. I asked if she thought that this would help her feel better and if it would help him. She said that she wasn't sure that he would listen, but she needs to say it. (\#366, Depressed) Nursing services were directed toward smoking cessation, housing instability, personal relationships, work issues, pregnancy-related concerns, safety and emotional well-being. In this example, the nurse helps the patient in several areas, illustrating the variety of nursing services available and used by the depressed patients:

Her grandfather recently got out of a nursing home and her grandmother has been taking care of him. She is overwhelmed with his care since he is very sick and she also babysits a grandchild. The client goes to help her. We talked about how difficult this situation is for both the grandmother and the client. I suggested contacting the social worker at the nursing home to inquire about respite care so 
her grandmother has some help. The client said she would do this. We talked about breastfeeding. I had asked a lactation consultant about her questions regarding using the patch while breastfeeding. I told the client that the lactation consultant said she needed to discuss it with her dr [sic] but the problem with both smoking and the patch is that nicotine decreases the milk supply. The client thanked me for this information. The client asked about childbirth classes again and said she missed the one I had told her about before because of the weather. I gave her the number again and some other ideas in her area for asking about classes. (\#406, Depressed) The nurse offers counseling, comfort, advice, information and resources for the patient to use. In return, the patient expresses her gratitude. Previously in this relationship, the patient had explained her history of depression and anxiety, indicating that she sought the nurse's expertise and knowledge to help alleviate her anxiety. The nurse records:

She told me she has a problem with anxiety and used to be on medication for this and for depression. We talked about this for awhile [sic]. She is improved now, just anxious about delivery. I encouraged her to learn as much as possible about labor because information can lessen anxiety. I also encouraged her to talk to her dr [sic] about her anxiety and past depression so he can help and so he will be aware to watch her postpartum. (\#406,

\section{Depressed)}

This is an example of the direct way in which interaction with a nurse and work in the exploitation phase of the relationship can address mental health issues and help to alleviate the depression and anxiety experienced by many of these high risk patients.

Resolution. The resolution phase came as the relationship reached its conclusion at the end of the participant's time in the study. In other settings, the relationship would have been allowed to 
reach its natural conclusion when both parties became mutually satisfied at the result of their work and interaction. In the case of the Baby BEEP intervention, the parameters of the study required that the relationship end at six weeks postpartum. Because coding for this study stopped with delivery, the resolution phase was not examined. Further evaluation of this stage by examining the data through the postpartum period, would provide insight into additional use of the exploitation phase and allow for the characterization of the interactions as both participants realized the relationship was coming to a close.

Both the depressed and improved group experienced the orientation and identification phases in the relationship, with the amount of identification related to the progression of the relationship into the exploitation phase. For those relationships that progressed into exploitation at an earlier point, less identification was needed, whereas in other relationships, the nurse and patient spent a longer time in identification, trying to reach a point of mutual alignment, trust and readiness to work. The depressed group had a much greater amount of "exploitation" than the group who were improved, resulting in 100 coded episodes, compared with 52 in those improved. This suggests that the nurses may have been able to provide more direct nursing service and act in a wider variety of roles to a much greater degree than they were able to for those who were improved. The resolution phase was not explicitly examined in this study because of the extension of the relationship past the end of the pregnancy. Table 3 provides a brief overview of Peplau's phases of the nurse patient relationship, a description of how this phase was manifest in the Baby BEEP phone interactions, a coded excerpt exemplifying each phase and the number of coded excerpts in each phase, by group. 
Table 3.

Phases of Relationship

\begin{tabular}{|c|c|c|c|c|c|}
\hline & Peplau's Definition & $\begin{array}{c}\text { Evidence in Baby BEEP } \\
\text { Interactions }\end{array}$ & Example & Topics & Frequency \\
\hline Orientation & $\begin{array}{l}\text { The initial phase of the } \\
\text { relationship where the } \\
\text { patient and nurse meet and } \\
\text { become oriented to their } \\
\text { relationship and its } \\
\text { parameters. }\end{array}$ & $\begin{array}{l}\text { Typically occurred during the first encounter between } \\
\text { nurse and patient with informed consent process and } \\
\text { the initial interview. During this phase, nurses } \\
\text { initially acted as strangers, but began to enter the } \\
\text { identification phase. }\end{array}$ & $\begin{array}{l}\text { Responded to client page. She apologized } \\
\text { for not getting in touch with me, and said } \\
\text { that she had been entering the wrong pager } \\
\text { number. I said that I'm just glad to finally } \\
\text { get to talk to her and know that she's okay. } \\
\text { (\#381, Improved) }\end{array}$ & $\begin{array}{l}\text { Introduction, } \\
\text { informed } \\
\text { consent } \\
\text { process, data } \\
\text { collection. }\end{array}$ & $\begin{array}{l}\text { One time, before phone } \\
\text { intervention. }\end{array}$ \\
\hline Identification & $\begin{array}{l}\text { The first part of the working } \\
\text { stage of the relationship. } \\
\text { Nurse and patient become } \\
\text { aligned in goals and } \\
\text { purpose. Patient learns to } \\
\text { trust nurse and identifies her } \\
\text { as source of help. }\end{array}$ & $\begin{array}{l}\text { This was the initial purpose of every interaction: to } \\
\text { establish trust, understand the potential of the } \\
\text { relationship, and communicate about issues. This was } \\
\text { a subtle process, not overt, and was significantly } \\
\text { influenced by the desires of the patient, personal style } \\
\text { of the nurse and subjective experience of both. } \\
\text { During this phase, the nurse continued to establish } \\
\text { trust and often acted as a surrogate (friend), but was } \\
\text { not able to act in other nursing roles. }\end{array}$ & $\begin{array}{l}\text { I asked how her weekend had gone. She } \\
\text { said that it had been fine, and that she } \\
\text { hadn't been able to cut back at all over the } \\
\text { weekend. I told her that's okay, and said } \\
\text { that I don't call just to check up on her } \\
\text { smoking. I told her that we can work on } \\
\text { that week to week, but that we can talk } \\
\text { about whatever she wants. She said that } \\
\text { would be great. (\#358, Improved) }\end{array}$ & $\begin{array}{l}\text { Updates on } \\
\text { social events, } \\
\text { health, } \\
\text { pregnancy, } \\
\text { family, work, } \\
\text { and smoking. }\end{array}$ & $\begin{array}{l}\text { Ongoing throughout each } \\
\text { interaction and the default } \\
\text { position of the nurse if the } \\
\text { patient did not seek out or } \\
\text { respond to her efforts to help. }\end{array}$ \\
\hline Exploitation & $\begin{array}{l}\text { The second part of the } \\
\text { working stage of the } \\
\text { relationship. The patient } \\
\text { recognizes and is willing to } \\
\text { use nursing services and the } \\
\text { nurse acts in a variety of } \\
\text { roles to assist patient in } \\
\text { obtaining goals. }\end{array}$ & $\begin{array}{l}\text { This phase occurred when the patient specifically } \\
\text { asked the nurse for help in an area, or the nurse } \\
\text { offered help above and beyond that typical of a social } \\
\text { interaction. During this phase, nurses acted most } \\
\text { often as counselors, teachers, resources and leaders. }\end{array}$ & $\begin{array}{l}\text { I asked my client if she knew of the } \\
\text { suicide hotline phone \# and she said yes. } \\
\text { She tried to get Dawn to call it, but she } \\
\text { won't. I told my client that she could call it } \\
\text { too, but my client said that Dawn is okay } \\
\text { right now but will keep that in mind. I told } \\
\text { her that Dawn is very lucky to have her } \\
\text { and the best thing she can do for her friend } \\
\text { is to "be w/ her". (\#127, Depressed) }\end{array}$ & $\begin{array}{l}\text { Seeking help } \\
\text { with smoking, } \\
\text { relationship } \\
\text { issues, coping } \\
\text { with stress, goal } \\
\text { attainment or } \\
\text { failure, worries } \\
\text { or concerns. }\end{array}$ & $\begin{array}{l}\text { Reached with greater } \\
\text { frequency between nurses and } \\
\text { depressed women ( } 100 \text { coded } \\
\text { excerpts) when compared } \\
\text { with women who were } \\
\text { improved ( } 52 \text { coded excerpts) } \\
\text { at time two. }\end{array}$ \\
\hline Resolution & $\begin{array}{l}\text { The final stage of the } \\
\text { relationship where goals } \\
\text { have been met to the mutual } \\
\text { satisfaction of the } \\
\text { participants and the } \\
\text { relationship ends. }\end{array}$ & $\begin{array}{l}\text { This occurred as a result of the end of the study, } \\
\text { rather than a mutual agreed upon attainment of goals. } \\
\text { Often, goals were met during the course of the } \\
\text { interactions, but because the study continued } \\
\text { postpartum, resolution did not "officially" occur in } \\
\text { this sample by the end of pregnancy. }\end{array}$ & $\begin{array}{l}\text { She is still not smoking. She said when } \\
\text { family came for Christmas, everyone } \\
\text { smoked outside. I am so proud of her. Her } \\
\text { partner is smoking outside as well. She is } \\
\text { glad that she will have a smoke free home } \\
\text { for her baby girl. ( } \# 258, \text { Improved) }\end{array}$ & $\begin{array}{l}\text { Review of } \\
\text { experience, } \\
\text { lessons learned, } \\
\text { future strategies } \\
\text { for goal } \\
\text { attainment. }\end{array}$ & $\begin{array}{l}\text { Final meeting between nurse } \\
\text { and patient, somewhat } \\
\text { artificially imposed because } \\
\text { of study constraints. }\end{array}$ \\
\hline
\end{tabular}

Note. Mann-Whitney $\mathrm{U}$ used to calculate $p$-value for group differences in exploitation. $p=.887$ 


\section{Peplau's Nursing Roles}

Peplau identifies several roles that nurses play throughout their relationships with patients, but specifies the six most prevalent as that of stranger, surrogate, resource, teacher, counselor and leader. Although these roles often overlap in practice, with several roles being used simultaneously to help the patient, these roles are presented here separately and explored as evident in the Baby BEEP interactions. Table 4 further illustrates examples of these roles and provides a comparison of the frequency with which each role was coded for by depression group.

Stranger. The role of stranger occurred as each nurse met the patient and proceeded through the informed consent process and data collection at the first interview. Evidence of this role was apparent in the phone logs during many of the initial interactions, as the conversation took on a polite, deferential tone, seeking to reestablish the connection between the nurse and patient and reorienting both parties to the purpose of the interactions. Nurses were careful to demonstrate their motives of supporting the women by asking about the details of their lives, specifically any "stressors" that may be present. They allowed the patients to direct the topics and extent of the conversation and reaffirmed the goal of smoking cessation by asking the patient "how's it going?" (in terms of quitting). The length of time that the nurse acted as a stranger depended on the personal style of the nurse, the previous experience of the patient, and perceptions of both as to the role they should play in the relationship, as well as the desire and ability of the patient to connect with the nurse in the context of the study. Most nurses seemed to have passed through the role of stranger very quickly, with the patients opening up and communicating extensively about their lives with the nurse, even in the first interaction.

Surrogate. As the phone logs were analyzed, it became clear that the role of surrogate was difficult to identify because of its psychological purpose and subtle manifestations. This role 
may best be identified by the nurse or patient upon direct questioning or reflection on the relationship. There was extensive evidence in the phone logs that the nurses acted as surrogate friends for the patients, discussing family matters, social events, plans for the future, current activities and events in their lives. The nurses and patients shared recipes, discussed plans for the baby and "vented" about current difficulties. Establishing friendship seemed to be an important precursor to the actual nursing work that would come later as both parties discussed difficult issues and worked toward their resolution.

At times, it was difficult for the nurses to identify where the line between friendship and nursing should be, with different nurses coming to different conclusions. One nurse records several instances when the patient tries to further their friendship by asking about the nurse and specific events in her life, such as, "She asked several questions about my pregnancy. I said that it is sweet of her to think of me, answered as minimally as I could, and tried to turn the conversation back to her" (\#358, Improved). In another interaction the nurse records that, "She asked me several personal questions about my delivery and baby, which I answered as minimally as I could, and then turned the focus back to her" (\#358, Improved). In this case, the nurse deflected conversation that became too focused on her and shifted the attention back to the patient. The extent to which the friendship developed was determined by the preferences of nurse and patient. Friendship was established to some degree in all of the cases, and although it may not have been the initial motivation for the relationship, it became an important foundation in those relationships that reached their full potential.

Resource. The nurse often acted as a resource to the patient, providing specific information that was typically health related. The nurses acted as a resource in relation to smoking, personal difficulties and pregnancy concerns. Upon recognizing that the patient was 
having difficulty quitting smoking, one nurse records how she acted as a resource, offering specific advice about how to reduce smoking:

She said she wants to quit. I asked her if it would be okay to suggest something, she said sure. I suggested to maybe not try to just quit cold turkey, but to try to smoke 10 cigs/day for a week, then 9/day for a week, and so on. She said that sounded good, but she wants to start w/ 5 cigs/day. I said that's fine. (\#127, Improved)

Other specific information about smoking included negative effects of smoking on health, how to deal with cravings, the benefits of quitting smoking, common signs and symptoms of withdrawal, how to discuss smoking goals with others and ideas about how to cope with smoking in the patient's environment.

Important use of the nurses' knowledge of obstetric issues was evident when patients asked specific questions about the pregnancy. In the following excerpt, the patient expressed a common concern about pregnancy — when should she expect to feel the baby move - and the nurse responded with reassurance and specific information that alleviated the patient's concern.

She is a little worried about the baby though. She is concerned b/c she hasn't felt the baby move. I told her that usually most of my clients (and in the literature that I have read) say that it's usually around 20 weeks when you feel the baby move. So it could be another whole month before she feels the baby move. She was relieved. I told her that some women can feel it sooner. Every pregnancy is so different. (\#214, Depressed)

Some nurses were very comfortable giving the patient specific direction about health concerns, while others deferred entirely to the patient's obstetric team and always recommended the patient talk to her doctor. In several cases, the nurse helped the patient to recognize and 
respond to important events in the pregnancy such as the initiation of labor, signs of preterm labor, preterm rupture of membranes and, in this case, pre-eclampsia:

She had a doctor's appointment scheduled today to check her blood pressure, but that she cancelled it because she was really tired. I asked when her next appointment is, and she said next Tuesday. I cautioned her to be very conscious of any changes in her vision or of any headaches, or epigastric pain, and to call her doctor immediately if she felt any of this. She denied these symptoms, and said that she would call if they showed up. (\#333, Depressed)

An important area in which the nurses acted as a resource was when the patient was having difficulty coping with personal circumstances. Nurses gave out phone numbers, looked on the internet for answers to questions, found resources and gave advice about how to access those resources. In this excerpt, the nurse lists the various resources she offered to the patient as well as her efforts to help the patient think through transportation issues and potential solutions:

Food Stamps, MC plus, Home for unwed Mothers, Housing Assist, Job

Crossline (Food and clothing) 417-588-3559

Pregnancy Support Center 417-532-8555

Job Service- 417-532-6146

Transportation

Cope House 417-532-2885

MOCA-funding 417-588-2620

Helped client explore options for transportation tomorrow to local job fair... Father might take her if he finishes deer hunting in time Sister most likely won't be willing or available 
Aunt may very well be able/willing. (\#525, Depressed)

Sharing specific health information with the patient helped to alleviate patient anxiety and provide motivation for them to make changes in their health behaviors. These changes were primarily evident in smoking cessation efforts, but seemed to spill over into other areas of the patient's life. One nurse records a patient that expressed her enthusiasm for obtaining information and the effect that increased understanding had on her:

She said since she felt the baby moving, the baby seems so real now and she feels very motivated to work toward quitting. She wants to educate herself on everything she can about the baby and we talked about ways to do this. I offered to send her some good web sites since she has access to a computer and she was very excited about this. (\#406, Depressed)

When nurses acted as a resource they not only provided information to direct the change, they also helped to motivate the patient and express confidence that the patient could take action. Teacher. The nurses acted as teachers in the sense that they helped the patients learn from life experiences. This was a subtle distinction from acting as a resource, but involved more general direction and discussion of principles as opposed to the more specific information offered as a resource. In the excerpt below, the nurse helps the client learn how to troubleshoot her childcare issues:

Explored the possibilities for babysitting-client thinks her half-brother's grandmother (who sits for other children) would watch him without charge for job hunting. Discussed local employment opportunities: client has experience as a CNA and thinks she could get hired at the local nursing home. Had not considered checking with unemployment office. (\#525, Depressed) 
Another important area in which the nurses tried to teach the patients was in dealing with interpersonal relationships and family dynamics. The nurses were careful always to side with the patient and clarify their support for her, but at times they needed to teach the patient about what was and was not acceptable within their relationships. In this case, the patient has become involved helping a friend who she believes has AIDS:

She looked up a whole lot of information on AIDS, it's medicines and how it's transmitted and will go over it w/ Dawn. I told her that she is one smart woman and that Dawn is so lucky. She said that she stripped the room of things that Dawn could use to hurt herself. She took shoe laces and cords. I told her that was good. I encouraged my client to get Dawn some help by calling the hotline or involving her family so that she is safe. She said that she will watch her. I told her to be very careful b/c she could escape or hurt someone else in the process of Dawn hurting herself. (\#127, Depressed)

The nurse coaches the patient through helping a friend and teaches the patient how important her own safety is, and by association, the health of her baby. In this case, the patient's friend did not have AIDS, but was using the patient as a place to "hideout" from a bounty hunter. This leads to further discussion with the nurse and processing of the experience as the nurse serves as a counselor. "I told her that it will be hard and she will be hurt for sometime [sic]. She then changed the subject $\mathrm{b} / \mathrm{c}$ she didn't want to talk about Dawn anymore. I told her I understood"' (\#127, Depressed).

Counselor. The nursing role that most directly dealt with the emotional health of the patient was that of counselor. In this role, nurses used their interpersonal skills and professional knowledge to help facilitate the emotional health and personal growth of the patients. As a counselor, the nurses addressed the patients' feelings and helped them to respond to what was 
happening within and around them. They did this by restating what the patient had told them, asking probing questions that further explored how the patient felt, helping the patient reframe the situation or look at things from another perspective, and by pointing out the successes that the patient had experienced.

Counseling was offered in subtle ways and received to varying degrees by the patients. The nurses determined whether or not counseling was initiated through their responses to the patients' sharing of personal information and their further inquiries and follow-up. Some nurses were very likely to inquire further and explore topics, whereas others may have simply stated their sympathy and offered (but not pursued) further discussion as needed, as in this excerpt: I asked how things were going otherwise. She said that she had been "blue" lately. I asked her what was bringing her down. She said that it was the holidays, and that she was going to have to go to her work party alone. I sympathized with her feelings, and told her that when she is feeling low, she can always page me, and I would be happy to help her. (\#333, Depressed)

The patient does not continue to discuss the topic, nor bring it up later, further limiting the amount of counseling that could occur. In cases where the patients responded favorably, the nurses were able to continue discussing the topic, and even address other topics, helping the patients further their efforts towards emotional well-being. Topics that the nurses and patients addressed when counseling were hopes for the future, personal relationships, the pregnancy, personal health, smoking, family dynamics, work and housing.

One of the most poignant examples of counseling occurred when the nurses assisted the patients in dealing with personal tragedy and difficulties. In this excerpt, the nurse helps the 
patient recognize and begin to deal with her feelings of loss after her grandfather's suicide. The nurse records:

Client was crying. She said her grandfather had committed suicide over the weekend. We talked about this for a few minutes and how hard this is for her and for her grandmother. I told her I was so sorry... She told me the funeral was during the time we were to meet on Thurs. I told her not to worry, we could do her T2 over the phone sometime next week if she felt up to it, or I would come back to her area later in the month and we could do it then... She asked me how to lower her BP. She said her BP was up yesterday at her dr appt. I suggested maybe it was up because she was upset about her grandfather and she said she thought that was probably true. We talked about some relaxation techniques and resting more on her left side. Her next $\mathrm{dr}$ appt is not for $31 / 2$ more weeks. Her $\mathrm{dr}$ told her to stop by Walmart and check her BP on a machine. I asked if she could stop by the health department for BP checks too and she said she will find out...I offered to get her a phone number to arrange counseling if she felt like she needed it, and reminded her she could page me anytime if she needed to talk. I also encouraged her to give the phone number for CMAAA to her grandmother if she had not already done this so her grandmother could see about counseling also if she needed it. (\#406, Depressed)

These interactions ensue in response to a page from the patient, and over the course of the next eight days, the nurse interacts with the patient four more times. The nurse listens to the patient and then responds, helping her to process her feelings, think through how to obtain help, prioritize taking care of herself and reflect on her coping process.

In another case, a nurse helps a patient to process her difficult experience of incarceration during the pregnancy. Although her record of the interaction is brief and includes details about 
smoking, pregnancy labs and coordination of the study, the nurse records that "Remaining conversation was spent... listening to client reflect on her experiences related to incarceration. Handcuffs and shackles were especially difficult for her emotionally” (\#525, Depressed).

This interaction lasted for an hour, in which it is reasonable to assume the majority of the time was spent processing a very trying experience. The fact that the patient used the interaction to address this subject reveals the confidence that the patient had in the nurse, the value of the nurse's presence in her life, and her need to process a very emotional subject. This interaction laid a foundation of trust, increasing the likelihood that the patient would use the nurse in a counseling role again. In subsequent interactions, the patient continued to confide in the nurse and use her as a counselor, discussing sensitive topics such as concern for her children's care if she dies. The nurse includes more detail about what was said during the interaction, and the strategies she used to counsel the patient:

Client abruptly: "What if I die?"

Nurse: "Well, let's think about that for a while. What is it that concerns you most when you consider the possibility of dying?"-

CLIENT: "My kids-What would happen to my kids?"

NURSE: "Have you ever thought about how you'd want them to be taken care of if you weren't able to be involved?"

CLIENT: "They'd definitely stay in the family — no strangers are going to take care of my kids. My aunt said 'maybe one more but two?'”

NURSE: "Sounds to me like you really care about seeing that your kids are well taken care of - that's a good sign that you are just getting your act together more all of the time; good for you." 
Mentioned possibility of having a will drawn up to specify guardianship etc. but client was ready to hop to other subjects. [sic] (\#525, Depressed)

The nurse helped the patient to understand her feelings, clarify her concerns, think through potential solutions and recognize the strength the patient possesses in coping with difficult circumstances. She also offers practical advice, but leaves the decision making and control of the situation in the patient's hands.

Leader. Within the interactions, evidence of leadership came from both the nurse and patient. Leadership was demonstrated when the initiative to and responsibility for change were communicated. Change was sought primarily in relation to smoking, but also was discussed in terms of housing situations, employment, relationship status, and health care use. Nurses often introduced the idea of change, especially in relation to smoking, but patients varied in the responsibility they took for change, and it was reflected in how they responded to the nurses' inquiries. One nurse records an interaction where she discusses smoking with the patient. Although the nurse initiates the discussion of smoking, the patient takes the lead, specifying her goals and thought process about the next step in a long process of quitting:

I asked how quitting on the 24th went, and she said not so good. She said that she and her boyfriend have decided that there will be no smoking in their new apartment. She thinks that this will keep her from smoking, and she is making quitting by the move her new goal. I asked when they are moving, and she said in the next couple of weeks. I said that quitting is a very hard thing to do, and I said that I'm glad that she's set a new goal. She is trying to keep her smoking low, under 5, usually 2-3/day I said that this is fantastic, and she's a very strong woman to do this. (\#366, Depressed) 
In this interaction, although the patient has not been successful, she continues to set goals toward change, acting as a leader. This set a trend for future interactions, creating a pattern of leadership, where one or the other accepted the primary responsibility for change. When the nurses acted as leaders, the interactions were much more one directional. In this exchange, the nurse tries to get the patient to commit to change, with little success:

We then talked a little about her smoking. She said that she is still smoking lights and that she has stayed cut down, but that she doesn't think that she'll be able to quit because she's been smoking for 8 years. I asked if she had thought about setting a goal for where she'd like to end up. She said that she hadn't, she just wanted to stay cut down. I told her that that was in itself a goal, and that if she needed any encouragement or needed a pep talk or diversion, I was available to her. I told her about how the baby stops breathing movements in utero when the mother inhales. She didn't say much. I told her that I don't want to bug her about smoking, but if she wants to talk about it, I'm here. She thanked me. (\#333, Depressed)

After unsuccessful attempts to facilitate change, interactions continued, but became much more superficial and limited in scope. Not only was progress in smoking cessation halted, but in some cases, the nurse was unable to help the patient by serving in other nursing roles.

Group Differences in Nursing Roles. The frequency with which nurses could act in Peplau's various nursing roles differed by group. Although nurses were able to act as a stranger and surrogate to both groups of women, there were apparent and dramatic differences between groups in each of the other roles. In the depressed group, nurses acted more often as a resource (71 versus 42 excerpts from those improved), teacher (62 versus 38 excerpts from those improved) and counselor (119 versus 71 excerpts from those improved). The role of leadership 
was taken on by both the nurse and patient, but varied substantially by group, with nurses taking more leadership in the depressed group (20 versus 11 excerpts) and patient taking more leadership in the improved group (23 versus 19 excerpts). 
Table 4.

Nursing Roles

\begin{tabular}{|c|c|c|c|c|c|c|}
\hline & \multirow{2}{*}{$\begin{array}{l}\text { Peplau's } \\
\text { Definition }\end{array}$} & \multirow{2}{*}{$\begin{array}{c}\text { Evidence in } \\
\text { Baby BEEP Interactions }\end{array}$} & \multirow{2}{*}{ Example } & \multicolumn{2}{|c|}{ Number of Coded Excerpts } & \multirow[b]{2}{*}{$p$-value } \\
\hline & & & & Depressed & Improved & \\
\hline Stranger & $\begin{array}{l}\text { Initial contact with } \\
\text { the patient. Shows } \\
\text { "respect and positive } \\
\text { interest" and begins } \\
\text { to "orient the family } \\
\text { to the purpose of the } \\
\text { visit and the services } \\
\text { offered in a simple } \\
\text { manner. }\end{array}$ & $\begin{array}{l}\text { When the nurses and } \\
\text { participants first met, the } \\
\text { nurses acted as a stranger, but } \\
\text { quickly used their } \\
\text { interpersonal skills to } \\
\text { establish a relationship. } \\
\text { Thereafter, the personal styles } \\
\text { of the nurses and the views of } \\
\text { their roles within the study } \\
\text { impacted the other roles in } \\
\text { which they were able to } \\
\text { engage with the participants. }\end{array}$ & $\begin{array}{l}\text { Initial contact and meeting at } \\
\text { WIC clinics. Brief introduction } \\
\text { of self, establishment of } \\
\text { rapport, explanation of the } \\
\text { study, gathering data about the } \\
\text { patient and answering } \\
\text { questions. }\end{array}$ & Initial contact & Initial contact & \\
\hline Surrogate & $\begin{array}{l}\text { "The patient views } \\
\text { the nurse as someone } \\
\text { else... Surrogate } \\
\text { roles are determined } \\
\text { by psychological } \\
\text { needs; they give rise } \\
\text { to psychological } \\
\text { tasks to be met in } \\
\text { nursing situations by } \\
\text { nurses." }\end{array}$ & $\begin{array}{l}\text { As a part of establishing } \\
\text { rapport the nurses showed an } \\
\text { interest in the participants as } \\
\text { people and interacted with } \\
\text { them as a friend would, by } \\
\text { listening and responding in a } \\
\text { sympathetic, supportive way. } \\
\text { Participants often expressed } \\
\text { their appreciation for the } \\
\text { nurse "letting me vent." }\end{array}$ & $\begin{array}{l}\text { Client has been making apple } \\
\text { jelly. She estimates that they } \\
\text { have } 20 \text { apple trees in orchard } \\
\text { that was planted by her } \\
\text { Grandfather. Client remembers } \\
\text { how she liked applesauce, } \\
\text { apple pies and jelly made by } \\
\text { her Grandmother who raised } \\
\text { her and her sister after parents } \\
\text { divorced when client was very } \\
\text { young. Nurse shared info } \\
\text { about her experience making } \\
\text { apple butter-client requested } \\
\text { the recipe, "even if I don't get } \\
\text { around to making it, I love to } \\
\text { collect recipes." } \\
\text { (\#525, Depressed) }\end{array}$ & Every contact & Every contact & \\
\hline
\end{tabular}


Teacher

"Teaching always proceeds from what the patient knows and it develops around his interest in wanting and being able to use

...information." May encompass several other roles.

\section{Resource}

"Provides specific answers to questions usually formulated with relation to a larger problem." May include health information or other knowledge available only from a professional expert.

\section{Counselor Facilitates "self-}

renewal, self-repair, and self-awareness" within the

individual. Helps patient to understand
The nurses acted as teachers in many instances, seeking to facilitate learning on the part of the participants. This included instances when the nurses sought to help the patient learn from their experiences as well as how to address specific problems.

Nurses acted as resources when they provided specific information to the participants. Participants often presented the nurses with health-related questions, giving the nurses the opportunity to respond as a resource. Nurses also acted as a resource when giving specific information about smoking cessation strategies, pregnancy related concerns or community resources.

The nurses most often acted as counselors, helping the participants work through emotions and experiences in a healthy way, reflecting back to them their feelings, and
He said she could be

the and gave was great. I told her I was very proud of her for sticking up for herself and telling him how she felt. I told her she should

be proud of herself too. She said she was. I told her that when you work hard at

something usually the outcome is favorable.

(\#127, Depressed)

I asked if she needs food right

now-did she need something for dinner. She said no, she'd be okay for a while. We talked about her options with respect to her being denied for food stamps. We talked about appealing the decision,

reapplying, or getting a letter from the school stating that she was a full time student and unable to work enough to pay all of her expenses, including food. She thought that was a good idea. I suggested that she make an appointment with a

$D F S$ worker so that they would give her their attention, and so that she would have time to make her case. (\#336,

Improved)

She said when she called the office the nurse told her to not be upset. She told me that it was easy for her to say $b / c$ it's not her body. She wanted some answers and wanted 
better how they feel about themselves and how $\mathrm{s} / \mathrm{he}$ feels about what is happening.

\section{Leader "Individual patients identify with nurses and expect them to offer direction during the current difficulty."}

helping them see their situations in a new light and discover coping strategies or solutions to their problems.

Nurses and participants both acted as leaders in suggesting and following up on potential solutions to problems.

Nurse-directed leadership occurred when the nurses took the initiative to talk to the participants about healthrelated goals, most often smoking.

\section{Patient-directed leadership} occurred when the

participants were the initiators and directors of health-related goals, as well as goals to improve other areas of their lives. them now. She said she is

never too shy to ask questions.

I told her that was a very good personal trait to keep. I told her that it is perfectly normal to react the way she did. It's upsetting and worrisome.

$$
\text { (\#214, Depressed) }
$$

I asked if she was trying to cut down anymore on her smoking and she said she was trying again. I asked what she was doing to cut down and she said she is trying to eat more instead of smoking and that she has switched to a low nicotine cigarette. I said I was really glad she was still trying and to keep trying. (\#381, Improved)

She is still not smoking. Nobody is smoking in the apartment anymore either. She put a big NO SMOKING sign on her door for her friends to see. Even her partner is smoking outside. (\#258, Improved)

Note. Quotes taken from Peplau, 1991. Group differences in nursing roles calculated, where applicable, using Mann-Whitney U. 


\section{Topics Addressed within Interactions}

There were striking differences and similarities between the groups in terms of the topics they discussed most frequently on the phone. Figures 4 and 5 illustrate the similarities and differences between the two groups. A query of the 20 most frequently discussed topics showed that both groups discussed the baby, their feelings (thankfulness, happiness), job situations and smoking to similar degrees (group differences in the number of references to any topic were less than $20 \%$ ). The groups varied more dramatically in their discussion of doctor, home, wants, needs, quitting and hope. Topics exclusive to those who were improved (of top 20) were husband and mom. Topics exclusive to the depressed group (of top 20) were boyfriend and nurse.

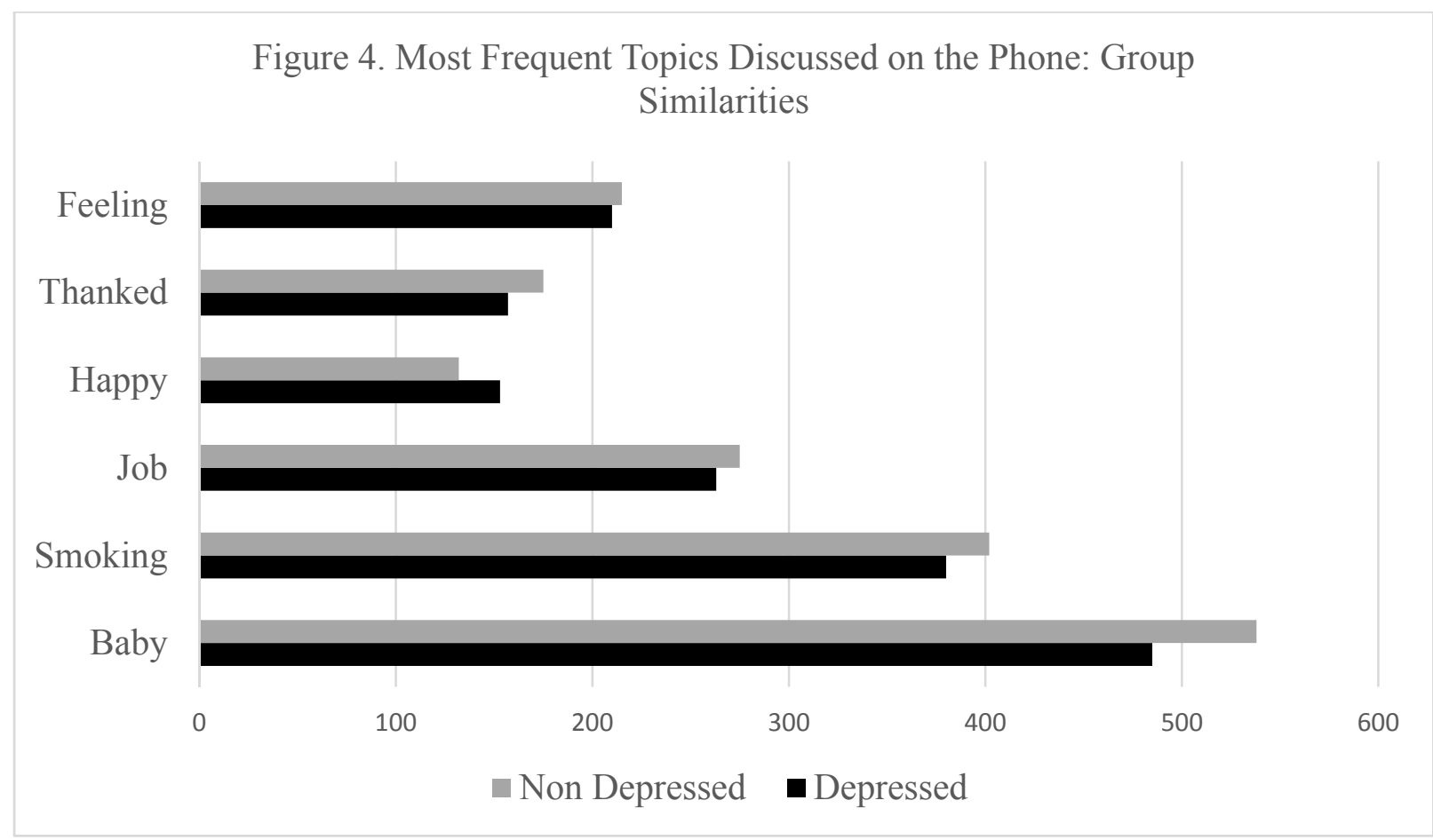

Note: Differences between groups $<20 \%$ 
Figure 5. Most Frequent Topics Discussed on the Phone: Group

Differences

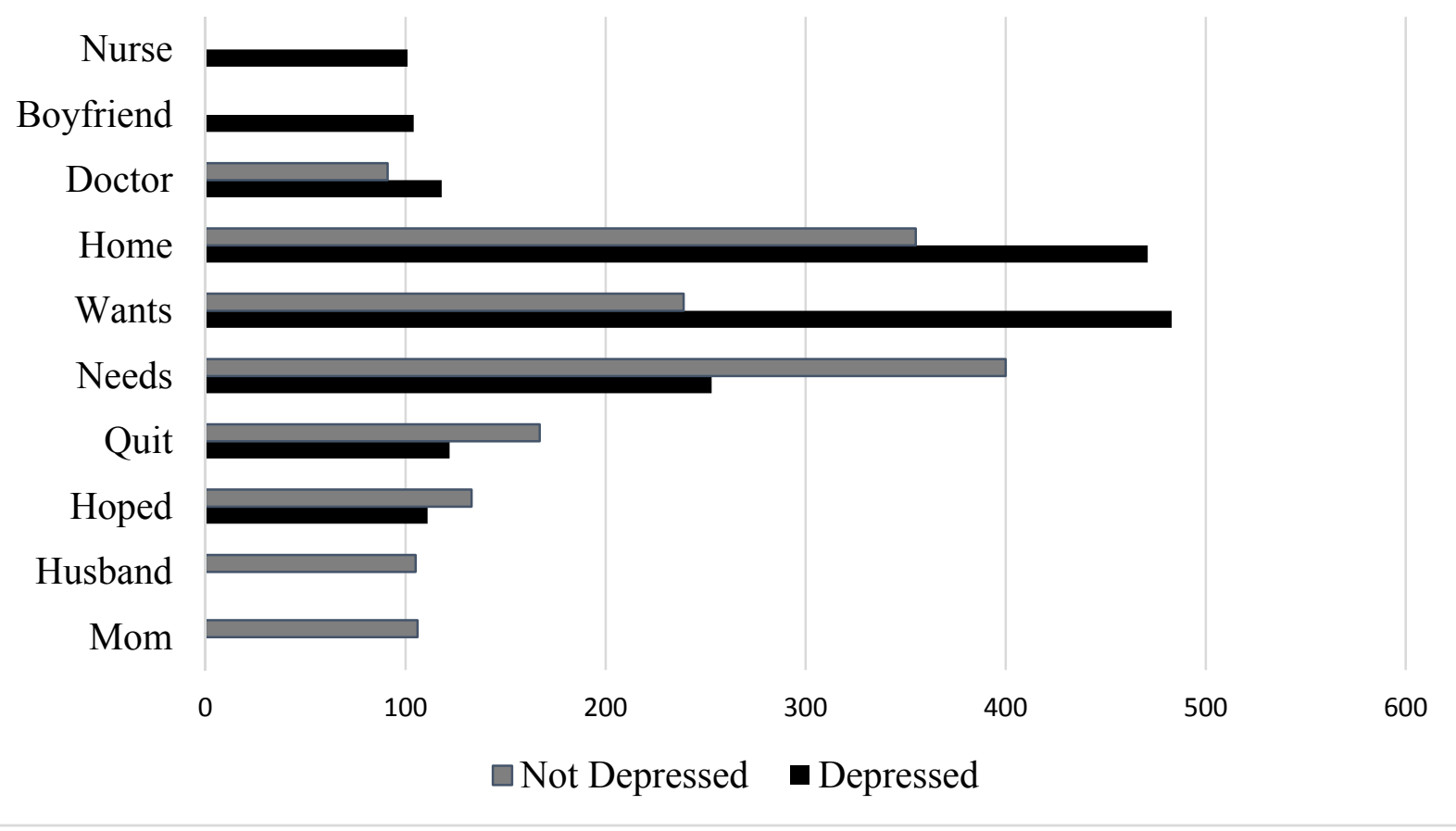

Note: Differences between groups $>20 \%$ 


\section{Discussion}

The presence of low partner and other support scores in combination with the increased utilization of the exploitation phase, as well as nursing roles in the more depressed group, is a striking finding of this study. Women who were in the depressed group of this sample experienced support at a much lower level than that reported for the national average. Curry, Burton and Fields (1998), in reporting mean scores from large samples of white women, showed average partner support scores of 54 (11.5) other support scores of 52 (10.9) (Curry, Burton, \& Fields, 1998). This is higher than the reported scores for the depressed group in this sample, indicating the severe lack of support prevalent in this population. The differences in type of support available to both groups of women was also evident in the most frequently discussed topics with the nurse. This deficiency of partner and other support, combined with the increased use of the nurses by depressed women, points toward the possibility that the Baby BEEP nurses were able to fill a void in these women's lives and support their mental health.

Although nurses spent similar amounts of time on the phone for both groups of women, the interactions of nurses with depressed women were corresponded to a greater degree with Peplau's roles, meaning these interactions potentially provided more nursing "care" to the depressed women. These increased, lengthy interactions may have had an impact on the continued improvement in depression scores, even after the pregnancy ended, in the depressed group when compared with those from the improved group. Those NPIs among women who were in the improved group exhibited less time in Peplau's exploitation phase of the relationship, consistent with their use of less nursing help and a lower count of the teacher, resource and counselor roles. Looking at the change in the average depression scores for the improved group 
from $74\left(\mathrm{~T}_{2}\right)$ to $73\left(\mathrm{~T}_{3}\right)$, this lower frequency of exploitation and nursing roles may explain the relatively stable mental health scores for the second half of the intervention for this group.

The nursing roles identified by Peplau continue to be relevant to the nursing care of women with AND. Specifically, in acting as a resource, teacher, counselor and leader, nurses provided skilled and professional service to participants above and beyond that afforded them through simply friendship or social support. In the Baby BEEP study, as nurses and patients progressed through the phases of the relationship, the nurses served in different roles, as allowed by the patients, and when fully functional, used their services to the greatest degree in affecting change in the women's lives, including improved mental health.

The contrast between those women who were depressed and those who were improved in the topics frequently addressed during the telephone conversations also sheds light on the differences between groups. In general, both groups mentioned feelings at a similar rate when interacting with the nurse; however, the content of those feelings varied widely between groups. Depressed women talked more about their wants, whereas non-depressed women talked more about their needs. This may reflect contrasting perspectives of desperation and demand on the part of the depressed women and potential and justification on the part of the non-depressed women. Depressed women viewed the issues in their lives as wants; desirable but not attainable, whereas the women who were improved viewed the issues in their lives as needs; required, deserved and attainable. This also is reflected in the greater frequency with which those who were improved discussed hope, an idea that things would and could get better, as well as quitting smoking, feelings of empowerment and the ability to achieve specific goals. These findings support the idea that optimism supports mental health and is more prevalent in women with less 
depression. Cultivating optimism may help to offset or prevent the development of depressive symptoms to some degree in this vulnerable population.

Lack of support and instability also were reflected in the topics of the depressed women. These women discussed home and housing with a much greater frequency than those who were improved. This reflects the housing instability that was often experienced by these women, and the constant psychological distress associated therewith. The frequency with which the term boyfriend is mentioned also is an indicator of relationship instability and a potential lack of support. Women who were improved group mentioned the term husband more frequently, illustrative of a traditionally more stable relationship. Additionally, those who were improved made more frequent mention of their mothers, indicating the presence of this elemental and powerful relationship in their lives, which has been shown to be inversely correlated with depression scores in other low-income samples of women (Rose et al., 2010).

Another important aspect of the Baby BEEP intervention was the high rate at which it was used by the patients. The Baby BEEP study had astonishing retention rates, losing only ten participants to follow up over the course of the study. One of the important elements that the nurses were able to incorporate into their phone support was the distribution of power to the patients. The power dynamic is an important consideration in NPIs. Within any interaction, there is a distribution of power that varies in the degree to which it is shared by nurse and patient. Power is shaped by the social construct within which the interaction occurs as well as the interpersonal dynamics between the two participants. Power in NPIs is typically held by the nurse and brokered to the patient through use of language and involvement in decision making (Hewison, 1995; Krouse, Helene, Krouse, \& Roberts, 1988; Millard et al., 2006). However, in the Baby BEEP intervention, the power was with the woman to discuss whatever she wanted and 
the nurse was there to provide support. In this context, language does not serve only to communicate information, but also symbolizes another dimension of reality - the dynamics involved between the two participants, and the attitudes, beliefs and perspectives that shape those dynamics (Hewison, 1995). Power is evident in the way the nurse speaks to the patient, the language they use, the focus of the conversation and the involvement the nurse solicits from the patient either in decision making or acts of care.

Several characteristics of the Baby BEEP interactions reflect the nurses' desires to provide the patients with significant power in the interaction. Deference to the patients' preferences for interaction times, which was not always during regular business hours; duration and content of the telephone call; interest in what was happening in the patients' lives; and reassurance that they were available to listen or respond to a page all demonstrate the nurses' desires for the patients' involvement in the interactions and the power available to the patients to affect the course of the interactions. Power also developed for the patients as the nurses sought to empower them to make choices and changes that would improve their health. The nurses used reflection to increase patients' self-awareness and build up the sense of power. This may have enhanced the patient's self-efficacy. In one instance, the nurse praises the patient and then asks if she is "proud of herself." This invites the patient to reflect what has caused her to make important changes in her life in the past and begin to consider action in the present. Although the patients pursued change to varying degrees, indicating that they felt empowered to differing degrees, the control and respect they were afforded in the intervention made it an acceptable, and even desirable, means of support throughout their pregnancies and into the postpartum period. 


\section{Implications for Nursing Practice}

Tele-health, specifically tele-nursing, has not been widely examined as a means of supporting low-income rural women during pregnancy. Tele-nursing is the provision of nursing care using technology and includes mobile, telephone, internet and distance care provision. It has been used in a variety of disciplines, including oncology, HIV, cardiac and primary care, but has not been examined as a means to provide prenatal care or psychosocial support to women experiencing depression during pregnancy (Schlachta-Fairchild, Elfrink, \& Deickman, 2008). Tele-nursing interventions delivered over long distances have included symptom management, patient education, follow-up, case management and social support (Agency for Health Care Research \& Quality, 2008). Tele-nursing offers advantages in time and cost efficiency, as well as the ability to access difficult to reach populations during more accessible hours (Scharer, Colon, Moneyham, Hussey, Tavakoli \& Schugart, 2009). Low-income women living in rural settings stand to gain a great deal from this type of nursing care in which childcare and work obligations can be accommodated. Additionally, the long-term nature of continued contact using tele-nursing allows for significant relationships of trust to be built between nurse and patient. The Baby BEEP study illustrates the feasibility, acceptability and possibilities of tele-nursing to provide meaningful and supportive NPIs that can help support mental health and improve depression rates during pregnancy.

The prevalence of depression during early pregnancy, as well as the consistency required for the development of a long term and invested relationship, reflects the need to begin treatment for AND at the earliest possible point during the pregnancy. There is some evidence in the Baby BEEP study phone logs that contact between the nurse and patient tapered off toward the end of the pregnancy. At least in some cases, this was because patients lost motivation to progress 
towards smoking cessation, or felt uncomfortable because they had not yet achieved those goals, and had not established another purpose in the interactions. This reflects the unique sphere of interaction made available by the intersection of pregnancy, a desire to stop smoking and the availability of a research nurse for weekly interactions. As the patients anticipated the end of the interaction, they may have decreased their responsiveness to the nurse, envisioning the closing of the door on this unique opportunity for interaction. This speaks to the importance of initiating such interactions at an early stage in pregnancy, a time when women may be more receptive to the relationship created by the interaction. In addition, early initiation of interaction would provide for more consistent contact over a longer period of time, helping the patient reach a more stable mental health state before the dramatic hormonal shift of birth occurs. Further research is needed to determine if timing and length of interaction affect depression scores.

One of the striking characteristics of the interactions are their extension into what Millard classifies as the social dimension of interaction, or the "exchange of information, often personal, that was over and above that required for polite, social conversation/interaction" (p.148). Millard et al. point out that social interaction is what set the nurse and patient on equal footing and "affirmed to each other their individuality and their essential 'humanity'," significantly shaping the power dynamic within the interaction and creating a therapeutic relationship (Millard et al., 2006, p. 148). By suggesting the social dimension as a critical component in shaping the nursepatient relationship, Millard provides a concrete strategy for establishing a therapeutic, patientcentered relationship where emotional care is provided. By concentrating on the social dimension, the Baby BEEP study nurses established the foundation for a meaningful relationship to develop, placing the interaction in a comfortable dimension for the patient, and continually reaffirming to the patient their importance as a person. Although the social dimension was not 
the arena in which nursing care was formally provided, it was a necessary precursor to the provision of nursing care and may be an important part of the identification phase as explained by Peplau. This may be especially meaningful to low-income, rural women, who may receive little societal reinforcement of their worth and value.

\section{Validity}

Validity and trustworthiness of the proposed qualitative research was enhanced through a variety of methods. Retention of all study materials and documentation of the process by which the data were reduced, displayed and analyzed occurred through the use of analytic memos and a reflective journal. Potential biases were kept in check through reflection and memoing, as well as discussion with experts in qualitative research as well as those with intimate knowledge of the dataset. Throughout the coding process, the data were approached from a constructivist perspective, trying to make meaning of the interactions and discern the values from the perspective of the patients. This was facilitated through the writing of narrative summaries, as well as constant attention to how the interactions may have been affecting both nurse and patient, particularly in terms of patients' mental health.

Comparison cases of NPIs in which depressed patients remained depressed at the end of pregnancy provided a contrasting sample from which to analyze the findings and to identify those processes, constructs and explanations that were unique versus shared (Huberman \& Miles, 1994). Case-oriented strategies, where differences between cases were examined, and variableoriented strategies, where differences based on characteristics of the patients were sought, were used. Findings were checked for representativeness of the sample, although small, and further verification of the findings may be possible though contacting the nurses who provided the intervention and sharing with them the conclusions of the qualitative analysis (Huberman \& 
Miles, 1994, p.438). By reaching out to the nurses who provided the NPIs, providing them with a condensed version of the findings, and ascertaining their responses to what occurred during the interactions, trustworthiness of the study will be enhanced.

\section{Conclusion}

Antenatal depression is a common perinatal mental health disorder with negative consequences for maternal and infant health, with underserved women at heightened risk. In spite of this increased risk, AND has not been extensively studied in women with lower incomes who live in rural settings. This is true in the United States and other developed countries as well as in developing countries. Lack of treatment for AND is common because of concerns over the safety of anti-depressant medications for the fetus, inability or reluctance to utilize psychological treatments, and few, if any, other effective treatment options. Pregnancy provides a unique window of opportunity for nursing support of depressed women. Few nursing interventions have been developed and examined aimed at reducing risk and enhancing resources of depressed pregnant women. Nurse-patient interactions have been demonstrated over time as an effective means of supporting mental health and facilitating well-being. This study demonstrates that NPI, such as that used in the Baby BEEP study, is an effective means of supporting women who experience depression during pregnancy and may contribute to improved mental health over the course of pregnancy and postpartum. Peplau's Theory of Interpersonal Relations provides a useful framework from which to conceptualize, design and implement programs designed to prevent and treat AND. These findings can inform future studies examining the potential of NPI as an effective means of supporting depressed women during pregnancy. 


\section{References}

Allen, F. M., \& Warner, M. (2002). A developmental model of health and nursing. Journal of Family Nursing, 8(2), 96-135. doi:10.1177/107484070200800202

Aranda, S. K., \& Street, A. F. (1999). Being authentic and being a chameleon: Nurse-patient interaction revisited. Nursing Inquiry, 6(2), 75-82. Retrieved from http://www.ncbi.nlm.nih.gov/pubmed/10696199

Bazeley, P. (2013). Qualitative Data Analysis Practical Strategies. (J. Seaman, Ed.) (p. 444). Thousand Oaks, CA: Sage Publications.

Beddoe, A. E., \& Lee, K. A. (2008). Mind-body interventions during pregnancy. Journal of Obstetric, Gynecologic, and Neonatal Nursing : JOGNN / NAACOG, 37(2), 165-75. doi:10.1111/j.1552-6909.2008.00218.x

Bennett, H. A., Einarson, A., Taddio, A., Koren, G., \& Einarson, T. R. (2004a). Depression during pregnancy : Overview of clinical factors. Clinical Drug Investigation, 24(3), 157-79. Retrieved from http://www.ncbi.nlm.nih.gov/pubmed/17516702

Bennett, H. A., Einarson, A., Taddio, A., Koren, G., \& Einarson, T. R. (2004b). Prevalence of depression during pregnancy: systematic review. Obstetrics and Gynecology, 103(4), 698709. doi:10.1097/01.AOG.0000116689.75396.5f

Bennett, I. M., Culhane, J. F., Webb, D. a, Coyne, J. C., Hogan, V., Mathew, L., \& Elo, I. T. (2010). Perceived discrimination and depressive symptoms, smoking, and recent alcohol 
use in pregnancy. Birth (Berkeley, Calif.), 37(2), 90-7. doi:10.1111/j.1523-

536X.2010.00388.x

Bennett, I. M., Marcus, S. C., Palmer, S. C., \& Coyne, J. C. (2010). Pregnancy-related discontinuation of antidepressants and depression care visits among Medicaid recipients. Psychiatric Services, 61(4), 386-91. doi:10.1176/appi.ps.61.4.386

Bhandari, S., Bullock, L. F. C., Bair-Merritt, M., Rose, L., Marcantonio, K., Campbell, J. C., \& Sharps, P. (2012). Pregnant women experiencing IPV: impact of supportive and nonsupportive relationships with their mothers and other supportive adults on perinatal depression: a mixed methods analysis. Issues in Mental Health Nursing, 33(12), 827-37. doi: $10.3109 / 01612840.2012 .712628$

Bhandari, S., Levitch, A. H., Ellis, K. K., Ball, K., Everett, K., Geden, E., \& Bullock, L. (2008). Comparative analyses of stressors experienced by rural low-income pregnant women experiencing intimate partner violence and those who are not. Journal of Obstetric, Gynecologic, and Neonatal Nursing : JOGNN / NAACOG, 37(4), 492-501. doi:10.1111/j.1552-6909.2008.00266.x

Bloom, T., Glass, N., Curry, M. A., Hernandez, R., \& Houck, G. (2012). Maternal stress exposures, reactions, and priorities for stress reduction among low-income, urban women. Journal of Midwifery \& Women's Health, 58(2), 167-74. doi:10.1111/j.15422011.2012.00197.x

Boström, E., Isaksson, U., Lundman, B., Graneheim, U. H., \& Hörnsten, Å. (2014). Interaction between diabetes specialist nurses and patients during group sessions about self- 
management in type 2 diabetes. Patient Education and Counseling, 94(2), 187-92. doi:10.1016/j.pec.2013.10.010

Brooks-Carthon, J. M., Kutney-Lee, A., Sloane, D. M., Cimiotti, J. P., \& Aiken, L. H. (2011). Quality of care and patient satisfaction in hospitals with high concentrations of black patients. Journal of Nursing Scholarship : An Official Publication of Sigma Theta Tau International Honor Society of Nursing / Sigma Theta Tau, 43(3), 301-10. doi:10.1111/j.1547-5069.2011.01403.x

Brown, J., \& Goldstein, L. (1967). Nurse-patient interaction before and after the substitution of street clothes for uniforms. International Journal of Socail Psychiatry, 14(1), 32-43.

Brunt, D., \& Rask, M. (2013). Validation of the Verbal and Social Interaction questionnaire: carers' focus in the carer-resident relationship in supported housing facilities for persons with psychiatric disabilities (VSI-SH). Journal of Psychiatric and Mental Health Nursing, 20(3), 279-85. doi:10.1111/j.1365-2850.2012.01925.x

Bullock, L., Everett, K. D., Mullen, P. D., Geden, E., Longo, D. R., \& Madsen, R. (2009). Baby BEEP: A randomized controlled trial of nurses' individualized social support for poor rural pregnant smokers. Maternal and Child Health Journal, 13(3), 395-406. doi:10.1007/s10995-008-0363-z

Caris-Verhallen, W., Timmermans, L., \& van Dulmen, S. (2004). Observation of nurse-patient interaction in oncology: Review of assessment instruments. Patient Education and Counseling, 54(3), 307-20. doi:10.1016/j.pec.2003.12.009 
Castillo, J., \& Sanche-Sosa, J. J. (2002). Well-being and medical recovery in the critical care unit: The role of the nurse-patient interaction. Salud Mental, 25(2), 21-31.

Chatwin, J. (2008). Hidden dimensions : The analysis of interaction in nurse - patient encounters. Quality in Primary Care, 16, 109-115.

Cleary, M., Edwards, C., \& Meehan, T. (1999). Factors influencing nurse-patient interaction in the acute psychiatric setting: An exploratory investigation. The Australian and New Zealand Journal of Mental Health Nursing, 8(3), 109-16. Retrieved from http://www.ncbi.nlm.nih.gov/pubmed/10661080

Cleary, M., Hunt, G. E., Horsfall, J., \& Deacon, M. (2012). Nurse-patient interaction in acute adult inpatient mental health units: A review and synthesis of qualitative studies. Issues in Mental Health Nursing, 33(2), 66-79. doi:10.3109/01612840.2011.622428

Cossette, S., Cara, C., Ricard, N., \& Pepin, J. (2005). Assessing nurse-patient interactions from a caring perspective: Report of the development and preliminary psychometric testing of the Caring Nurse--Patient Interactions Scale. International Journal of Nursing Studies, 42(6), 673-86. doi:10.1016/j.ijnurstu.2004.10.004

Cossette, S., Cote, J. K., Pepin, J., Ricard, N., \& D’Aoust, L.-X. (2006). A dimensional structure of nurse-patient interactions from a caring perspective: Refinement of the Caring NursePatient Interaction Scale (CNPI-Short Scale). Journal of Advanced Nursing, 55(2), 198214. doi:10.1111/j.1365-2648.2006.03895.x 
Cossette, S., Pepin, J., Côté, J. K., \& de Courval, F. P. (2008a). The multidimensionality of caring: A confirmatory factor analysis of the Caring Nurse-Patient Interaction Short Scale. Journal of Advanced Nursing, 61(6), 699-710. doi:10.1111/j.1365-2648.2007.04566.x

Cossette, S., Pepin, J., Côté, J. K., \& de Courval, F. P. (2008b). The multidimensionality of caring: A confirmatory factor analysis of the Caring Nurse-Patient Interaction Short Scale. Journal of Advanced Nursing, 61(6), 699-710. doi:10.1111/j.1365-2648.2007.04566.x

Curry, M. A., Burton, D., \& Fields, J. (1998). The Prenatal Psychosocial Profile: A research and clinical tool. Research in Nursing and Health, 21(3), 211-9. Retrieved from http://www.ncbi.nlm.nih.gov/pubmed/9609506

Dennis, C., \& Dowswell, T. (2013). Interventions ( other than pharmacological , psychosocial or psychological ) for treating antenatal depression. Cochrane Database of Systematic Reviews, (7). doi:10.1002/14651858.CD006795.pub3.Copyright

Dennis, C. L., \& Allen, K. (2010). Interventions ( other than pharmacological, psychosocial or psychological ) for treating antenatal depression ( Review ). The Cochrane Library, (6).

Dennis, C. L., Ross, L. E., \& Grigoriadis, S. (2010). Psychosocial and psychological interventions for treating antenatal depression ( Review ). In The Cochrane Collaboration. John Wiley \& Sons, Ltd.

Denyes, M. J., Orem, D. E., \& Bekel, G. (2001). Self-care: A foundational science. Nursing Science Quarterly2, 14(1), 48-55. 
Dimidjian, S., \& Goodman, S. (2009). Nonpharmacologic intervention and prevention strategies for depression during pregnancy and the postpartum. Clinical Obstetrics and Gynecology, 52(3), 498-515. doi:10.1097/GRF.0b013e3181b52da6

Donohue, R. K. (2003). Nurse practitioner - client interaction as resource exchange in a women ' s health clinic : an exploratory study, 011(617), 717-725.

Evans, E. C., \& Bullock, L. F. C. (2012). Optimism and other psychosocial influences on antenatal depression: A systematic review. Nursing \& Health Sciences, 14(3), 352-61. doi:10.1111/j.1442-2018.2012.00700.x

Fisher, J., Cabral de Mello, M., Patel, V., Rahman, A., Tran, T., Holton, S., \& Holmes, W. (2012). Prevalence and determinants of common perinatal mental disorders in women in low- and lower-middle-income countries: a systematic review. Bulletin of the World Health Organization, 90(2), 139G-149G. doi:10.2471/BLT.11.091850

Fosbinder, D. (1994). Patient perceptions of nursing care: an emerging theory of interpersonal competence. Journal of Advanced Nursing, 20(6), 1085-93. Retrieved from http://www.ncbi.nlm.nih.gov/pubmed/7860855

Furber, C. M., Garrod, D., Maloney, E., Lovell, K., \& McGowan, L. (2009). A qualitative study of mild to moderate psychological distress during pregnancy. International Journal of Nursing Studies, 46(5), 669-77. doi:10.1016/j.ijnurstu.2008.12.003 
Gavin, N. I., Gaynes, B. N., Lohr, K. N., Meltzer-brody, S., Gartlehner, G., \& Swinson, T. (2005). Perinatal depression: A systematic review of prevalence and incidence. Obstetrics and Gynecology, 106(5), 1071-1083.

Gaynes, B. N., Gavin, N., Meltzer-Brody, S., Lohr, K. N., Swinson, T., Gartlehner, G., ... Miller, W. C. (2005). Perinatal depression: Prevalence, screening accuracy, and screening outcomes. Evidence Report/technology Assessment (Summary), (119), 1-8. Retrieved from http://www.ncbi.nlm.nih.gov/pubmed/15760246

Goldzwieg, C. L., Orshansky, G., Paige, N. M., Twosgih, A. A., Haggstrom, D. A., Maike-Lye, I., ... Shekelle, P. G. (2013). Annals of internal medicine review electronic patient portals : Evidence on health outcomes, satisfaction, efficiency, and attitudes. A review. Annals of Internal Medicine, 159(10), 679-.

Grigoriadis, S., VonderPorten, E. H., Mamisashvili, L., Tomlinson, G., Dennis, C.-L., Koren, G., ... Ross, L. E. (2013). The impact of maternal depression during pregnancy on perinatal outcomes: a systematic review and meta-analysis. The Journal of Clinical Psychiatry, 74(4), e321-41. doi:10.4088/JCP.12r07968

Haugan, G., Innstrand, S. T., \& Moksnes, U. K. (2013). The effect of nurse-patient interaction on anxiety and depression in cognitively intact nursing home patients. Journal of Clinical Nursing, 22(15-16), 2192-205. doi:10.1111/jocn. 12072

Hewison, a. (1995). Nurses' power in interactions with patients. Journal of Advanced Nursing, 21(1), 75-82. Retrieved from http://www.ncbi.nlm.nih.gov/pubmed/7897081 
Holyoake, D. (1997). Exploring the nature of nurse interaction using an interaction interview schedule: The results. Psychiatric Care, 4, 83-87.

Huberman, A. M., \& Miles, M. B. (1994). Handbook of Qualitative Research. (N. K. Denzin \& Y. S. Lincoln, Eds.) (1st ed., pp. 428-444). Thousand Oaks, CA: Sage Publications.

Jeong, H.-G., Lim, J.-S., Lee, M.-S., Kim, S.-H., Jung, I.-K., \& Joe, S.-H. (2013). The association of psychosocial factors and obstetric history with depression in pregnant women: Focus on the role of emotional support. General Hospital Psychiatry, 35(4), 354-8. doi:10.1016/j.genhosppsych.2013.02.009

Jesse, D. E., Dolbier, C. L., \& Blanchard, A. (2008). Barriers to seeking help and treatment suggestions for prenatal depressive symptoms: focus groups with rural low-income women. Issues in Mental Health Nursing, 29(1), 3-19. doi:10.1080/01612840701748664

Jomeen, J. (2004). The importance of assessing psychological status during pregnancy, childbirth and the postnatal period as a multidimensional construct: A literature review. Clinical Effectiveness in Nursing, 8(3-4), 143-155. doi:10.1016/j.cein.2005.02.001

Kandler, H., Behymer, A. F., Kegeles, S. S., Boyd, R. W., \& Kandler, B. H. (1952). A study of nurse-patient interaction in a mental hospital. The American Journal of Nursing, 52(9), $1100-1103$.

Kasch, C. R. (1986). Toward a theory of nursing action: Skills and competency in nurse-patient interaction. Nursing Research, 35(4), 226-230. 
Kim, H. S., \& Collak, I. (2006). Nursing Theories: Conceptual and Philosophical Foundations. (H. suzie Kim \& I. Kollak, Eds.) (2nd ed.). New York, NY: Springer Publishing Company.

King, I. M. (2007). King's conceptual system, theory of goal attainment, and transaction process in the 21st century. Nursing Science Quarterly, 20(2), 109-111.

Knackstedt, M. K., Hamelmann, E., \& Arck, P. C. (2005). Mothers in stress: consequences for the offspring. American Journal of Reproductive Immunology (New York, N.Y. : 1989), 54(2), 63-9. doi:10.1111/j.1600-0897.2005.00288.x

Konradsen, H., Kirkevold, M., \& Zoffmann, V. (2009). Surgical facial cancer treatment: the silencing of disfigurement in nurse-patient interactions. Journal of Advanced Nursing, 65(11), 2409-18. doi:10.1111/j.1365-2648.2009.05102.x

Kopelman, R. C., Moel, J., Mertens, C., Stuart, S., Arndt, S., \& O’Hara, M. W. (2008). Barriers to care for antenatal depression. Psychiatric Services (Washington, D.C.), 59(4), 429-32. doi:10.1176/appi.ps.59.4.429

Krouse, Helene, J., Krouse, J. H., \& Roberts, S. J. (1988). Preliminary validation of a nursepatient interaction tool. Perceptual and Motor Skills, 67, 281-282.

Lancaster, C. A., Gold, K. J., Flynn, H. A., Yoo, H., Marcus, S. M., \& Davis, M. M. (2010). Risk factors for depressive symptoms during pregnancy: A systematic review. American Journal of Obstetrics and Gynecology, 202(1), 5-14. doi:10.1016/j.ajog.2009.09.007.Risk 
Levy, L. B., \& O’Hara, M. W. (2010). Psychotherapeutic interventions for depressed, lowincome women: a review of the literature. Clinical Psychology Review, 30(8), 934-50. doi:10.1016/j.cpr.2010.06.006

Lieber, J. L. (2014). How do your patient satisfaction scores measure up? Nursing Management, 45(2), 22-5. doi:10.1097/01.NUMA.0000442647.39442.32

McFarlane, J., Parker, B., Soeken, K., \& Bullock, L. (1992). Assessing for abuse during pregnancy. Journal of American Medical Association, 267(23), 3167-3178.

Medicine, I. of. (2010). The future of nursing: leading change, advancing health. Journal for Nurses in Professional Development (Vol. 29). Washington, DC. doi:10.1097/NND.0b013e318287d1ad

Miles, M. B., Huberman, A. M., \& Saldana, J. (2013). Qualitative Data Analysis: A Methods Sourcebook (3rd ed., pp. 69-104). Thousand Oaks, CA: Sage Publications.

Millard, L., Hallett, C., \& Luker, K. (2006). Nurse-patient interaction and decision-making in care: Patient involvement in community nursing. Journal of Advanced Nursing, 55(2), 14250. doi:10.1111/j.1365-2648.2006.03904.x

Morse, J. M., Havens, G. A. D., \& Wilson, S. (1997). The comforting interaction: Developing a model of nurse-patient relationship. Scholarly Inquiry for Nursing Practice: An International Journal, 11(4), 321-347.

Muzik, M., Marcus, S. M., Heringhausen, J. E., \& Flynn, H. (2009). When depression complicates childbearing: Guidelines for screening and treatment during antenatal and 
postpartum obstetric care. Obstetrics and Gynecology Clinics of North America, 36(4), 77188, ix-X. doi:10.1016/j.ogc.2009.10.006

Norton, L. B., Peipert, J., Zeirler, S., Lima, B., \& Hume, L. (1995). Battering in pregnancy: An assessment of two screening methods. Obstetrics and Gynecology, 85(3).

Peplau, H. (1997). Peplau's theory of interpersonal relations. Nursing Science Quarterly, 10(4), $162-167$.

Peplau, H. E. (1991). Interpersonal relations in nursing: A conceptual frame of reference for psychodynamic nursing (p. 355). New York, NY: Springer Publishing Company.

Poggenpoel, M. (1994). Psychiatric nurse-patient interaction facilitating mental health. Curationis, 17(1), 51-57.

Rask, M., \& Brunt, D. (2007). Verbal and social interactions in the nurse-patient relationship in forensic psychiatric nursing care: A model and its philosophical and theoretical foundation. Nursing Inquiry, 14(2), 169-76. doi:10.1111/j.1440-1800.2007.00364.x

Rask, M., Brunt, D., \& Fridlund, B. (2008a). Validation of the verbal and social interaction questionnaire: nurses' focus in the nurse-patient relationship in forensic nursing care. Journal of Psychiatric and Mental Health Nursing, 15(9), 710-6. doi:10.1111/j.13652850.2008.01292.x

Rask, M., Brunt, D., \& Fridlund, B. (2008b). Validation of the verbal and social interaction questionnaire: nurses' focus in the nurse-patient relationship in forensic nursing care. 
Journal of Psychiatric and Mental Health Nursing, 15(9), 710-6. doi:10.1111/j.13652850.2008.01292.x

Rasmussen, H. N., Scheier, M. F., \& Greenhouse, J. B. (2009). Optimism and physical health: a meta-analytic review. Annals of Behavioral Medicine : A Publication of the Society of Behavioral Medicine, 37(3), 239-56. doi:10.1007/s12160-009-9111-x

Ravert, P., Williams, M., \& Fosbinder, D. M. (1997). The interpersonal competence instrument for nurses. Western Journal of Nursing Research, 17(6), 781-791.

Records, K., \& Rice, M. (2007). Psychosocial Correlates of Depression of Pregnancy, 231-242. doi:10.1111/J.1552-6909.2007.00140.x

Reichenheim, M. E. (2004). Comparison between the abuse assessment screen and the revised conflict tactics scales for measuring physical violence during pregnancy. Journal of Epidemiology \& Community Health, 58(6), 523-527. doi:10.1136/jech.2003.011742

Reid, B. H., Power, M., \& Cheshire, K. (2007). Factors influencing antenatal depression , anxiety and stress.

Rickelman, B. L. (1971). Bio-psycho-social linguistics: A conceptual approach to nurse-patient interaction. Nursing Research, 20(5), 398-403.

Rose, L., Alhusen, J., Bhandari, S., Soeken, K., Marcantonio, K., Bullock, L., \& Sharps, P. (2010). Impact of intimate partner violence on pregnant women's mental health: mental distress and mental strength. Issues in Mental Health Nursing, 31(2), 103-11. doi: $10.3109 / 01612840903254834$ 
Rumpf, H. J., Meyer, C., Hapke, U., \& John, U. (2001). Screening for mental health: Validity of the MHI-5 using DSM-IV Axis I psychiatric disorders as gold standard. Psychiatry Research, 105(3), 243-53. Retrieved from http://www.ncbi.nlm.nih.gov/pubmed/11814543

Rundell, S. (1991). A study of nurse-patient interaction in a highg dependency unit. Intensive Care Nursing, 7, 171-178.

Saghafi, F., Hardy, J., \& Hillege, S. (2012). New graduate nurses' experieces of interactions in the critical care unit. Contemporary Nurse, 42(1), 20-27.

Saldana, J. (2013). The Coding Manual for Qualitative Researchers (Second ed.). Thousand Oaks, CA.

Scheier, M. F., \& Carver, C. S. (1985). Optimism, coping, and health: assessment and implications of generalized outcome expectancies. Health Psychology : Official Journal of the Division of Health Psychology, American Psychological Association, 4(3), 219-47. Retrieved from http://www.ncbi.nlm.nih.gov/pubmed/4029106

Schetter, C. D. (2009). Stress Processes in Pregnancy and Preterm Birth. Current Directions in Psychological Science, 18(4), 205-209. doi:10.1111/j.1467-8721.2009.01637.x

Schlachta-Fairchild, L., Elfrink, V., \& Deickman, A. (2008). Patient Safety, Telenursing , and Telehealth. Patient Safety and Quality: An Evidence-Based Handbookfor Nurses. Rockville, MD: Agency for Healthcare Research and Quality. Retrieved from http://www.ahrq.gov/professionals/cliniciansproviders/resources/nursing/resources/nurseshdbk/index.html 
Sharac, J., McCrone, P., Sabes-Figuera, R., Csipke, E., Wood, A., \& Wykes, T. (2010). Nurse and patient activities and interaction on psychiatric inpatients wards: a literature review. International Journal of Nursing Studies, 47(7), 909-17. doi:10.1016/j.ijnurstu.2010.03.012

Shattell, M. (2004). Nurse-patient interaction: A review of the literature. Journal of Clinical Nursing, 13(6), 714-22. doi:10.1111/j.1365-2702.2004.00965.x

Shin, H., \& White-Traut, R. (2005). Nurse-child interaction on an inpatient paediatric unit. Journal of Advanced Nursing, 52(1), 56-62. doi:10.1111/j.1365-2648.2005.03564.x

Stoddart, K. M. (2012). Social meanings and understandings in patient-nurse interaction in the community practice setting: A grounded theory study. BMC Nursing, 11, 14. doi:10.1186/1472-6955-11-14

Tejero, L. M. S. (2012). The mediating role of the nurse-patient dyad bonding in bringing about patient satisfaction. Journal of Advanced Nursing, 68(5), 994-1002. doi:10.1111/j.13652648.2011.05795.x

Tropea, S. (2012). “Therapeutic emplotment”: A new paradigm to explore the interaction between nurses and patients with a long-term illness. Journal of Advanced Nursing, 68(4), 939-47. doi:10.1111/j.1365-2648.2011.05847.x

Våga, B. B., Moland, K. M., Evjen-Olsen, B., Leshabari, S. C., \& Blystad, A. (2013). Rethinking nursing care: an ethnographic approach to nurse-patient interaction in the context of a HIV prevention programme in rural Tanzania. International Journal of Nursing Studies, 50(8), 1045-53. doi:10.1016/j.ijnurstu.2012.11.025 
Wagner, D., \& Bear, M. (2008). Patient satisfaction with nursing care: a concept analysis within a nursing framework. Journal of Advanced Nursing, 65(3), 692-701. doi:10.1111/j.13652648.2008.04866.x

Walker, L. O., \& Avant, K. C. (2005). Strategies for theory construciton in nursing (4th ed.). Upper Saddle River, JH: Pearson Education.

Watson, J. (2009). Caring science and human caring theory: Transforming personal and professional practices of nursing and health care. Journal of Health and Human Services Administration, 31(4), 466-482.

Williams, A. M., \& Irurita, V. F. (2004). Therapeutic and non-therapeutic interpersonal interactions: The patient's perspective. Journal of Clinical Nursing, 13(7), 806-15. doi:10.1111/j.1365-2702.2004.01020.x

Williams, A. M., \& Kristjanson, L. J. (2009). Emotional care experienced by hospitalised patients: Development and testing of a measurement instrument. Journal of Clinical Nursing, 18(7), 1069-77. doi:10.1111/j.1365-2702.2008.02586.x 


\section{Appendix A}

Development and Psychometric Properties of Instruments

Demographic Information Form (DIF). The study team developed a demographic questionnaire for the purpose of collecting general health and personal information from each participant. Information collected at baseline included, but was not limited to, the following: date of birth (month/day/year); week's gestation; ethnicity; number live births; marital status (0 = not married, 1 = married or living in married like relationship); and years of school completed. All items were collected through self-report from the study subject by the research nurse who recorded the answers with paper and pencil. Ratio and ordinal level data were entered as written; nominal data were recoded to have 0 represent the referent group. Completion time for demographic items was less than 5 minutes.

Mental Health Inventory-5 (MHI-5). The MHI-5 was initially part of the SF-36 Health Survey (Ware \& Gandek, 1998). This survey was designed as a multidimensional measure of general health status with eight subscales that make up a physical and mental health summary. The theoretical basis for this instrument stems from the construct that as a complex phenomenon, general health has many different components. As measured by the SF-36, the physical component of health is comprised of physical functioning, role-physical, bodily pain and general health. The mental component of health is comprised of vitality, social functioning, roleemotional and mental health. The MHI-5 is the subscale for mental health in the SF-36. The SF36 has undergone extensive psychometric evaluation through the International Quality of Life Assessment (IQOLA) Project, undertaken by Ware \& Gandek (1998) to justify and systematically oversee the translation of the SF-36 for international use. Much of the reliability and validity information for the MHI-5 comes from this project. 
Scoring. The MHI-5 consists of five items that evaluate the subject's mood through a 5point Likert scale. Respondents are asked to circle the number that reflects how often they have felt a certain way, for example "calm and peaceful," during the last month $(1=$ all of the time, 2 $=$ most of the time, $3=$ a good bit of the time, $4=$ some of the time, $5=$ a little bit of the time, 6 $=$ none of the time) (see Appendix A for a copy of the instrument). Two of the items are written in the negative and then reverse scored. A total scale score is obtained by summation of all the items and multiplying by four. The level of measurement is interval level, but can be dichotomized into risk for mood or anxiety disorders, with scores under 65 having a sensitivity of 0.87 and specificity of 0.70 for detecting mood disorders (Rumpf et al., 2001). The possible range of scores is $0-100$, with higher scores indicating better mental health.

Administration. The administration time for the MHI-5 is under five minutes. Although the readability index is not detailed here, the instrument has been used over a long period of time (since 1991) in a variety of populations with no known reports of difficulty understanding either the instructions or items (Ware\& Gandek, 1998). Compliance for this instrument is high among staff and subjects because of its brevity and ease of comprehension.

Psychometric testing. Psychometric testing for the SF-36 was guided by the standards of the American Psychological Association. Reliability for the MHI-5 has been examined in over 20 patient groups with varying diagnoses and levels of sociodemographic characteristics. In all cases, reliability coefficients have been greater than 0.70 or 0.80 . The MHI-5 has shown especially high reliability in an alternate forms method of evaluation, with an alpha of 0.93 (Ware \& Gandek, 1998). Content validity has been established empirically through the systematic comparison of the SF-36 subscales to other measures of general health and health concepts. When compared with other measures of health status in the U.K., U.S. and Sweden, the 
SF-36 subscales were able to explain two-thirds of the total variance in scores. Construct validity has been demonstrated with factor analysis in a variety of countries and populations, including the U.S. general population, indicating that the two summary scales, mental and physical health, account for $80-85 \%$ of the variance in the eight subscales, including the MHI-5. Additionally, the item-to-total correlations have been shown to be 0.04 or greater. Criterion-related validity for the MHI-5 has been established as it has been measured against actual DSM-IV Axis I diagnoses of mood and anxiety disorders and Diagnostic Interview Schedule disorders in the general population (Berwick et al., 1991, Rumpf et al., 2001, Ware \& Gandek, 1998). In factor analytic studies, the MHI-5 has been shown to be most responsive to change in severity of depression (Ware \& Gandek, 1998).

The psychometric properties of the MHI-5 have been supported with ample evidence over the past two decades. Feasibility for the low-income, rural population has been established as the instrument has been administered to a variety of populations, including those with sociodemographic diversity. Reliability for the MHI-5 has exceeded the standard level designated by Nunnally and Berstein (1994) of 0.70. As indicated by Anastasi (1988) and Polit and Hungler (1995), validity is not established at one point in time with specific statistical values, but supported with continued evaluation over time. Validity for the MHI-5 has been supported by the continued examination of content construct and criterion-related validity with a variety of methods, including logical examination of content and factor analysis and comparison with other "gold standard" measures of psychological health. Norms for the MHI-5 have been established in the U.S. general population with a mean of 74.7 (SD 18.1) (Ware \& Gandek, 1998). Cut off values predictive of mood or anxiety disorders for the scale vary, depending on desired sensitivity and specificity. For the purposes of this study to detect mood disorders, a cut- 
off value of 60 points or less has a sensitivity of 0.83 and specificity of 0.78 in detecting DSMIV Axis I mood disorders, such as depression, as taken from a random sample of the German general population (Rumpf, et al., 2001).

Perceived Stress Scale (PSS). The PSS was developed by Cohen, Kamarck and Mermelstein (1983) to measure the degree to which an individual's life is perceived as stressful. The theoretical basis for the scale was based on the concept that stress is more than a sum of objectively "stressful" experiences that occur in an individual's life. Rather, stress is based on the cognitive appraisal of the individual and characterized by life seeming unpredictable, uncontrollable and overloading. It is a multidimensional construct whose perception encompasses stress from ongoing life circumstances, from expectations concerning future events, events not listed on a particular life-events scale and to reactions to the specific events included on any scale (Cohen, Kamarck \& Mermelstein, 1983). The intent of the developers of the PSS was to use it as an aid in predicting those health-related outcomes associated with stress (Cohen \& Williamson, 1988).

Scoring. The shortest form of the PSS, the PSS4, contains four items, each rated on a 5point Likert scale, where respondents report feelings and thoughts they have had over the past month. An example item is: "In the past month, how often have you felt that things were going your way?" The subject then circles a number from one through five rating if they rarely or never (1) felt this way or very often (5) felt this way. The total stress score is calculated at the ratio level by reverse scoring items two and three and summing all four items. Scores range from 016, where a high score indicates high levels of stress.

Administration. The four-item version of the PSS (PSS4) takes less than five minutes to administer and was developed for use in populations with a junior high or equivalent reading 
level. Compliance with the scale is high because of its readability, brevity and the general nature of its concepts.

Psychometric testing. Reliability and validity for the measure were initially obtained from a young, more highly educated, non-minority population of college students, but subsequent use of the scale as the most widely used psychological instrument for measuring the perception of stress have added substantial psychometric support from a wide range of samples. Reliability of the scale was documented through the administration of the PSS4 to a large sample $(n=2387)$ of adults representing the U.S. population at the time. Cronbach's alpha for the PSS4 was 0.60 , compared to the 0.78 and 0.75 for the ten-item and 14 -item scales, respectively (Cohen \& Williamson, 1988). In evaluation of the stability of the measure, a two day test-retest among college students yielded a reliability of 0.85 . Subsequently, reliability drops off as an individual's experiences and perceptions change over the course of weeks, as demonstrated by the six week test-retest reliability of 0.55 among the general population sample (Cohen, Kamark \& Mermelstein, 1983). Content validity for the scale was established theoretically through the logical derivation of the items and concepts by the developers. Although less useful as an indication of validity now, high face validity for the instrument and its items existed at the time (Cohen, Kamark \& Mermelstein, 1983). Construct validity was accomplished through factor analysis of the scale with a national area-probability sample, with the PSS4 demonstrating only one factor, accounting for $45.6 \%$ of the variance in scores. Additionally, groups contrasted by gender, age, income, education, household composition, marital status and employment were found to have statistically significant differences in PSS4 scores (Cohen \& Williamson, 1988). Criterion-related validity was a dominant focus of psychometric evaluation for the developers of the instrument, and PSS scores were found to be moderately correlated with other measures of 
appraised stress. Further support for criterion-related validity was given by statistically significant associations between PSS score and self-reported physical illness, as well as life satisfaction scale (Cohen \& Williamson, 1988).

The psychometric properties of the PSS4 have been established over decades of use. Its brevity, ease of use and adequate readability make it a sound choice to measure perceptions of stress among low-income, rural women. Although the 0.60 reliability for the PSS 4 did not meet the 0.70 criterion established by Nunnally and Berstein (1994), the developers argue that it is adequate "for use in situations requiring a very brief measure of perceptions of stress" (Cohen \& Williamson, 1988, p. 46). Validity for the instrument has been supported as evidence has accumulated with its use over the years, as encouraged by Polit and Hungler (1995) in their classic treatment of psychometric validation. Multiple procedures, including contrasted group $t$ tests, factor analyses and correlations with other health status indicators, as encouraged by Anastasi (1988), have lent support for construct and criterion-related validity. Norms from the general population are available for comparison to the study sample (mean 4.2-5.9), and indicate that higher stress scores exist in single women with lower income, less years of formal education and higher parity. No cut-offs or clinically significant differences are given for this measure, as it is intended to provide relative stress information not used for diagnostic purposes.

Prenatal Psychosocial Profile (PPP). The PPP was developed by Curry, Campbell and Christian (1994) for the purpose of measuring psychosocial variables in pregnant women who are socially or economically disadvantaged. The instrument utilizes a multidimensional construct with domains of self-esteem, perceived stress and social support from partner and others. For this study, only the social support components were evaluated. The conceptual basis of the instrument is based on the link that has been established between psychosocial factors and 
pregnancy outcomes. Although physiological factors have been identified as potential moderators of this relationship, behavioral factors are thought to have substantial modifying capability as they significantly impact health.

Scoring. The social support scales for the PPP consist of 11 statements of support, such as "helps keep up my morale." The subject is asked to rate their partner and then other people in a 6-point Likert scale for each of these statements according to whether they are very dissatisfied (1) or very satisfied (6) with the support they receive. Scores for each item are summed to calculate an interval level social support score for partner and others that range from 11-66, with 66 indicating greater satisfaction with support.

Administration. The social support scales of the PPP can be completed in less than 10 minutes. Readability of the instrument is not reported. Compliance with the instrument is high, given the ease with which it is understood and the general nature of the items.

Psychometric testing. Internal consistency reliability of the 11 -item SBI was 0.89 for the total support scales (partner and other taken together) in a sample of 313 expectant couples (Brown, 1986). Stability was assessed using test-retest reliability in a convenience sample of 67 pregnant women recruited from a University Prenatal Clinic. Correlations between the tests ranged from 0.78 to 0.84 depending on space between administrations (Curry, Campbell \& Christian, 1994). Content validity for the PPP was initiated with a thorough review of the literature for each domain, specifically seeking to substantiate the potential relationship between each domain and pregnancy outcomes. After a conceptual framework was developed, items or instruments representing each domain were procured. Brown's Support Behaviors Inventory (SBI) was selected for the social support instrument because of its brevity and representation of the dual nature of support (partner as well as other). This instrument was originally developed to 
capture the multidimensional nature of social support and was tested in childbirth education classes at eight hospitals in two large northwestern cities. Construct validity for the SBI was tested with factor analysis, suggesting the single factor of broad social support accounted for $48 \%$ of the variance in partner support and $61 \%$ of the variance in other support (Brown, 1986). Additionally, support for validity of the PPP was obtained with expected correlations between the subscales (stress negatively correlates with support from partner, others and self-esteem) and factor analysis of all four domains. All scale items had higher factor loadings for their domain than for any of the other domains, with negligible overlap. Criterion-related validity was not discussed in the evaluation of the SBI or the PPP.

The PPP is a newer instrument with less reliability and validity measures than either the PSS4 or MHI-5. Yet, it appears to be a feasible and potentially valuable measurement tool for low-income, socially disadvantaged pregnant women. Reliability has been established at the 0.89 level for expectant women, exceeding Nunnally and Berstein's (1994) criteria of 0.70 or 0.80 for reliability. Support for the validity of the PPP, specifically the social support scales, stems from the multiple methods used to develop its content and constructs. Anastasi (1988) indicates that support for validity requires multiple procedures assessed at various stages of the instrument's use. The social support scales of the PPP require continued accumulation of evidence, according to Polit and Hungler (1995) to establish validity, particularly criterion-related validity. Norms from a sample of 67 low-income, partnered, high school-educated pregnant women in their twenties showed mean (SD) scores of 19.16 (4.99) for the stress subscale, 51.36 (12.62) for the partner support subscale, 49.05 (12.64) for the other support subscale and 34.46 (4.56) for the self-esteem subscale. No additional literature was found describing the norms, minimally important differences or clinical significance of this measure. 
Abuse Assessment Screen (AAS). The Abuse Assessment Screen was developed by the Nursing Research Consortium of Violence and Abuse to assess for the presence of abuse in pregnant and non-pregnant women (McFarlane, Parker, Soeken, \& Bullock, 1992). The instrument was intended to be "straightforward and direct," providing the potential for more accurate identification of abuse through ease of administration (McFarlane et al., 1992, p. 196). The instrument measures past and present instances of abuse, as well as prevalence, perpetrator, severity, location and type of abuse. The AAS has been examined through direct comparison with other abuse screening tools, such as the Conflict Tactics Scale (CTS), Index of Spouse Abuse (ISA) and Danger Assessment (DA).

Scoring. The AAS consists of five items that assess the presence (yes or no) over time (current, ever, last year, during pregnancy), perpetrator (husband, ex-husband, boyfriend, stranger, other, multiple), and frequency of abuse. Respondents are asked to circle the answer that reflects the presence (or not) of abuse, the perpetrator (if any), in addition to filling in the blank as to the number of times the abuse was experienced. One question assesses whether the abuse was sexual and one question assesses whether the respondent is currently afraid of any potential perpetrators. A body map is included as part of the instrument, where the respondent is asked to "mark the area of injury on the body map" and rate the injury as to level of severity on a scale of one to six $(1=$ threats of abuse including use of a weapon, $6=$ use of weapon; wound from weapon). No total score is calculated for the AAS. Positive responses to questions two, three or four are considered positive for abuse.

Administration. The administration time for the AAS is less than five minutes. Readability has not been established, but the instrument has been used effectively in populations with educational levels less than or equal to high school equivalency. Compliance for the 
instrument is high, but may vary depending upon the setting in which the instrument is administered. It is essential that the instrument be administered in a private and confidential manner to optimize reliability and validity (McFarlane et al., 1992).

Psychometric testing. Psychometric testing for the AAS began in 1992 and has continued through 2004 (McFarlane et al., 1992; Reichenheim, 2004). Reliability and validity for the AAS has been examined in low-income pregnant women of Latina, African-American and Caucasian ethnicities $(n=1,203)$ using a test-retest approach and hypothesis testing. When compared with the other standardized assessments of abuse, the AAS showed internal consistencies of 0.79 with CTS, 0.93 with ISA and 0.84 with DA. Reliability was assessed using test-retest methods with two samples of 40 women, with agreement in one sample reaching $83 \%$ and in the other $100 \%$. Content validity has been established by a panel of 12 nurse researchers with expertise in abuse among women (McFarlane et al., 1992). To establish a criterion-related validity, a hypothesis about the instrument's validity in identifying the presence, severity, frequency and ability to detect abuse during pregnancy were tested and found adequate when compared with the CTS, ISA and DA. Investigation of the AAS in international settings has identified the need for continued psychometric testing. In a direct comparison of the three anchor questions of the AAS with the CTS2 psychical aggression scale, a point-biserial correlation of 0.68 was found, indicating the need for further studies to establish its construct validity and ability to detect specific incidents of minor abuse (Reichenheim, 2004).

Overall, the AAS has been widely used and accepted over the past two decades as an accurate measure of abuse, especially in identifying the prevalence of instances of severe abuse (Reichenheim, 2004). Feasibility for the AAS has been established for low-income, diverse, pregnant populations through its administration among a variety of samples (Bullock et al., 2009; 
McFarlane et al., 1992; Norton, Peipert, Zeirler, Lima, \& Hume, 1995; Reichenheim, 2004; Rose et al., 2010). Reliability for the AAS has exceeded the standard level designated by Nunnally and Berstein (1994) of 0.70. Support of the validity of the AAS has occurred through the approval of expert nurse researchers, psychometric testing and continued use in a wide range of samples over an extended period, as required by Anastasi (1988) and Polit and Hungler (1995), although continued psychometric testing has revealed the need for more specific examination. Because it measures data at a nominal level, cut off values for the instrument are not required. For this study, any report of abuse throughout the course of the study indicated a positive screen and accounted for the cumulative effects of abuse that have been identified in the literature and are particularly relevant to the mental health of pregnant women (Rose et al., 2010). 


\section{Appendix $B$}

Instruments

Mental Health Inventory-5 (MHI-5)

\section{BABY BEEP STUDY}

MHI
Study ID \#

Date

EDD

Gestational Age

$$
\text { Interview } 1 \quad 2 \quad 3
$$

(Circle One)

For each of the following questions, I will circle the number for the one answer that comes closest to the way you have been feeling during the last month.

(Circle One Number On Each Line)

MH1. How much of the time, during the past month, have you been a very nervous person?

MH2. During the past month, how much of the time have you felt calm and peaceful?

MH3. How much of the time, during the past month, have you felt downhearted and blue?

MH4. During the past month, how much of the time have you been a happy person?

MH5. How often, during the past month, have you felt so down in the dumps that nothing could cheer you up?

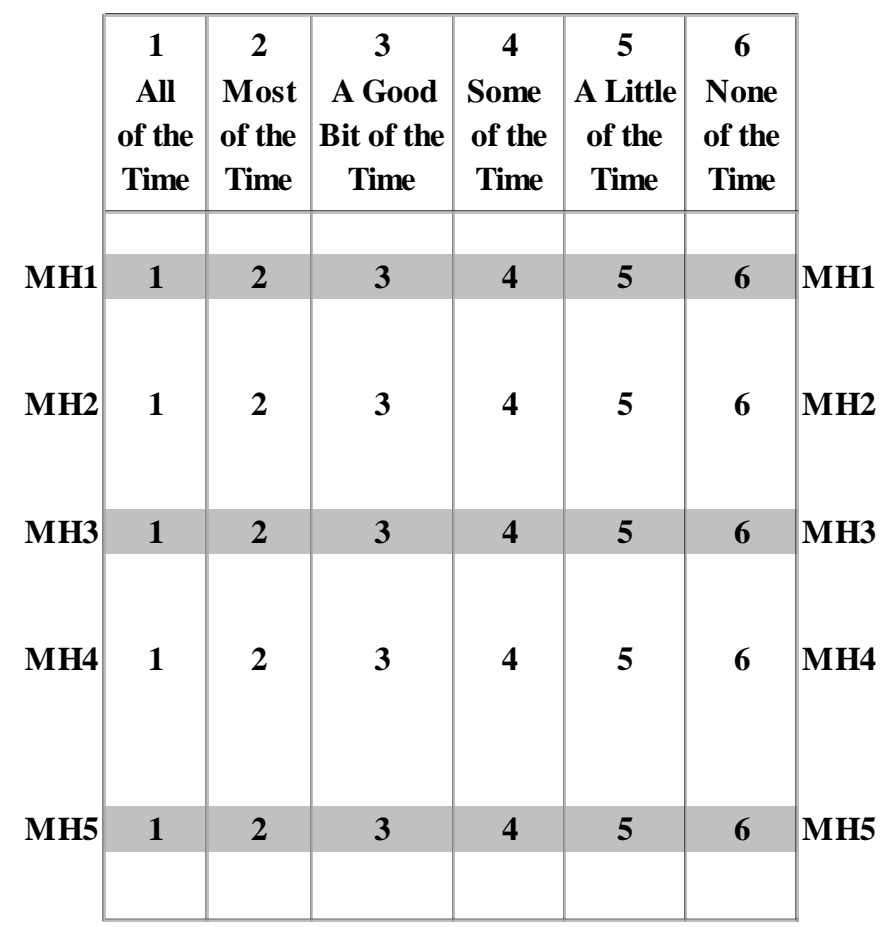


Perceived Stress Scale (PSS)

BABY BEEP STUDY

COHEN'S STRESS SCALE
Study ID \#

Date

EDD

Gestational Age

Interview \# $12 \quad 2 \quad 3$

(Circle One)

The next questions are about how things have been for you in the last month. Now tell me how often each of the following has happened in the past month using the scale where $1=$ Rarely or Never and $5=$ Very Often

C1. In the past month, how often have you felt that you were unable to control the important things in your life?

C2. In the past month, how often have you felt confident about your ability to handle personal problems?

C3. In the past month, how often have you felt that things were going your way?

C4. In the past month, how often have you felt difficulties were piling up so high that you could not overcome them?

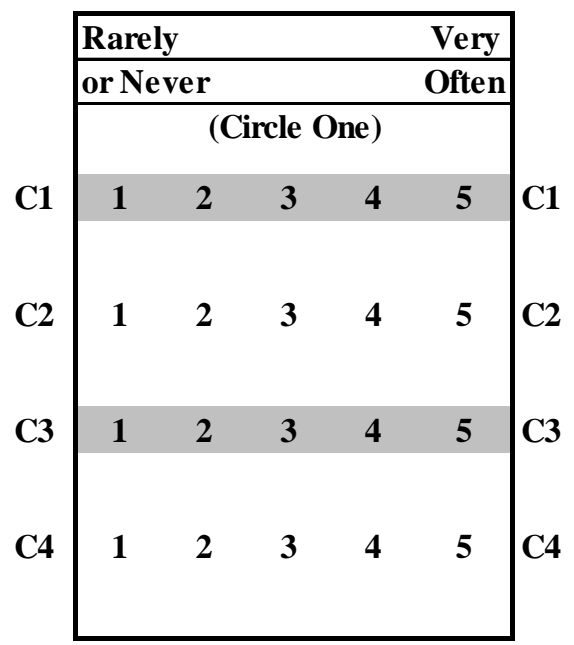


Prenatal Psychosocial Profile (PPP)

\section{BABY BEEP STUDY}

PPP
Study ID \#

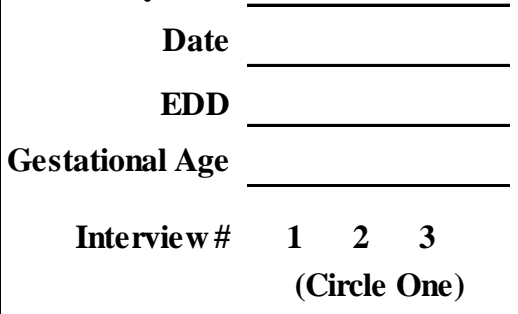

* Administer the Prenatal Psychosocial Profile by following this script:

This set of questions is concerned with the kinds of stress you might be experiencing. I am going to read some types of stress women commonly report during pregnancy. I would like you to answer as to what extent the following items are a current stress or hassle for you. Your choices are: No Stress, Some Stress, Moderate Stress or Severe Stress. Here's a card with the choices and numbers for each level of stress, with some "smiling faces".

* Hand the women the card with response choices and begin questionnaire.

A18A. Financial worries (e.g.., food, shelter, health care, transportation).

$\begin{array}{cccc}\text { No } & \text { Some } & \text { Moderate } & \text { Severe } \\ \text { Stress } & \text { Stress } & \text { Stress } & \text { Stress }\end{array}$

A18B. Other money worries (e.g.., bills, etc...).

$\begin{array}{llllll}1 & 2 & 3 & 4 & \text { A18A }\end{array}$

A18C. Problems related to family (e.g.., partner, children, etc...).

$\begin{array}{lllll}1 & 2 & 3 & 4 & \text { A18B }\end{array}$

A18D. Having to move, either recently or in the future.

A18E. Recent loss of loved one (e.g.., death, divorce, long distance).

$\begin{array}{lllll}1 & 2 & 3 & 4 & \text { A18C } \\ 1 & 2 & 3 & 4 & \text { A18D } \\ 1 & 2 & 3 & 4 & \text { A18E } \\ 1 & 2 & 3 & 4 & \text { A18F }\end{array}$

A18G. Current abuse (e.g.., sexual, emotional or physical).

$\begin{array}{llllll}1 & 2 & 3 & 4 & \text { A18G }\end{array}$

A18H. Problems with alcohol and/or drugs.

1

A18I. Work problems (e.g.., being laid off, etc...).

12

3

$4 \quad \mathbf{A 1 8 H}$

A18J. Problems related to friends.

$\begin{array}{llll}1 & 2 & 3 & 4\end{array}$

A18I

A18K. Feeling generally "overloaded".

12

3


BABY BEEP STUDY

PPP
Study ID \#

Date

EDD

Gestational Age

Interview\# $11 \quad 2 \quad 3$

(Circle One)

The next set of questions asks how satisfied you are with the amount of support you receive from your partner and/or from other people.

I will read you a list of statements describing types of support. On a scale of 1 to 6, with 1 being very dissatisfied and 6 being very satisfied, I want you to tell me how satisfied you are with the support you receive from Your Partner and/or, then also, from Other People.

A19A. Shares similar experiences with me.

A19B. Helps keep up my morale.

A19C. Helps me out when I'm in a pinch.

A19D. Shows interest in my daily activities and problems.

A19E. Goes out of the way to do special or thoughtful things for me.

A19F. Allows me to talk about things that are very personal and private.

A19G. Lets me know I am appreciated for the things I do for him/her.

A19H. Tolerates my ups and downs and unusual behaviors.

A19I. Takes me seriously when I have concerns.

A19J. Says things that make my situation clear and easier to understand.

A19K. Lets me know that he/she will be around if $I$ need assistance.

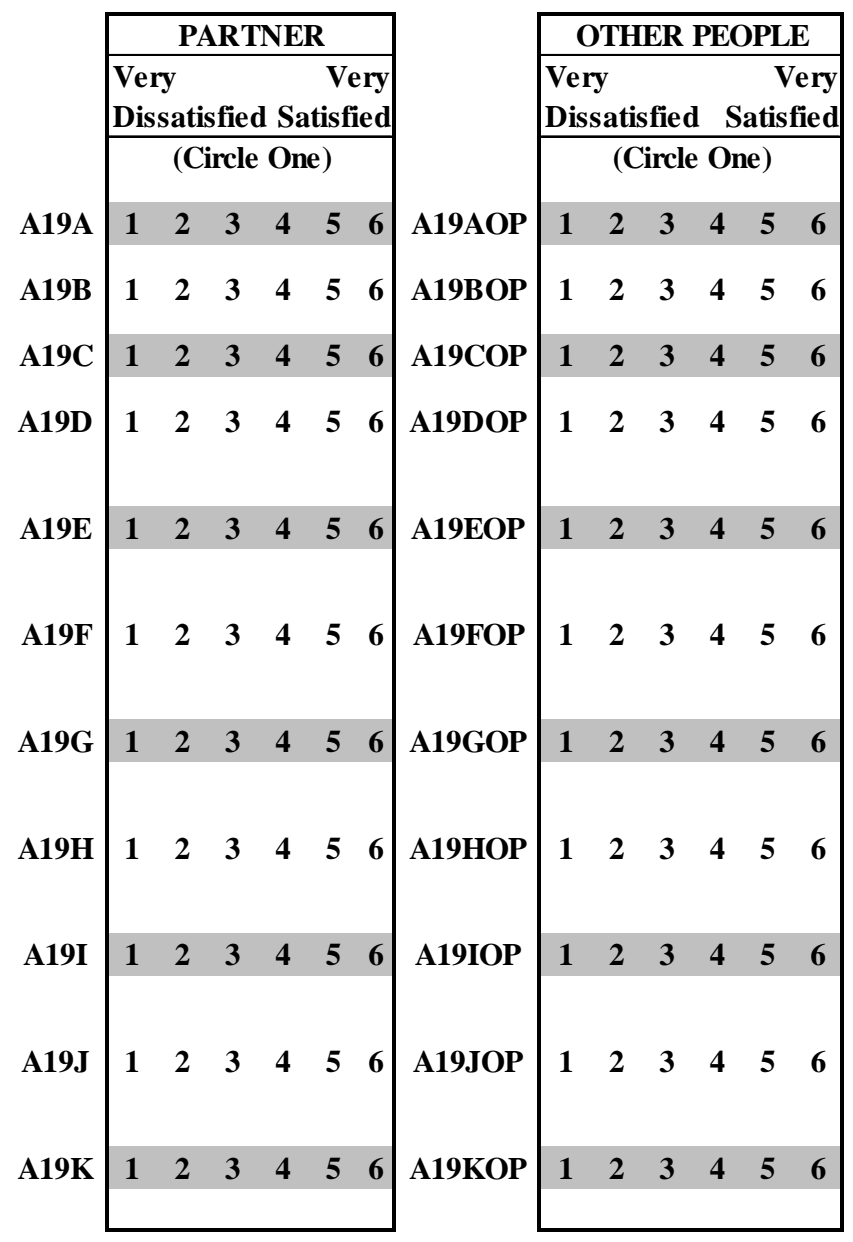


BABY BEEP STUDY

PPP
Study ID \#

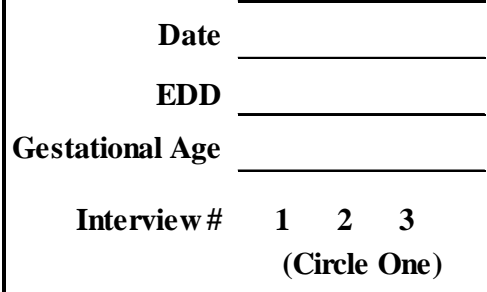

We all have some kind of "picture" of ourselves we carry with us. I'm going to read to you from a list of statements that people have used to describe themselves. I would like you, to tell me, how much you agree or disagree with how each statement describes you. You can refer to the card with the smiling faces, if that helps.

\begin{tabular}{|c|c|c|c|c|c|c|}
\hline & & $\begin{array}{l}\text { Strongly } \\
\text { Agree }\end{array}$ & Agree & Disagree & $\begin{array}{l}\text { Strongly } \\
\text { Disagree }\end{array}$ & \\
\hline A20A. & $\begin{array}{l}\text { Feel that you're a person of worth, at least on an equal basis } \\
\text { with others. }\end{array}$ & 1 & 2 & 3 & 4 & A20A \\
\hline A20B. & Feel that you have a number of good qualities. & 1 & 2 & 3 & 4 & A20B \\
\hline A20C. & All in all, feel that you are a failure. & 1 & 2 & 3 & 4 & A20C \\
\hline A20D. & Feel you are able to do things as well as most other people. & 1 & 2 & 3 & 4 & A20D \\
\hline A20E. & Feel you do not have much to be proud of. & 1 & 2 & 3 & 4 & A20E \\
\hline A20F. & Take a positive attitude toward yourself. & 1 & 2 & 3 & 4 & A20F \\
\hline A20G. & On the whole, feel satisfied with yourself. & 1 & 2 & 3 & 4 & A20G \\
\hline А20H. & Wish you could have more respect for yourself. & 1 & 2 & 3 & 4 & A20H \\
\hline A20I. & Feel useless at times. & 1 & 2 & 3 & 4 & A20I \\
\hline A20J. & At times, think you are no good at all. & 1 & 2 & 3 & 4 & A20J \\
\hline A20K. & Feel like you have control over your life. & 1 & 2 & 3 & 4 & A20K \\
\hline
\end{tabular}


Abuse Assessment Screen (AAS)

BABY BEEP STUDY

AAS

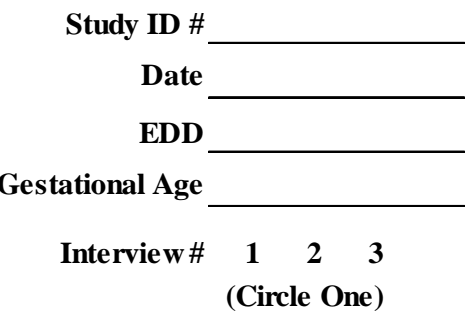

\section{I am going to ask the next questions because abuse of women is a serious health} problem that happens to women of all ages.

(Place an $\mathrm{X}$ in the box beside only one appropriate answer.)

AA1. Have you ever been emotionally or physically abused by your partner or someone close to you?

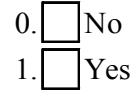

AA2. In the year before you were pregnant, were you hit slapped, kicked or otherwise physically hurt by someone?

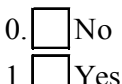

AA2Y. If yes, by who?

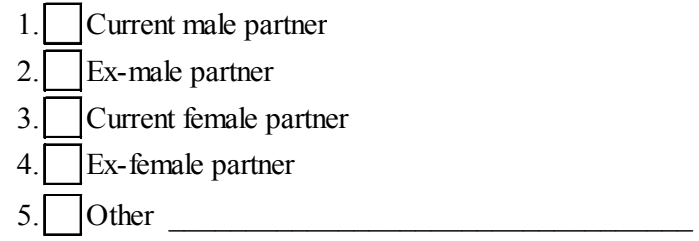

AA3. Since the last time we did these questions together, have you been hit, slapped, kicked or otherwise physically hurt by someone?

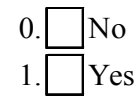

AA3Y. If yes, by who?

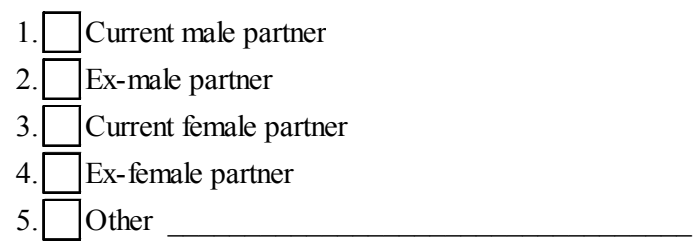

AA4. Within the last year, has anyone forced you to have sexual activities?

$$
\begin{aligned}
& 0 . \square \text { No } \\
& 1 . \square \text { Yes }
\end{aligned}
$$

AA5. Are you afraid of your partner or anyone else?

$$
\begin{aligned}
& 0 . \square \text { No } \\
& 1 . \square \text { Yes }
\end{aligned}
$$




\section{Chapter 5: Conclusion}

\section{Impact of Antenatal Depression}

Antenatal Depression (AND) is a pressing international health concern with increased incidence among disadvantaged women living in rural settings (C. L. Dennis et al., 2010; Fisher et al., 2012; Jesse, Dolbier, \& Blanchard, 2008). Women who experience AND suffer from debilitating symptoms that limit their functionality, decrease health promoting behaviors, and increase their likelihood of engaging in poor health practices such as substance abuse $(\mathrm{H}$. A. Bennett, Einarson, Taddio, Koren, \& Einarson, 2004; I. M. Bennett, Marcus, Palmer, \& Coyne, 2010; Furber, Garrod, Maloney, Lovell, \& McGowan, 2009). Women with AND often suffer from comorbid mental health conditions such as stress and anxiety (Fisher et al., 2012; Reid, Power, \& Cheshire, 2007). This contributes to the effects of AND extending beyond the pregnant woman and her family to the unborn fetus, causing alterations in pregnancy pathways and neurobehavioral performance during infancy and childhood (Grigoriadis et al., 2013). Epigeneticists are beginning to examine how maternal bioneurohormonal changes associated with maternal stress can impact the development of fetal systems on a large scale, even extending effects into adulthood (Knackstedt, Hamelmann, \& Arck, 2005).

\section{Treatment for Antenatal Depression}

Primary strategies for treating depression in the non-pregnant population center on the use of anti-depressant medications and psychotherapy. These treatment avenues have not been well-utilized in pregnant populations, particularly underserved women with high risk for AND (Bennett et al., 2010; Kopelman et al., 2008). Women living in rural settings have few resources, little social support, and high levels of stress, making them particularly vulnerable to AND (Bhandari et al., 2008). In addition, women with limited financial resources face significant 
barriers to obtaining care and are more likely to discontinue antidepressant use (Bennett, Marcus, et al., 2010; Jesse et al., 2008). Remedies for these disadvantages have not been fully explored in the literature. Complementary treatment options for AND, such as acupuncture, massage, yoga, bright light therapy and omega-3 fatty acids have begun to emerge, but have not been substantiated as effective, feasible and acceptable in pregnant populations, particularly those who are underserved (C. Dennis \& Dowswell, 2013). This has led to a scarcity of treatment options for pregnant women suffering from a prevalent and dangerous health condition, with low-income rural women most likely to suffer from this health disparity.

\section{Evaluating Baby BEEP as an Intervention for AND}

Nurse delivered interventions that address psychosocial variables may hold promise as safe, effective and acceptable treatments for AND. The purpose of this dissertation was to explore potential pathways for effective non-pharmacological treatment options for AND, particularly those that may be relevant and acceptable to underserved populations. The characteristics of the Baby BEEP study intervention provide a model for supportive, psychosocial-based AND treatment that was well received by underserved women. This intervention provided ongoing support throughout the course of pregnancy to women with a high incidence of depressive symptoms, involved a novel approach to interacting with patients (telehealth), had a high retention rate in an undeserved population, and was supported by nursing theory as an effective means of providing therapeutic psychiatric nursing care (Bullock et al., 2009; H. Peplau, 1997).

\section{Relevance to Nursing Theory}

Nursing theorist Hildegard Peplau pioneered the concept of using nurse-patient interaction (NPI) to facilitate mental health in her Theory of Interpersonal Relations (H. Peplau, 
1997). Nurse-patient interaction has long been heralded by nurse theorists such as Peplau, Watson, King, Allen and Orem as the core of nursing care and a primary means whereby therapeutic nursing care is delivered (Allen \& Warner, 2002; Denyes et al., 2001; King, 2007; H. Peplau, 1997; Watson, 2009). In spite of its widespread use in nursing theory, and perhaps because of it, the concept of NPI is often taken for granted and not fully investigated as an integral part of the nursing process. This dissertation explores the concept of NPI, providing greater clarity about what happens between nurse and patient, and the role nurses can play in providing support (social and emotional) to women suffering from depression during pregnancy. Understanding exactly how interactions between nurse and patient are shaped, what these consist of, and the potential impact can facilitate a more direct and mindful approach to this powerful tool, particularly as it is used to support mental health.

\section{NPI in Baby BEEP}

The primary use of NPI has occurred with inpatient psychiatric patients, grounded in Peplau's work to illuminate the therapeutic potential within the nurse-patient relationship (Sharac et al., 2010; Shattell, 2004). Recently, the use of NPI has been examined in other settings as it has been recognized to impact patient satisfaction to such a great degree (Millard et al., 2006; Shin \& White-Traut, 2005; Wagner \& Bear, 2008). Nurse-patient interactions have been shown to effect health-related outcomes as well as the patient's ability to cope, the amount of caring, power, and involvement they feel, and their satisfaction with care (Cossette et al., 2006; Hewison, 1995; Millard et al., 2006; Wagner \& Bear, 2008; Williams \& Irurita, 2004; Williams \& Kristjanson, 2009). The direct relationship of NPI with depression has been examined in cognitively intact nursing home patients, and found to have a significant relationship with decreased depression and anxiety (Haugan et al., 2013). This dissertation extended the 
application of NPI to other patient populations in different settings. The Baby BEEP study demonstrates one such use of NPI, and mimics traditional inpatient therapy in that it is provided consistently over a long period of time, allowing for the development of a relationship. Over this longer period, habits, perspectives and practices are more likely to be fostered and developed as a result of the NPI than during brief, isolated incidents. In contrast to inpatient psychiatric care, the Baby BEEP study intervention was not constrained by time or other nursing responsibilities, allowing each patient the power and opportunity to maintain control over the relationship and direct its development according to their needs.

The Baby BEEP study NPI consisted of research nurses providing telephone support throughout the course of pregnancy to low-income, rural women who smoked. These NPIs reflect the concepts identified in Peplau's theory and exemplify the type of interaction that can benefit high-risk, depressed women. In a sample of 24 nurse-patient dyads, all of whom experienced mental health scores indicative of depression at the baseline interview, evidence of Peplau's phases of relationship and nursing roles were abundant. The roles played by Baby BEEP study nurses throughout the interaction include surrogate, counselor, teacher, resource and leader. Those women who began the study with more severe depression received a substantially greater "dose" of NPI in terms of Peplau's phases and roles, and showed steady improvement in mental health through the end of pregnancy and continuing through six weeks postpartum. This provides evidence and an initial template of a nurse provided AND treatment that is wellsupported by nursing theory, focuses on addressing psychosocial factors and is well-received by underserved women. 


\section{Need for Social and Emotional Support}

Psychosocial variables play an important role in mediating and moderating depression during pregnancy (Evans \& Bullock, 2012; Records \& Rice, 2007). Stress, anxiety and social support have consistently been identified as correlates of AND (Schetter, 2009). In fact, stress and anxiety are often comorbid with depression, causing some scientists to refer to this cluster of disorders as Common Perinatal Mental Disorders (CPMD) (Fisher et al., 2012). Women in the Baby BEEP study experienced high levels of stress, with women suffering from more severe depression when experiencing higher levels of housing instability and intimate partner violence (IPV). This concurs with the IPV literature as well as research with low-income, urban women that has established the association between abuse, stress and mental health over extended periods of time (Bhandari et al., 2012; Bloom, Glass, Curry, Hernandez, \& Houck, 2012).

Within this body of literature, there is a clear identification of "intense isolation and loneliness" that is experienced by these women who perceive very little social support (Bloom et al., 2012, p. 167). Alhusen, Gross, Hayat, Rose and Sharps (2012) examine the relationship between mental health and maternal-fetal attachment in low-income women, finding that women were very sensitive to the level of social support available to them, particularly during pregnancy. Women in the Baby BEEP study reported rates of partner and other support below norms established for the Prenatal Psychosocial Profile (PPP), with the more severely depressed women reporting even lower levels of support (Curry et al., 1998). The current study identifies the great extent to which the nurses were able to be involved in these women's lives, perhaps filling a void created by the lack of social support. The higher rate of work in Peplau's exploitation phase, as well as the variety and depth of the nursing roles evident in the more 
severely depressed group, suggests that NPI became a type of nursing support that helped to offset depressive symptoms in this low-income, rural population.

Emotional care also has been identified as a result of high-quality NPI, and should become an important focus of interventions designed to treat AND (Williams \& Kristjanson, 2009). The need for emotional support has been explored in relationship to AND, along with other, well-established correlates of depression (Jeong et al., 2013). These studies have found that emotional support provided by the partner and mother, but not the father, significantly influenced depression during pregnancy. This type of emotional support was evident in the Baby BEEP study participants whose depression improved more quickly. The frequency with which these women mentioned mothers and husbands in their conversations with nurses, as well as their scores of higher partner and other support, reflects the support they felt. Jeong et al. (2013) also suggest that emotional support is a modifiable factor that may be used to prevent or decrease the experience of depression, and, as such, should be facilitated and even provided by health care professionals. The Baby BEEP study intervention is a strong example of this type of emotional care, how it was received by low-income rural women, and the potential it has to offset depression.

\section{Positive Psychology}

In addition to stress, anxiety and social support, there are other variables that may impact a woman's risk for and experience of depression. In the field of positive psychology, those qualities that enhance life and support mental health are identified, with attention given to how these qualities may be nurtured and developed in the individual (Scheier \& Carver, 1985). Optimism is one such quality that has been examined in relationship to health, but not extensively studied in the pregnant population (Rasmussen, Scheier, \& Greenhouse, 2009). 
Fostering and facilitating optimism in pregnant women may help to offset their experience of anxiety, stress and depression, and holds promise as an influential component of AND treatment programs (Evans \& Bullock, 2012).

Optimism was evident in the Baby BEEP study NPIs given that the women discussed their feelings of hope and acted as leaders, setting goals and making changes in their lives. The contrasting perspectives of the more severely depressed group versus the group that improved more quickly were evident in the frequency with which they discussed needs versus wants. The more depressed group was focused on their wants, those things that were desirable but unattainable. This connotes a pessimistic perspective, that things may not improve in the future and that the woman felt relatively helpless in her ability to attain those wants. The less depressed group was focused on their needs, those things that they were entitled to and capable of getting. This connotes an optimistic perspective, that they deserved and could attain those things that were essential. Self-efficacy may also be related to the perspectives of the women, with the less depressed, more optimistic women feeling more capable and confident about their ability to effect change in their lives.

\section{Directions for Future Research}

Nursing research must continue to consider the impact of psychosocial variables on the experience of mental health among pregnant women. Further exploration of the relationship between stress, anxiety, and depression is warranted, in addition to the ways in which specific types of social support, knowledge, and NPI may counterbalance the negative effects of psychological distress in pregnant women's lives. The benefits of positive psychology have not been fully examined during pregnancy, nor has the ability of nurses to enhance the mental health 
of their patients in a non-psychiatric setting. Special attention should be given to developing interventions suited to the needs and preferences of low-income women.

Evidence from this dissertation may be used in the development of an intervention protocol based on Peplau's Theory and the interactions of the Baby BEEP study nurses. This intervention should be tested for feasibility and effectiveness on a small scale with a local sample and then modified accordingly. Eventual implementation in a large-scale randomized, controlled trial will allow for an in depth assessment of the effect of the intervention on stress, anxiety and depression across a more diverse sample in terms of ethnicity and socioeconomic status. A comparison of intervention delivery between face-to-face versus telephone provision and at home versus clinic setting is warranted, as is an exploration of the frequency, length and duration that is optimal in terms of benefit and cost.

Awareness of the impact of AND, its prevalence and the need for effective treatment is a priority for all women's health advocates, particularly as anti-depressant use during pregnancy continues to be perceived with greater risk and hesitancy. It is important that practitioners be aware that lack of treatment for depression does not necessarily equal lack of risk, and that the consequences of untreated depression are significant to the mother and fetus. In light of the promising findings regarding NPI as an effective, economical and acceptable way of supporting depressed women, it is imperative that non-pharmacologic, non-psychological treatment options for AND continue to be explored and developed at an increased rate.

\section{Contributions to Nursing Policy}

This dissertation underscores the need for continued funding to address perinatal mental health disorders, particularly AND. It is important that health care providers assess for depression early in pregnancy and repeat screening in subsequent trimesters. Because of its 
potential to impact the developing fetus, the increased use of health care service during pregnancy and the potential for mental health issues to continue into the postpartum period, pregnancy is an optimal time to identify women who may be at risk for mental health problems and intervene to prevent or offset their development.

It is essential that institutional policy makers consider NPI and its impact on health care outcomes, in addition to providing a health care setting that ensures the highest quality NPI for patients. Nurse-patient interactions can be significantly affected by health care culture and climate, including adequate staffing, nurse-patient ratios, and collaborative care. Ensuring highquality NPI is a clear way to improve patient satisfaction and health outcomes, including mental health.

Continued development and implementation of health care policy changes in the United States can incorporate novel means of providing nursing care such as tele-health. Mobile and tele-interventions are able to reach isolated populations with greater cost and time efficiency. These interventions also provide a more focused interaction, with less distraction, at the patient's convenience. The use of tele-health as a means to provide nursing care is a viable alternative to inefficient and limited interactions that typically occur in a clinical setting, particularly when addressing mental or emotional health.

\section{Limitations}

Limitations of this dissertation are related to its design and data. Because it is qualitative in nature, the purpose of the study is to explore, illuminate and characterize the experiences of the nurses who worked with depressed women whose mental health improved. The study was not designed to determine the cause of depression in this sample or specific effects of the Baby BEEP study nursing intervention. Moreover, the original study was not designed as a treatment 
for depression, but rather as a smoking cessation program; thus, the findings cannot be generalized to a larger sample of depressed women. Although Peplau's Theory of Interpersonal Relations was used to frame the design and analysis of this study, it may not have captured all of the nursing process that occurred within the NPIs. There are many ways to interpret the actions and responses of the nurses that may reflect other psychological approaches to supporting mental health, such as motivational interviewing (MI). Although MI was not used explicitly by any of the nurses, the Baby BEEP intervention could be characterized as delivered in the spirit of MI.

This research does not represent the perspective of underserved women directly, but rather, their experiences as filtered through the perspectives of the Baby BEEP study nurses. The phone logs examined in this study were not verbatim recordings of phone conversations, but were the nurses' records of what was said by both parties over the course of the study period. As such, the phone logs vary in style and content, reflecting what the nurse thought was important to record about the interaction. Women in this sample were not diagnosed with depression using a clinical interview, but were screened for depression using a validated mental health instrument. Data about antidepressant used was not collected for this study. However, because the women in the sample were pregnant and low-income or without access to many health services, it is most likely that few, if any, were receiving pharmacotherapy.

\section{Conclusion}

This dissertation explores promising avenues for AND treatment research and sheds light on essential psychosocial factors that must be considered in the design of effective interventions that address depression. Depression treatment must address stress, social support and anxiety simultaneously to offset best the negative effects of psychological distress for the mother and fetus. Nurses are in an optimal position to assess the psychosocial risks and resources that a 
pregnant woman displays, and support her efforts to manage these in a way that best supports mental health. Whether in a clinic, over the phone or through home visits, nurses can address the psychosocial factors that are so fundamental to the experience of depression through their interactions with patients. Optimism, as a powerful tool of positive psychology, holds promise as a teachable perspective and acquired skill that may help decrease the likelihood of developing depression, or help depressed women shift their cognitive processes and improve their mental health.

Nurse-patient interaction is a simple and direct means of supporting pregnant women's mental health that has not been previously examined as a potential intervention for AND. This dissertation sheds light on the essential components of NPI that may be enhanced and manipulated in a way to support better the mental health of the patient. It also identifies those factors that significantly shape NPI and must be considered when designing programs, work environments and nursing protocols that are intended to enhance the patient's health. The use of NPI in the prenatal setting for underserved pregnant women is a logical extension of nursing theorist Hildegard Peplau's work, and extends the application of psychiatric nursing principles to a relevant population. This extension of the role of the prenatal nurse supports the idea that nurses in all settings can use NPI to address not only the physical, but also the emotional, cognitive and spiritual needs of patients.

Very little depression research has addressed the experience of AND in low-income women, particularly those in rural settings. This dissertation substantiates findings that rural, low-income women suffer from high rates of depressive symptoms, and explores the experiences of women suffering from depression, particularly as they interact with a nurse over the course of their pregnancy. Recognizing the variety of responses that the Baby BEEP study nurses used 
when interacting with these patients provides evidence of well-received and effective strategies that may be used in the design of future programs to support women who typically have very few resources with which to offset depressive symptoms. 


\section{References}

Allen, F. M., \& Warner, M. (2002). A developmental model of health and nursing. Journal of Family Nursing, 8(2), 96-135. doi:10.1177/107484070200800202

Aranda, S. K., \& Street, A. F. (1999). Being authentic and being a chameleon: Nurse-patient interaction revisited. Nursing Inquiry, 6(2), 75-82. Retrieved from http://www.ncbi.nlm.nih.gov/pubmed/10696199

Bazeley, P. (2013). Qualitative Data Analysis Practical Strategies. (J. Seaman, Ed.) (p. 444). Thousand Oaks, CA: Sage Publications.

Beddoe, A. E., \& Lee, K. A. (2008). Mind-body interventions during pregnancy. Journal of Obstetric, Gynecologic, and Neonatal Nursing : JOGNN / NAACOG, 37(2), 165-75. doi:10.1111/j.1552-6909.2008.00218.x

Bennett, H. A., Einarson, A., Taddio, A., Koren, G., \& Einarson, T. R. (2004a). Depression during pregnancy : Overview of clinical factors. Clinical Drug Investigation, 24(3), 157-79. Retrieved from http://www.ncbi.nlm.nih.gov/pubmed/17516702

Bennett, H. A., Einarson, A., Taddio, A., Koren, G., \& Einarson, T. R. (2004b). Prevalence of depression during pregnancy: systematic review. Obstetrics and Gynecology, 103(4), 698709. doi:10.1097/01.AOG.0000116689.75396.5f

Bennett, I. M., Culhane, J. F., Webb, D. a, Coyne, J. C., Hogan, V., Mathew, L., \& Elo, I. T. (2010). Perceived discrimination and depressive symptoms, smoking, and recent alcohol 
use in pregnancy. Birth (Berkeley, Calif.), 37(2), 90-7. doi:10.1111/j.1523-

536X.2010.00388.x

Bennett, I. M., Marcus, S. C., Palmer, S. C., \& Coyne, J. C. (2010). Pregnancy-related discontinuation of antidepressants and depression care visits among Medicaid recipients. Psychiatric Services, 61(4), 386-91. doi:10.1176/appi.ps.61.4.386

Bhandari, S., Bullock, L. F. C., Bair-Merritt, M., Rose, L., Marcantonio, K., Campbell, J. C., \& Sharps, P. (2012). Pregnant women experiencing IPV: impact of supportive and nonsupportive relationships with their mothers and other supportive adults on perinatal depression: a mixed methods analysis. Issues in Mental Health Nursing, 33(12), 827-37. doi: $10.3109 / 01612840.2012 .712628$

Bhandari, S., Levitch, A. H., Ellis, K. K., Ball, K., Everett, K., Geden, E., \& Bullock, L. (2008). Comparative analyses of stressors experienced by rural low-income pregnant women experiencing intimate partner violence and those who are not. Journal of Obstetric, Gynecologic, and Neonatal Nursing : JOGNN / NAACOG, 37(4), 492-501. doi:10.1111/j.1552-6909.2008.00266.x

Bloom, T., Glass, N., Curry, M. A., Hernandez, R., \& Houck, G. (2012). Maternal stress exposures, reactions, and priorities for stress reduction among low-income, urban women. Journal of Midwifery \& Women's Health, 58(2), 167-74. doi:10.1111/j.15422011.2012.00197.x

Boström, E., Isaksson, U., Lundman, B., Graneheim, U. H., \& Hörnsten, Å. (2014). Interaction between diabetes specialist nurses and patients during group sessions about self- 
management in type 2 diabetes. Patient Education and Counseling, 94(2), 187-92. doi:10.1016/j.pec.2013.10.010

Brooks-Carthon, J. M., Kutney-Lee, A., Sloane, D. M., Cimiotti, J. P., \& Aiken, L. H. (2011). Quality of care and patient satisfaction in hospitals with high concentrations of black patients. Journal of Nursing Scholarship : An Official Publication of Sigma Theta Tau International Honor Society of Nursing / Sigma Theta Tau, 43(3), 301-10. doi:10.1111/j.1547-5069.2011.01403.x

Brown, J., \& Goldstein, L. (1967). Nurse-patient interaction before and after the substitution of street clothes for uniforms. International Journal of Socail Psychiatry, 14(1), 32-43.

Brunt, D., \& Rask, M. (2013). Validation of the Verbal and Social Interaction questionnaire: carers' focus in the carer-resident relationship in supported housing facilities for persons with psychiatric disabilities (VSI-SH). Journal of Psychiatric and Mental Health Nursing, 20(3), 279-85. doi:10.1111/j.1365-2850.2012.01925.x

Bullock, L., Everett, K. D., Mullen, P. D., Geden, E., Longo, D. R., \& Madsen, R. (2009). Baby BEEP: A randomized controlled trial of nurses' individualized social support for poor rural pregnant smokers. Maternal and Child Health Journal, 13(3), 395-406. doi:10.1007/s10995-008-0363-z

Caris-Verhallen, W., Timmermans, L., \& van Dulmen, S. (2004). Observation of nurse-patient interaction in oncology: Review of assessment instruments. Patient Education and Counseling, 54(3), 307-20. doi:10.1016/j.pec.2003.12.009 
Castillo, J., \& Sanche-Sosa, J. J. (2002). Well-being and medical recovery in the critical care unit: The role of the nurse-patient interaction. Salud Mental, 25(2), 21-31.

Chatwin, J. (2008). Hidden dimensions : The analysis of interaction in nurse - patient encounters. Quality in Primary Care, 16, 109-115.

Cleary, M., Edwards, C., \& Meehan, T. (1999). Factors influencing nurse-patient interaction in the acute psychiatric setting: An exploratory investigation. The Australian and New Zealand Journal of Mental Health Nursing, 8(3), 109-16. Retrieved from http://www.ncbi.nlm.nih.gov/pubmed/10661080

Cleary, M., Hunt, G. E., Horsfall, J., \& Deacon, M. (2012). Nurse-patient interaction in acute adult inpatient mental health units: A review and synthesis of qualitative studies. Issues in Mental Health Nursing, 33(2), 66-79. doi:10.3109/01612840.2011.622428

Cossette, S., Cara, C., Ricard, N., \& Pepin, J. (2005). Assessing nurse-patient interactions from a caring perspective: Report of the development and preliminary psychometric testing of the Caring Nurse--Patient Interactions Scale. International Journal of Nursing Studies, 42(6), 673-86. doi:10.1016/j.ijnurstu.2004.10.004

Cossette, S., Cote, J. K., Pepin, J., Ricard, N., \& D’Aoust, L.-X. (2006). A dimensional structure of nurse-patient interactions from a caring perspective: Refinement of the Caring NursePatient Interaction Scale (CNPI-Short Scale). Journal of Advanced Nursing, 55(2), 198214. doi:10.1111/j.1365-2648.2006.03895.x 
Cossette, S., Pepin, J., Côté, J. K., \& de Courval, F. P. (2008a). The multidimensionality of caring: A confirmatory factor analysis of the Caring Nurse-Patient Interaction Short Scale. Journal of Advanced Nursing, 61(6), 699-710. doi:10.1111/j.1365-2648.2007.04566.x

Cossette, S., Pepin, J., Côté, J. K., \& de Courval, F. P. (2008b). The multidimensionality of caring: A confirmatory factor analysis of the Caring Nurse-Patient Interaction Short Scale. Journal of Advanced Nursing, 61(6), 699-710. doi:10.1111/j.1365-2648.2007.04566.x

Curry, M. A., Burton, D., \& Fields, J. (1998). The Prenatal Psychosocial Profile: A research and clinical tool. Research in Nursing and Health, 21(3), 211-9. Retrieved from http://www.ncbi.nlm.nih.gov/pubmed/9609506

Dennis, C., \& Dowswell, T. (2013). Interventions ( other than pharmacological , psychosocial or psychological ) for treating antenatal depression. Cochrane Database of Systematic Reviews, (7). doi:10.1002/14651858.CD006795.pub3.Copyright

Dennis, C. L., \& Allen, K. (2010). Interventions ( other than pharmacological, psychosocial or psychological ) for treating antenatal depression ( Review ). The Cochrane Library, (6).

Dennis, C. L., Ross, L. E., \& Grigoriadis, S. (2010). Psychosocial and psychological interventions for treating antenatal depression ( Review ). In The Cochrane Collaboration. John Wiley \& Sons, Ltd.

Denyes, M. J., Orem, D. E., \& Bekel, G. (2001). Self-care: A foundational science. Nursing Science Quarterly2, 14(1), 48-55. 
Dimidjian, S., \& Goodman, S. (2009). Nonpharmacologic intervention and prevention strategies for depression during pregnancy and the postpartum. Clinical Obstetrics and Gynecology, 52(3), 498-515. doi:10.1097/GRF.0b013e3181b52da6

Donohue, R. K. (2003). Nurse practitioner - client interaction as resource exchange in a women ' s health clinic : an exploratory study, 011(617), 717-725.

Evans, E. C., \& Bullock, L. F. C. (2012). Optimism and other psychosocial influences on antenatal depression: A systematic review. Nursing \& Health Sciences, 14(3), 352-61. doi:10.1111/j.1442-2018.2012.00700.x

Fisher, J., Cabral de Mello, M., Patel, V., Rahman, A., Tran, T., Holton, S., \& Holmes, W. (2012). Prevalence and determinants of common perinatal mental disorders in women in low- and lower-middle-income countries: a systematic review. Bulletin of the World Health Organization, 90(2), 139G-149G. doi:10.2471/BLT.11.091850

Fosbinder, D. (1994). Patient perceptions of nursing care: an emerging theory of interpersonal competence. Journal of Advanced Nursing, 20(6), 1085-93. Retrieved from http://www.ncbi.nlm.nih.gov/pubmed/7860855

Furber, C. M., Garrod, D., Maloney, E., Lovell, K., \& McGowan, L. (2009). A qualitative study of mild to moderate psychological distress during pregnancy. International Journal of Nursing Studies, 46(5), 669-77. doi:10.1016/j.ijnurstu.2008.12.003 
Gavin, N. I., Gaynes, B. N., Lohr, K. N., Meltzer-brody, S., Gartlehner, G., \& Swinson, T. (2005). Perinatal depression: A systematic review of prevalence and incidence. Obstetrics and Gynecology, 106(5), 1071-1083.

Gaynes, B. N., Gavin, N., Meltzer-Brody, S., Lohr, K. N., Swinson, T., Gartlehner, G., ... Miller, W. C. (2005). Perinatal depression: Prevalence, screening accuracy, and screening outcomes. Evidence Report/technology Assessment (Summary), (119), 1-8. Retrieved from http://www.ncbi.nlm.nih.gov/pubmed/15760246

Goldzwieg, C. L., Orshansky, G., Paige, N. M., Twosgih, A. A., Haggstrom, D. A., Maike-Lye, I., ... Shekelle, P. G. (2013). Annals of internal medicine review electronic patient portals : Evidence on health outcomes, satisfaction, efficiency, and attitudes. A review. Annals of Internal Medicine, 159(10), 679-.

Grigoriadis, S., VonderPorten, E. H., Mamisashvili, L., Tomlinson, G., Dennis, C.-L., Koren, G., ... Ross, L. E. (2013). The impact of maternal depression during pregnancy on perinatal outcomes: a systematic review and meta-analysis. The Journal of Clinical Psychiatry, 74(4), e321-41. doi:10.4088/JCP.12r07968

Haugan, G., Innstrand, S. T., \& Moksnes, U. K. (2013). The effect of nurse-patient interaction on anxiety and depression in cognitively intact nursing home patients. Journal of Clinical Nursing, 22(15-16), 2192-205. doi:10.1111/jocn.12072

Hewison, a. (1995). Nurses' power in interactions with patients. Journal of Advanced Nursing, 21(1), 75-82. Retrieved from http://www.ncbi.nlm.nih.gov/pubmed/7897081 
Holyoake, D. (1997). Exploring the nature of nurse interaction using an interaction interview schedule: The results. Psychiatric Care, 4, 83-87.

Huberman, A. M., \& Miles, M. B. (1994). Handbook of Qualitative Research. (N. K. Denzin \& Y. S. Lincoln, Eds.) (1st ed., pp. 428-444). Thousand Oaks, CA: Sage Publications.

Jeong, H.-G., Lim, J.-S., Lee, M.-S., Kim, S.-H., Jung, I.-K., \& Joe, S.-H. (2013). The association of psychosocial factors and obstetric history with depression in pregnant women: Focus on the role of emotional support. General Hospital Psychiatry, 35(4), 354-8. doi:10.1016/j.genhosppsych.2013.02.009

Jesse, D. E., Dolbier, C. L., \& Blanchard, A. (2008). Barriers to seeking help and treatment suggestions for prenatal depressive symptoms: focus groups with rural low-income women. Issues in Mental Health Nursing, 29(1), 3-19. doi:10.1080/01612840701748664

Jomeen, J. (2004). The importance of assessing psychological status during pregnancy, childbirth and the postnatal period as a multidimensional construct: A literature review. Clinical Effectiveness in Nursing, 8(3-4), 143-155. doi:10.1016/j.cein.2005.02.001

Kandler, H., Behymer, A. F., Kegeles, S. S., Boyd, R. W., \& Kandler, B. H. (1952). A study of nurse-patient interaction in a mental hospital. The American Journal of Nursing, 52(9), $1100-1103$.

Kasch, C. R. (1986). Toward a theory of nursing action: Skills and competency in nurse-patient interaction. Nursing Research, 35(4), 226-230. 
Kim, H. S., \& Collak, I. (2006). Nursing Theories: Conceptual and Philosophical Foundations. (H. suzie Kim \& I. Kollak, Eds.) (2nd ed.). New York, NY: Springer Publishing Company.

King, I. M. (2007). King's conceptual system, theory of goal attainment, and transaction process in the 21st century. Nursing Science Quarterly, 20(2), 109-111.

Knackstedt, M. K., Hamelmann, E., \& Arck, P. C. (2005). Mothers in stress: consequences for the offspring. American Journal of Reproductive Immunology (New York, N.Y. : 1989), 54(2), 63-9. doi:10.1111/j.1600-0897.2005.00288.x

Konradsen, H., Kirkevold, M., \& Zoffmann, V. (2009). Surgical facial cancer treatment: the silencing of disfigurement in nurse-patient interactions. Journal of Advanced Nursing, 65(11), 2409-18. doi:10.1111/j.1365-2648.2009.05102.x

Kopelman, R. C., Moel, J., Mertens, C., Stuart, S., Arndt, S., \& O’Hara, M. W. (2008). Barriers to care for antenatal depression. Psychiatric Services (Washington, D.C.), 59(4), 429-32. doi:10.1176/appi.ps.59.4.429

Krouse, Helene, J., Krouse, J. H., \& Roberts, S. J. (1988). Preliminary validation of a nursepatient interaction tool. Perceptual and Motor Skills, 67, 281-282.

Lancaster, C. A., Gold, K. J., Flynn, H. A., Yoo, H., Marcus, S. M., \& Davis, M. M. (2010). Risk factors for depressive symptoms during pregnancy: A systematic review. American Journal of Obstetrics and Gynecology, 202(1), 5-14. doi:10.1016/j.ajog.2009.09.007.Risk 
Levy, L. B., \& O’Hara, M. W. (2010). Psychotherapeutic interventions for depressed, lowincome women: a review of the literature. Clinical Psychology Review, 30(8), 934-50. doi:10.1016/j.cpr.2010.06.006

Lieber, J. L. (2014). How do your patient satisfaction scores measure up? Nursing Management, 45(2), 22-5. doi:10.1097/01.NUMA.0000442647.39442.32

McFarlane, J., Parker, B., Soeken, K., \& Bullock, L. (1992). Assessing for abuse during pregnancy. Journal of American Medical Association, 267(23), 3167-3178.

Medicine, I. of. (2010). The future of nursing: leading change, advancing health. Journal for Nurses in Professional Development (Vol. 29). Washington, DC. doi:10.1097/NND.0b013e318287d1ad

Miles, M. B., Huberman, A. M., \& Saldana, J. (2013). Qualitative Data Analysis: A Methods Sourcebook (3rd ed., pp. 69-104). Thousand Oaks, CA: Sage Publications.

Millard, L., Hallett, C., \& Luker, K. (2006). Nurse-patient interaction and decision-making in care: Patient involvement in community nursing. Journal of Advanced Nursing, 55(2), 14250. doi:10.1111/j.1365-2648.2006.03904.x

Morse, J. M., Havens, G. A. D., \& Wilson, S. (1997). The comforting interaction: Developing a model of nurse-patient relationship. Scholarly Inquiry for Nursing Practice: An International Journal, 11(4), 321-347.

Muzik, M., Marcus, S. M., Heringhausen, J. E., \& Flynn, H. (2009). When depression complicates childbearing: Guidelines for screening and treatment during antenatal and 
postpartum obstetric care. Obstetrics and Gynecology Clinics of North America, 36(4), 77188, ix-X. doi:10.1016/j.ogc.2009.10.006

Norton, L. B., Peipert, J., Zeirler, S., Lima, B., \& Hume, L. (1995). Battering in pregnancy: An assessment of two screening methods. Obstetrics and Gynecology, 85(3).

Peplau, H. (1997). Peplau's theory of interpersonal relations. Nursing Science Quarterly, 10(4), $162-167$.

Peplau, H. E. (1991). Interpersonal relations in nursing: A conceptual frame of reference for psychodynamic nursing (p. 355). New York, NY: Springer Publishing Company.

Poggenpoel, M. (1994). Psychiatric nurse-patient interaction facilitating mental health. Curationis, 17(1), 51-57.

Rask, M., \& Brunt, D. (2007). Verbal and social interactions in the nurse-patient relationship in forensic psychiatric nursing care: A model and its philosophical and theoretical foundation. Nursing Inquiry, 14(2), 169-76. doi:10.1111/j.1440-1800.2007.00364.x

Rask, M., Brunt, D., \& Fridlund, B. (2008a). Validation of the verbal and social interaction questionnaire: nurses' focus in the nurse-patient relationship in forensic nursing care. Journal of Psychiatric and Mental Health Nursing, 15(9), 710-6. doi:10.1111/j.13652850.2008.01292.x

Rask, M., Brunt, D., \& Fridlund, B. (2008b). Validation of the verbal and social interaction questionnaire: nurses' focus in the nurse-patient relationship in forensic nursing care. 
Journal of Psychiatric and Mental Health Nursing, 15(9), 710-6. doi:10.1111/j.13652850.2008.01292.x

Rasmussen, H. N., Scheier, M. F., \& Greenhouse, J. B. (2009). Optimism and physical health: a meta-analytic review. Annals of Behavioral Medicine : A Publication of the Society of Behavioral Medicine, 37(3), 239-56. doi:10.1007/s12160-009-9111-x

Ravert, P., Williams, M., \& Fosbinder, D. M. (1997). The interpersonal competence instrument for nurses. Western Journal of Nursing Research, 17(6), 781-791.

Records, K., \& Rice, M. (2007). Psychosocial Correlates of Depression of Pregnancy, 231-242. doi:10.1111/J.1552-6909.2007.00140.x

Reichenheim, M. E. (2004). Comparison between the abuse assessment screen and the revised conflict tactics scales for measuring physical violence during pregnancy. Journal of Epidemiology \& Community Health, 58(6), 523-527. doi:10.1136/jech.2003.011742

Reid, B. H., Power, M., \& Cheshire, K. (2007). Factors influencing antenatal depression , anxiety and stress.

Rickelman, B. L. (1971). Bio-psycho-social linguistics: A conceptual approach to nurse-patient interaction. Nursing Research, 20(5), 398-403.

Rose, L., Alhusen, J., Bhandari, S., Soeken, K., Marcantonio, K., Bullock, L., \& Sharps, P. (2010). Impact of intimate partner violence on pregnant women's mental health: mental distress and mental strength. Issues in Mental Health Nursing, 31(2), 103-11. doi: $10.3109 / 01612840903254834$ 
Rumpf, H. J., Meyer, C., Hapke, U., \& John, U. (2001). Screening for mental health: Validity of the MHI-5 using DSM-IV Axis I psychiatric disorders as gold standard. Psychiatry Research, 105(3), 243-53. Retrieved from http://www.ncbi.nlm.nih.gov/pubmed/11814543

Rundell, S. (1991). A study of nurse-patient interaction in a highg dependency unit. Intensive Care Nursing, 7, 171-178.

Saghafi, F., Hardy, J., \& Hillege, S. (2012). New graduate nurses' experieces of interactions in the critical care unit. Contemporary Nurse, 42(1), 20-27.

Saldana, J. (2013). The Coding Manual for Qualitative Researchers (Second ed.). Thousand Oaks, CA.

Scheier, M. F., \& Carver, C. S. (1985). Optimism, coping, and health: assessment and implications of generalized outcome expectancies. Health Psychology : Official Journal of the Division of Health Psychology, American Psychological Association, 4(3), 219-47. Retrieved from http://www.ncbi.nlm.nih.gov/pubmed/4029106

Schetter, C. D. (2009). Stress Processes in Pregnancy and Preterm Birth. Current Directions in Psychological Science, 18(4), 205-209. doi:10.1111/j.1467-8721.2009.01637.x

Schlachta-Fairchild, L., Elfrink, V., \& Deickman, A. (2008). Patient Safety, Telenursing , and Telehealth. Patient Safety and Quality: An Evidence-Based Handbookfor Nurses. Rockville, MD: Agency for Healthcare Research and Quality. Retrieved from http://www.ahrq.gov/professionals/cliniciansproviders/resources/nursing/resources/nurseshdbk/index.html 
Sharac, J., McCrone, P., Sabes-Figuera, R., Csipke, E., Wood, A., \& Wykes, T. (2010). Nurse and patient activities and interaction on psychiatric inpatients wards: a literature review. International Journal of Nursing Studies, 47(7), 909-17. doi:10.1016/j.ijnurstu.2010.03.012

Shattell, M. (2004). Nurse-patient interaction: A review of the literature. Journal of Clinical Nursing, 13(6), 714-22. doi:10.1111/j.1365-2702.2004.00965.x

Shin, H., \& White-Traut, R. (2005). Nurse-child interaction on an inpatient paediatric unit. Journal of Advanced Nursing, 52(1), 56-62. doi:10.1111/j.1365-2648.2005.03564.x

Stoddart, K. M. (2012). Social meanings and understandings in patient-nurse interaction in the community practice setting: A grounded theory study. BMC Nursing, 11, 14. doi:10.1186/1472-6955-11-14

Tejero, L. M. S. (2012). The mediating role of the nurse-patient dyad bonding in bringing about patient satisfaction. Journal of Advanced Nursing, 68(5), 994-1002. doi:10.1111/j.13652648.2011.05795.x

Tropea, S. (2012). “Therapeutic emplotment”: A new paradigm to explore the interaction between nurses and patients with a long-term illness. Journal of Advanced Nursing, 68(4), 939-47. doi:10.1111/j.1365-2648.2011.05847.x

Våga, B. B., Moland, K. M., Evjen-Olsen, B., Leshabari, S. C., \& Blystad, A. (2013). Rethinking nursing care: an ethnographic approach to nurse-patient interaction in the context of a HIV prevention programme in rural Tanzania. International Journal of Nursing Studies, 50(8), 1045-53. doi:10.1016/j.ijnurstu.2012.11.025 
Wagner, D., \& Bear, M. (2008). Patient satisfaction with nursing care: a concept analysis within a nursing framework. Journal of Advanced Nursing, 65(3), 692-701. doi:10.1111/j.13652648.2008.04866.x

Walker, L. O., \& Avant, K. C. (2005). Strategies for theory construciton in nursing (4th ed.). Upper Saddle River, JH: Pearson Education.

Watson, J. (2009). Caring science and human caring theory: Transforming personal and professional practices of nursing and health care. Journal of Health and Human Services Administration, 31(4), 466-482.

Williams, A. M., \& Irurita, V. F. (2004). Therapeutic and non-therapeutic interpersonal interactions: The patient's perspective. Journal of Clinical Nursing, 13(7), 806-15. doi:10.1111/j.1365-2702.2004.01020.x

Williams, A. M., \& Kristjanson, L. J. (2009). Emotional care experienced by hospitalised patients: Development and testing of a measurement instrument. Journal of Clinical Nursing, 18(7), 1069-77. doi:10.1111/j.1365-2702.2008.02586.x 